\title{
\#USGS
}

Prepared in cooperation with the U.S. Army Corps of Engineers

\section{Missouri River Emergent Sandbar Habitat Monitoring Plan- A Conceptual Framework for Adaptive Management}

सis $\rightarrow$
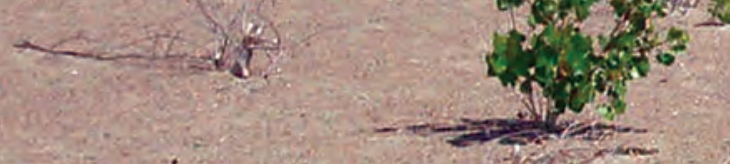

)
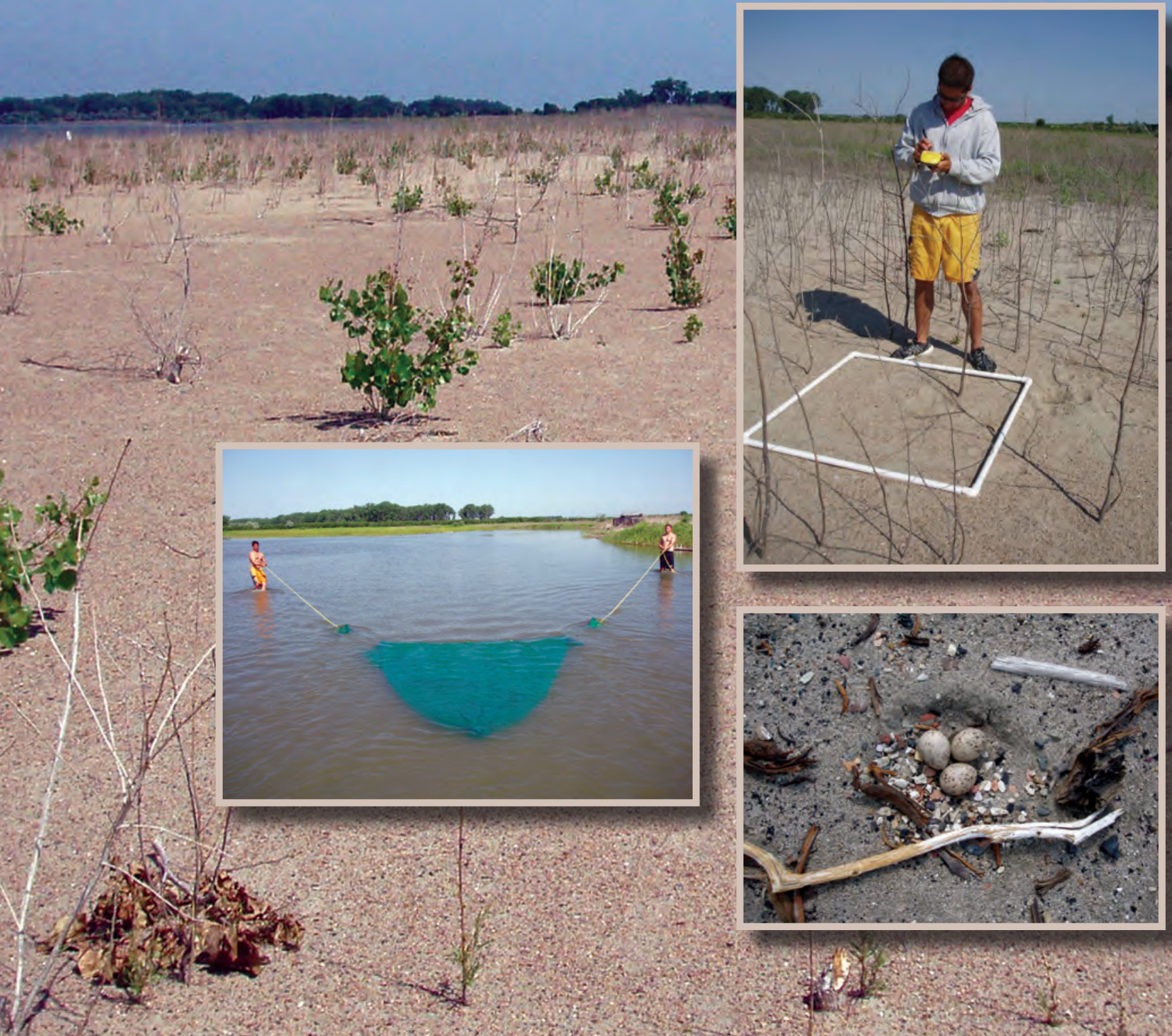

Open-File Report $2008-1223$

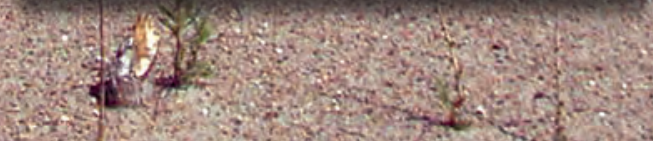

U.S. Department of the Interior

U.S. Geological Survey: 


\section{B}

\section{A}

C

Cover photographs: Emergent sandbar on the Missouri River (background photograph); $\boldsymbol{A}$, field crew collecting fish data by hand-trawling; $\boldsymbol{B}$, technician collecting terrestrial habitat data; and $\boldsymbol{C}$, least tern nest on a Missouri River sandbar. All photographs by M. Sherfy, U.S. Geological Survey. 


\section{Missouri River Emergent Sandbar Habitat Monitoring Plan-A Conceptual Framework for Adaptive Management}

By Mark H. Sherfy, Jennifer H. Stucker, and Michael J. Anteau

Prepared in cooperation with the U.S. Army Corps of Engineers

Open-File Report 2008-1223 


\section{U.S. Department of the Interior DIRK KEMPTHORNE, Secretary}

\section{U.S. Geological Survey \\ Mark D. Myers, Director}

\section{U.S. Geological Survey, Reston, Virginia: 2008}

For product and ordering information:

World Wide Web: http://www.usgs.gov/pubprod

Telephone: 1-888-ASK-USGS

For more information on the USGS — the Federal source for science about the Earth, its natural and living resources, natural hazards, and the environment:

World Wide Web: http://www.usgs.gov

Telephone: 1-888-ASK-USGS

Any use of trade, product, or firm names is for descriptive purposes only and does not imply endorsement by the U.S. Government.

Although this report is in the public domain, permission must be secured from the individual copyright owners to reproduce any copyrighted materials contained within this report.

Suggested citation:

Sherfy, M.H., Stucker, J.H., and Anteau, M.J., 2008, Missouri River Emergent Sandbar Habitat Monitoring Plan-a conceptual framework for adaptive management: U.S. Geological Survey Open-File Report 2008-1223, 51 p. 


\section{Preface}

\section{Habitat Monitoring: Scale and Linkage}

Understanding habitat as an indicator of animal condition is predicated on (1) an accurate understanding of habitat needs of animals, (2) use and distribution of animals in habitats, and (3) accurate measures of habitat features and how they are used at the appropriate temporal and spatial scales.

The iterative process of adaptive management requires identifying appropriate measurable habitat variables, initiating a management change, monitoring changes resulting from management on habitat, and assessing responses. Throughout the process, it is necessary to evaluate the measured variables and techniques deployed in order to identify additional habitat variables or include other spatial scales. Therefore, a monitoring plan should be designed with the ability to evaluate how appropriate the habitat variables are for predicting wildlife responses.

Processes involved in habitat change on the Missouri River are complex and dynamic. However, factors driving change in habitat at the sandbar scale may not describe landscape processes at the reach scale, and scale dependent factors may be directly or indirectly related. Management actions are applied on individual sandbars, but decisions regarding implementation are made at larger (for example reach) scales. Further, the extent or distribution of managed habitats may warrant evaluation of effects at reach or landscape scales. An effective monitoring program will provide data that facilitate analysis of biological responses at each of these scales.

This plan is a tool for initiating the process of habitat monitoring for least terns and piping plovers at multiple habitat scales (for example nest site, habitat type, river reach, or Missouri River system) on the Missouri River. Implementation of this plan will be enhanced by a concurrent commitment to assess spatial distribution of habitats at landscape scales, and to evaluate responses by least terns and piping plovers to management change. Parallel studies at Northern Prairie Wildlife Research Center (NPWRC) are currently focused on deriving methods for monitoring spatial distribution of habitats (NPWRC Task 1: Least tern foraging ecology and productivity on the Gavins Point Reach of the Missouri River) and productivity of least terns and piping plovers (NPWRC Task 2: Evaluation of procedures for monitoring numbers and productivity of least terns and piping plovers on the Missouri River). As these monitoring techniques become refined, they will be incorporated into annual Action Plans.

This plan is intended to serve the long-term needs of the Emergent Sandbar Habitat (ESH) Program for monitoring biological responses to management. Advance knowledge of all sites where ESH Program activities will be implemented in the future is not possible. Therefore, this plan does not identify specific sites or priorities for monitoring that will occur over time. What it does provide is a framework for making decisions about where habitat data should be collected to accomplish monitoring needs. This framework, illustrated in the accompanying flowcharts, is the essential element of the monitoring plan (fig. 1). To illustrate application of the design concepts embodied in this framework, the plan relies heavily on the field experience of the U.S. Geological Survey (USGS) habitat monitoring crew during 2006. The USGS crew encountered many unique field circumstances that are described to illustrate the manner in which the conceptual framework should be applied in decisionmaking. The decisions described should be considered unique to the conditions that were encountered in the field, and not as universal rules for implementation of the monitoring plan. Rather, the importance of these field experiences is that they illustrate how the framework can be implemented under various circumstances. Because each year will present unique circumstances, the framework provides for preparation of annual Action Plans that describe specific monitoring objectives for the year and establish appropriate response variables and sampling locations. 


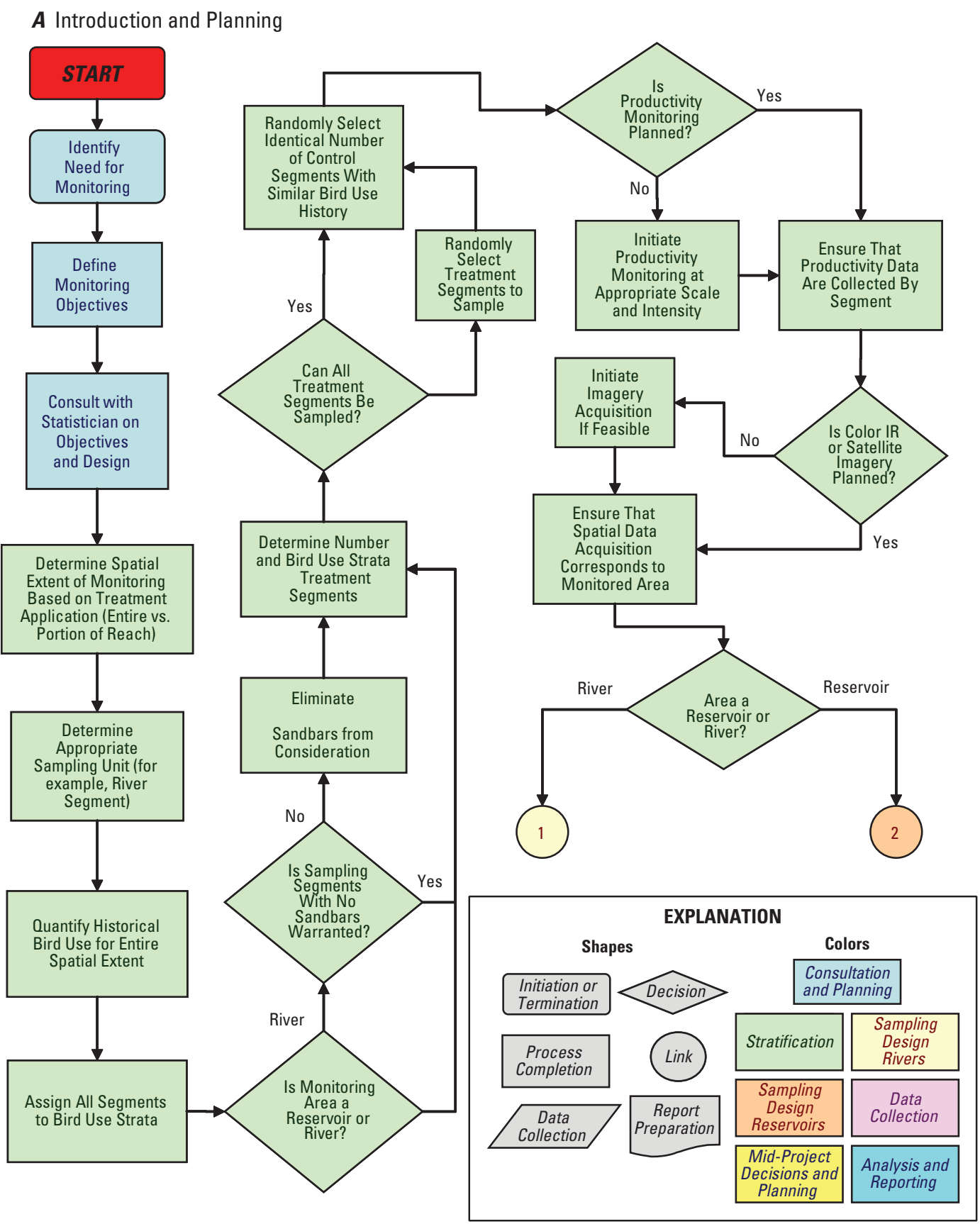

Figure 1. Conceptual framework for decisionmaking and implementation of habitat monitoring for management actions under the Emergent Sandbar Habitat (ESH) Program. The framework includes four phases: $A$, Introduction and Planning; $B$, Sampling Design; $C$, Data Collection; and $D$, Decisions and Analysis. 
B Sampling Design

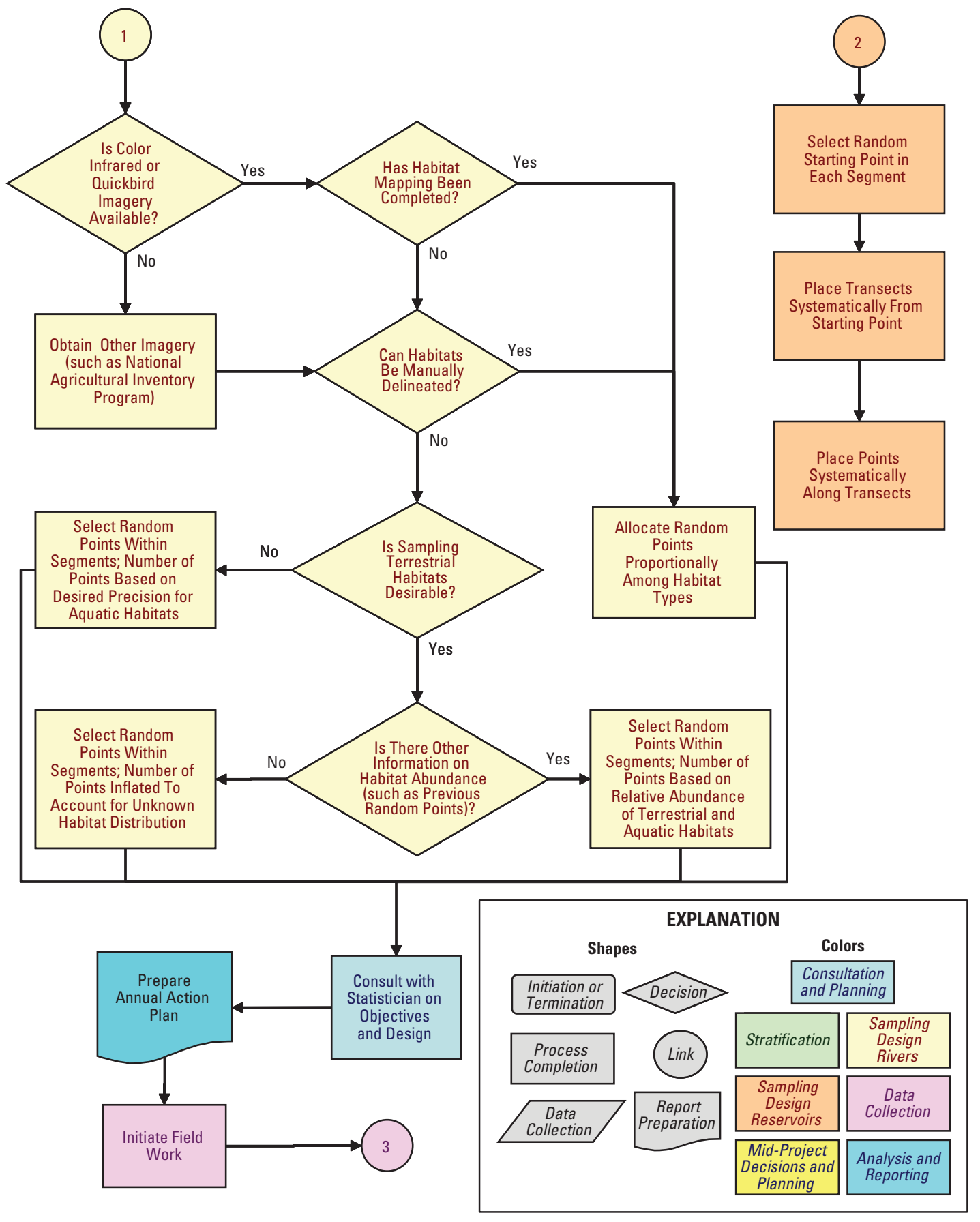

Figure 1. Continued 
C Data Collection

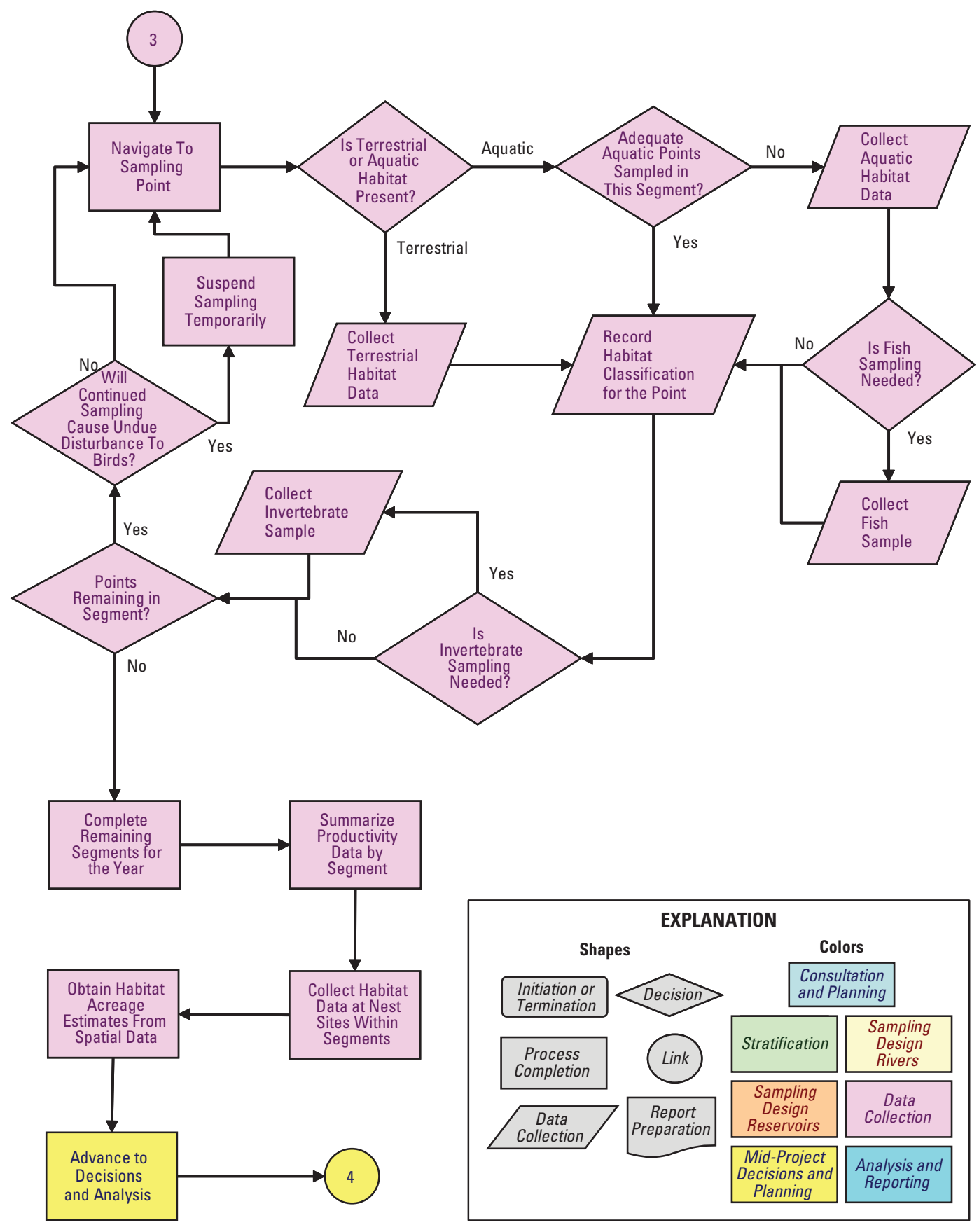

Figure 1. Continued 
D Decisions and Analysis

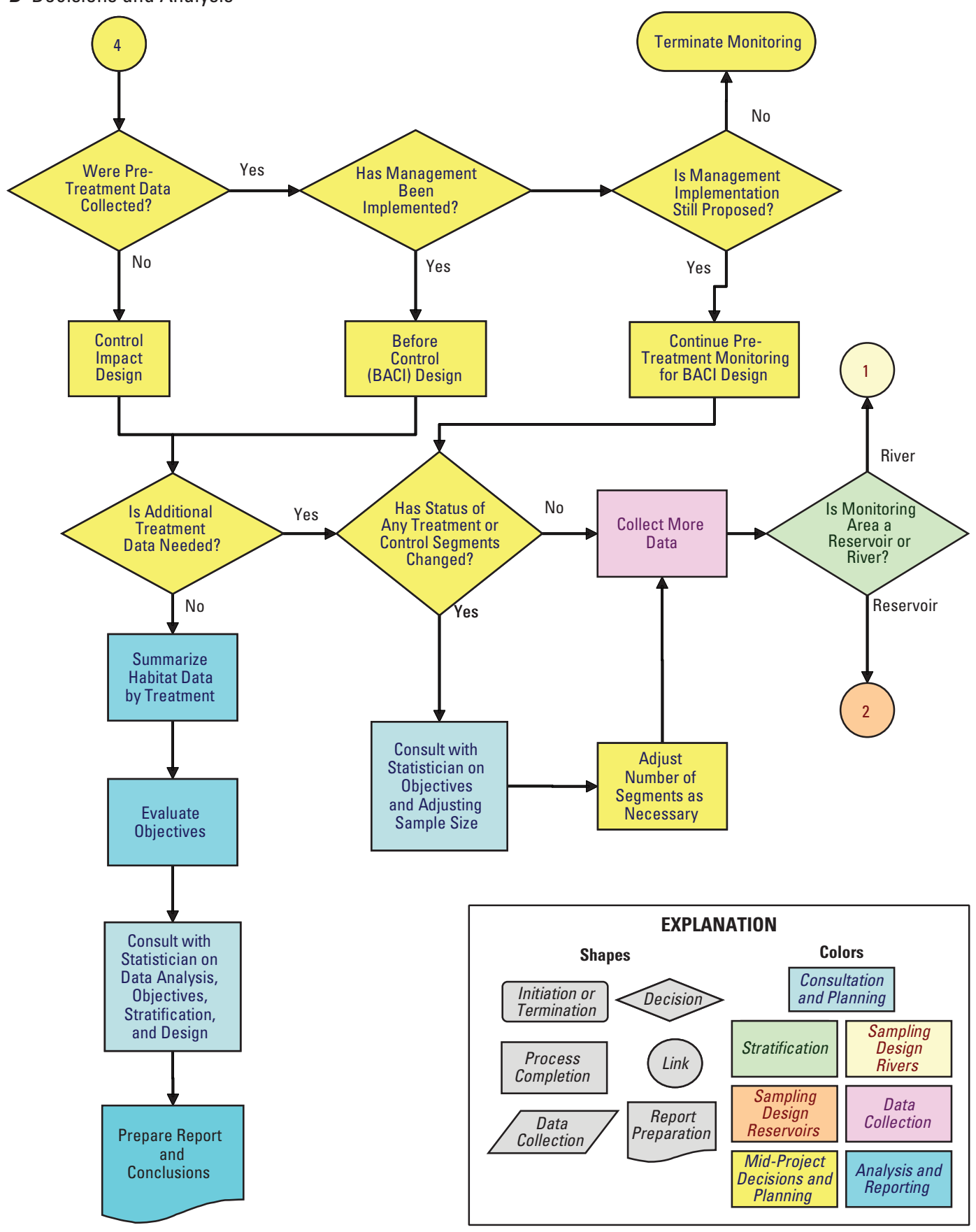

Figure 1. Continued 


\section{Emergent Sandbar Habitat Monitoring Framework}

The approach to monitoring of emergent sandbar habitat that is outlined in this plan can be broken down into a framework consisting of four phases. To illustrate these, the flowcharts on figure 1 identify the major decisions, processes, and data inputs required for implementing the process. The flowcharts are intended to capture the conceptual approach to monitoring and to identify the principal elements of the monitoring framework. Because each monitoring objective presents unique questions, priorities, and logistical hurdles, some aspects of the design (for example number of units to sample, number of points to measure per unit) cannot be prescribed in advance. Rather, the investigator must have the tools available to make decisions on a caseby-case basis that reflect the unique circumstances at hand. Therefore, accompanying each flowchart is a description of the monitoring activities conducted by a USGS field crew during 2006. The purpose of this report is to describe the various circumstances that occurred and the decision processes that were used by the principal investigators to address them. An important element of this process is consultation with statisticians to determine if the various phases are providing a design that adequately addresses the stated objectives.

The four principal phases of the monitoring framework are as follows:

1. Introduction and Planning-The initial phase sets the stage for the monitoring process through development of objectives, decisions regarding spatial extent and units of sampling, and ensuring that companion data (productivity and spatial data) are being collected concurrently (fig. 1). The end products of this phase are a set of objectives for the monitoring program, a stratification of the spatial extent based on these objectives, and a selection of sampling units to be sampled.

2. Sampling Design-This phase reflects selection of individual points within the sampling units for measurement of habitat variables. Selection of points will be completely random in some situations, but under most circumstances there should be some information available upon which to base allocation of points within the sampling unit. On reservoir shorelines, transects perpendicular to the water's edge are useful, while in many riverine situations analysis of satellite imagery can provide information on the distribution of major habitat types. The end product of this phase is an Action Plan that describes specific objectives of monitoring for the coming year and establishes the response variables and sampling locations to be included in monitoring.

3. Data Collection-This phase represents the collection of habitat data at the points selected in previous phases. It includes elements of disturbance avoidance, invertebrate and fish sampling (as applicable), and summary of productivity and spatial data by sampling unit. The end result of this phase is a complete habitat-productivityspatial data set for all areas sampled to address the objectives.

4. Decisions and Analysis-At the conclusion of each field season, this phase is conducted to decide upon direction and focus for the coming years. This phase allows for consideration of changing objectives, changing status of the sampling units, refining the scale of monitoring, and evaluating the effectiveness of response variables. It also provides for consultation with statisticians, formal data analysis, and reporting. 


\section{From Framework to Action: Implementation of the Plan}

Implementation of this plan will require annual assessments of the existing and proposed ESH projects for which monitoring is necessary. Because continual addition of new projects is anticipated, annual program reviews will become increasingly important exercises. Functions of these reviews would be to evaluate conclusions from the existing monitoring data, discuss scope and nature of upcoming ESH projects, and set priorities and objectives for monitoring during the coming year. These functions could all be accomplished in a single interagency meeting during the winter, if monitoring data, spatial analyses, and information on upcoming projects were simultaneously available.

There are two annual work products that should be produced through this process. The first is an annual Action Plan that establishes specific monitoring objectives for the coming year and describes proposed monitoring activities. Preparation of annual Action Plans would require adequate information on future ESH project locations so that sites for monitoring could be selected. Action Plans would provide detailed guidance to field crews on the locations, habitats, and response variables that will be included in that year's monitoring program. The second work product would consist of an overview of the previous year's monitoring activity, including summary of the data. This data summary would be useful in assessing whether sampling intensity was adequate to meet the stated objectives and to provide feedback to management decisionmaking.

In accordance with the principles of adaptive management, future revision of the conceptual framework outlined in this plan may be desirable. The framework and focus of the monitoring program will evolve as the ESH Program develops and knowledge accumulates regarding processes influencing least tern and piping plover habitat use. Accordingly, this plan will be periodically revisited to evaluate whether it continues to meet the science needs for monitoring of the ESH Program.

\section{Acknowledgments}

This plan was prepared in collaboration with the interagency Emergent Sandbar Habitat Product Delivery Team, which comprises scientists from the U.S. Army Corps of Engineers; National Park Service; U.S. Fish and Wildlife Service; U.S. Geological Survey; Yankton Sioux Tribe; North Dakota Game and Fish Department; South Dakota Department of Game, Fish, and Parks; Nebraska Game and Parks Commission; Virginia Polytechnic Institute and State University; and David Miller \& Associates. Field data collection was conducted by J. Kottsick, D. Prater, and M. Suchy. The plan was improved by comments on earlier drafts from C. Huber, C. Kruse, M. Morris, and J. Remus (U.S. Army Corps of Engineers), M. Olson (U.S. Fish and Wildlife Service), David Miller \& Associates, P. Hedren (National Park Service), and D. Buhl (USGS). 


\section{Contents}

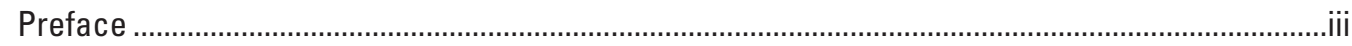

Habitat Monitoring: Scale and Linkage ......................................................................................ii

Emergent Sandbar Habitat Monitoring Framework .................................................................viii

From Framework to Action: Implementation of the Plan...............................................................ix

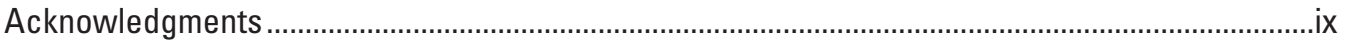

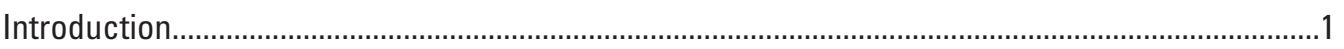

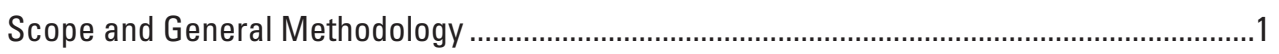

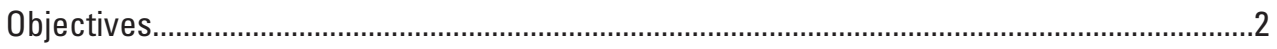

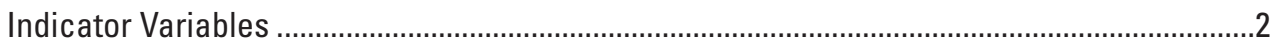

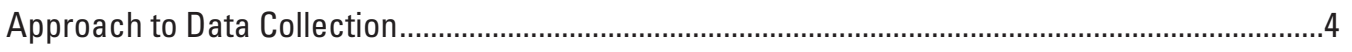

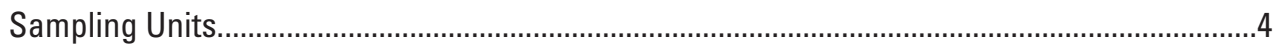

Units of Tern and Plover Nesting Habitat............................................................................. 5

A Stratified Sampling Approach to Monitoring ..........................................................................5

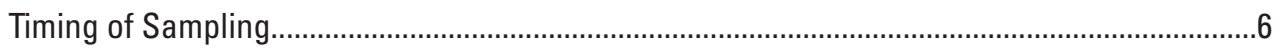

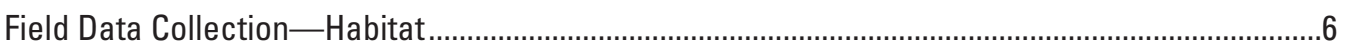

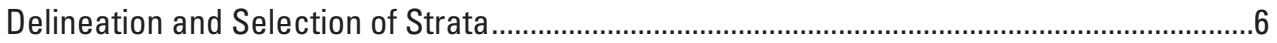

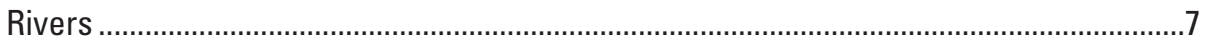

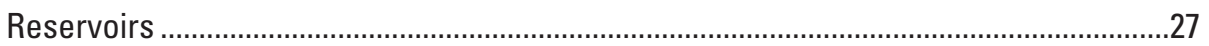

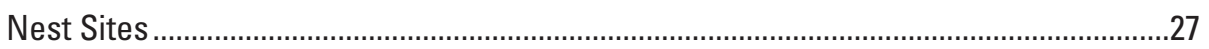

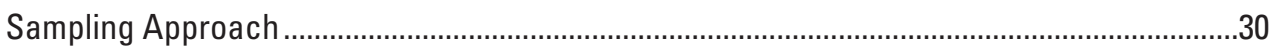

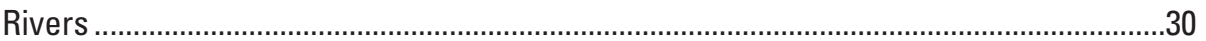

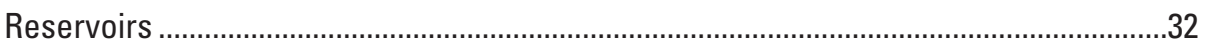

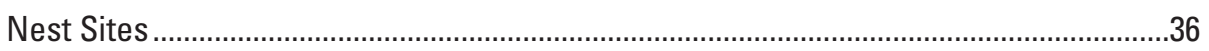

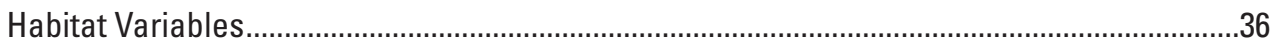

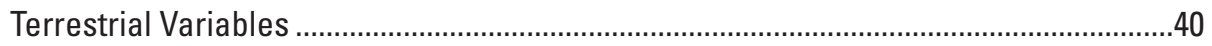

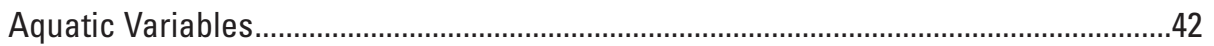

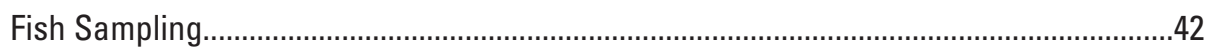

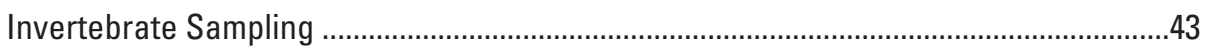

Timing of Habitat Sampling...................................................................................................... 44

Sample Sizes for Terrestrial Points ...........................................................................................46

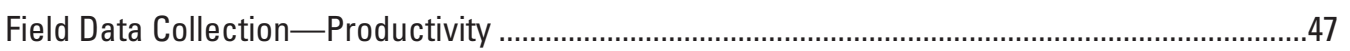

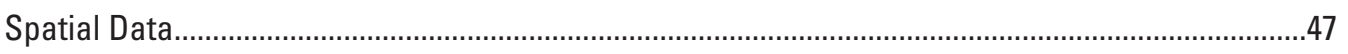

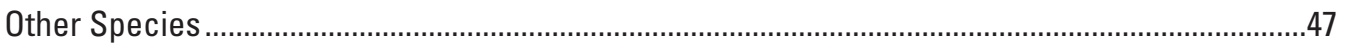

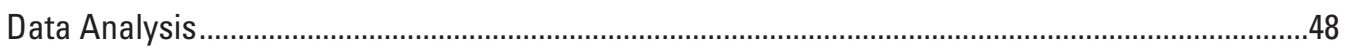

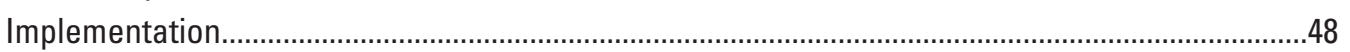

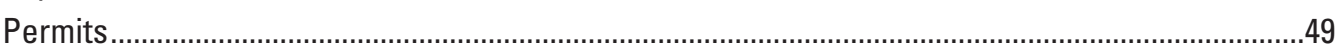

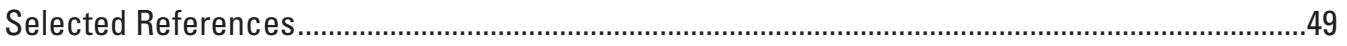




\section{Figures}

1. Conceptual framework for decisionmaking and implementation of habitat monitoring for management actions under the Emergent Sandbar Habitat (ESH) Program.

2. Map showing the Upper Missouri River system, including locations of selected reservoirs and free-flowing river reaches

2-19. Maps showing:

3. Example of 0.4-river-mile segments on the Gavins Point Reach, illustrating segments containing constructed emergent sandbar habitat (GAV09) and containing unmanaged natural emergent sandbar habitat (GAV08).

4. Example of 0.4-river-mile segments on the Gavins Point Reach, illustrating segments containing sprayed emergent sandbar habitat (GAV16) and containing unmanaged natural emergent sandbar habitat (GAV15)

5. Segments of the Gavins Point Reach of the Missouri River (RM 752-756) on which habitat data were collected for emergent sandbar habitat monitoring during 2006.

6. Segments of the Gavins Point Reach of the Missouri River (RM 757-767) on which habitat data were collected for emergent sandbar habitat monitoring during 2006.

7. Segments of the Gavins Point Reach of the Missouri River (RM 768-776) on which habitat data were collected for emergent sandbar habitat monitoring during 2006.

8. Segments of the Gavins Point Reach of the Missouri River (RM 777-786) on which habitat data were collected for emergent sandbar habitat monitoring during 2006.

9. Segments of the Gavins Point Reach of the Missouri River (RM 788-797) on which habitat data were collected for emergent sandbar habitat monitoring during 2006.

10. Segments of the Gavins Point Reach of the Missouri River (RM 801-808)

on which habitat data were collected for emergent sandbar habitat monitoring during 2006.

11. Segments of the North Dakota portion of Lake Oahe on which habitat data were collected for emergent sandbar habitat monitoring during 2006

12. Segments of the Fort Randall Reach of the Missouri River that were sampled in 2006 to characterize a proposed emergent sandbar habitat project near RM 827, at the headwaters of Lewis and Clark Lake

13. Segments of the Kensler's Bend Reach of the Missouri River on which habitat data were collected for emergent sandbar habitat monitoring during 2006 .

14. Spatial extent of habitat data for a proposed emergent sandbar habitat project on "Sonny's Island," Lake Sakakawea in 2006, depicting locations of transects composed of habitat evaluations every 5 meters.

15. Spatial extent of habitat data for a proposed emergent sandbar habitat project on "Randy's Island," Lake Sakakawea in 2006, depicting locations transects composed of habitat evaluations every 5 meters

16. Example of distribution of terrestrial and aquatic sampling points within two segments of the Gavins Point Reach of the Missouri River. 
17. Example of distribution of terrestrial and aquatic sampling points within two segments of the Gavins Point Reach of the Missouri River, showing the distribution of habitat types used to derive point locations..

18. Example of 100 completely random points distributed in a 0.4-river-mile habitat sampling segment on Lewis and Clark Lake, for which terrestrial habitat was known in advance to be present, but for which a habitat classification had not been derived.

19. Example of 20 completely random points distributed in a 0.4-river-mile habitat sampling segment on Kensler's Bend, for which terrestrial habitat was known in advance to be completely lacking. .35

20. Schematic of nest site, 3 meter, and 10 meter plot (1-meter-square plots) locations for evaluating nest-site and nest-area habitat characteristics

21. Map showing example of spatial extent of segment habitat data for Lake Sakakawea in 2006, depicting locations of nests, random points, transects composed of habitat evaluations every 5 meters, and additional transects needed for nest-beach scale analysis.

22-24. Graphs showing:

22. Least-square geometric mean counts per hour of invertebrates captured on sticky-stick traps during four time intervals at Lake Sakakawea in summer 2006

23. Least-square geometric mean counts per hour of invertebrates captured on sticky-stick traps by habitat type (tiers) during four time intervals at the Garrison Reach of the Missouri River in summer 2006

24. Least-square mean probability (95-percent confidence interval) that a nest site was available for sampling (not inundated) in August for each initial habitat classification after controlling for date of initial habitat assessment

\section{Tables}

1. Types of monitoring approaches with respect to a management action of interest.

2. Average number of piping plover and least tern nests found on the Gavins

Point Reach of the Missouri River during 2001-05 by 4-river-mile section.

3. Features of 0.4-river-mile segments of the Gavins Point Reach of the Missouri River in which habitat data were collected during 2006

4. Total number of least tern and piping plover nests found on the North Dakota portion of Lake 0 ahe during $2001-05$ by 4-river-mile section.

5. Features of 0.4-river-mile segments of the North Dakota portion of Lake Oahe on which habitat data were collected during 2006.

6. Total number of least tern and piping plover nests found on the Fort Randall Reach of the Missouri River during 2001-05 by 4-river-mile section

7. Features of segments of the Fort Randall Reach of the Missouri River on which habitat data were collected in 2006

8. Features of segments of the Kensler's Bend Reach of the Missouri River on which habitat data were collected in 2006. 
9. Summary of stratification of Lake Sakakawea, including numbers of 2-kilometer segments, segments sampled in 2006, and projected number of segments in 2007-09

10. Habitat types used to allocate sampling effort for emergent sandbar habitat monitoring on the Gavins Point Reach of the Missouri River in 2006

11. Numbers of least tern and piping plover nests where habitat characteristics were evaluated for reaches of the Missouri River in summer 2006..................................37

12. Daubenmire cover classes and corresponding ranges of percent cover .......................39

13. Size range of substrate classes used to describe habitats on the Missouri River

14. Standard classification scheme for weather observations at sampling points

15. Terrestrial habitat variables recorded at emergent sandbar habitat monitoring points on the Missouri River and the relationship with ongoing productivity monitoring and remote sensing efforts.

16. Aquatic habitat variables measured at emergent sandbar habitat monitoring points on the Missouri River and the relationship with ongoing productivity monitoring and remote sensing efforts.

17. Habitat classes recorded at nest upon discovery (initial) and during August revisits for least tern and piping plover nests $(n=345)$ on the Garrison Reach of the Missouri River in 2006.

18. Distribution of habitat sampling achieved by a three-technician crew on the Missouri River during the 2006 field season. .. .48

\section{Conversion Factors}

\begin{tabular}{lll}
\hline Multiply & By & To obtain \\
\hline & Length & \\
\hline centimeter $(\mathrm{cm})$ & 0.3937 & inch (in.) \\
millimeter $(\mathrm{mm})$ & 0.03937 & inch (in.) \\
meter $(\mathrm{m})$ & 3.281 & foot $(\mathrm{ft})$ \\
kilometer $(\mathrm{km})$ & 0.6214 & mile (mi) \\
square meter $\left(\mathrm{m}^{2}\right)$ & 10.76 & square foot $\left(\mathrm{ft}^{2}\right)$ \\
\hline
\end{tabular}

Temperature in degrees Fahrenheit $\left({ }^{\circ} \mathrm{F}\right)$ may be converted to degrees Celsius $\left({ }^{\circ} \mathrm{C}\right)$ as follows:

$$
{ }^{\circ} \mathrm{C}=\left({ }^{\circ} \mathrm{F}-32\right) / 1.8
$$

Vertical coordinate information is referenced to the North American Vertical Datum of 1988 (NAVD 88). 



\title{
Missouri River Emergent Sandbar Habitat Monitoring Plan-A Conceptual Framework for Adaptive Management
}

\author{
By Mark H. Sherfy, Jennifer H. Stucker, and Michael J. Anteau
}

\section{Introduction}

Habitat conditions are one of the most important factors determining distribution and productivity of least terns (Sternula antillarum) and piping plovers (Charadrius melodus) in the upper Missouri River system (Ziewitz and others, 1992; Kruse and others, 2002). Habitat conditions are known to change within and among seasons in response to variation in river flows, weather conditions, and management actions targeted at providing for the needs of terns and plovers. Although these principles are generally agreed upon, there is little empirical information available on the quantity and quality of tern and plover habitats in this system, particularly with reference to the major life history events that must be supported (egg laying, incubation, and brood rearing). Habitat requirements for these events are composed of two major categories: nesting and foraging habitat. In the case of piping plovers, these two requirements must occur on the same area because plover chicks are constrained to foraging near nesting sites prior to fledging (Knetter and others, 2002; Haffner, 2005). In contrast, least terns chicks are fed by the adults, allowing food procurement for broods to occur outside the immediate nesting area; however, food resources must be close enough to nesting locations to minimize foraging time.

The complexity and dynamics of the upper Missouri River system introduce considerable uncertainty into how best to manage tern and plover habitats, and how best to evaluate the effectiveness of this management. An extensive program of habitat monitoring will be needed to address this complexity and support the management of least terns and piping plovers under the Missouri River Recovery Program. These needs are being addressed, in part, through a program of habitat creation and management targeted at improving quality and quantity of habitats for terns and plovers. Given the momentum of these projects and their associated costs, it is imperative that the capacity be available to quantify changes in managed habitats for least terns and piping plovers, so that management effectiveness can be evaluated.

Extremely high flows and flooding of the Missouri River in 1997 created and improved vast amounts of nesting habitat for least terns and piping plovers. Since 1998, there has been an apparent loss and/or degradation of habitat throughout the river system. However, during the same timeframe reservoir water levels have declined, exposing extensive piping plover breeding habitat. For example, 64 percent of adult piping plovers using the Missouri River in 2005 were observed on reservoir habitats, and 43 percent were observed on Lake Sakakawea (Threatened and Endangered Species Section, Omaha District, U.S. Army Corps of Engineers, unpub. data, 2006). Given the vast dynamics of this river and reservoir system, systemwide monitoring of habitat is clearly needed for the U.S. Army Corps of Engineers (USACE) to employ adaptive management (with respect to river operations) to provide most optimal conditions for the maintenance of breeding habitat of least terns and piping plovers. As a result of this need, the U.S. Geological Survey, in cooperation with the U.S. Army Corps of Engineers, began work on a habitat monitoring plan in 2005 as a conceptual framework for adaptive management.

\section{Scope and General Methodology}

This report describes a monitoring program for collection of biological data for evaluation of system responses to creation and management of emergent sandbar habitat (ESH) on the Upper Missouri River system (fig. 2). The variables and field methods described were extensively tested by a crew of USGS field technicians during May-August 2006 as part of a research task funded by the USACE. This crew was tasked with testing the conceptual framework under a variety of circumstances to ensure that methodology and variables were broadly applicable. The decisions made during habitat sampling in 2006 are described to illustrate how the conceptual framework for monitoring could be implemented under these varied circumstances. None of the specifics encountered during 2006 nor the decisions made to accommodate them should be considered universal rules for implementation of the monitoring program. Rather, the conceptual framework should be viewed as providing guidance in future decisionmaking. The areas sampled during 2006 included: 
- Kensler's Bend-This is a reach of river that contains no existing ESH, and in which future construction of several ESH projects is under consideration. Projects would likely consist of top-width widening, chute excavation, and other means of restoring sandbar conditions within the river's flood plain. This component of the project reflected a preproject evaluation of sites for newly created sandbars in a riverine system.

- Gavins Point Constructed Islands-ESH complexes were created by the U.S. Army Corps of Engineers during 2004-05 at river mile (RM) 754.5, 761.5, and 770.0. This component of the 2006 monitoring reflected a postproject evaluation of newly created sandbars in a riverine system.

- Gavins Point Vegetation Control-An extensive program of mechanical and herbicidal vegetation control was implemented on the Gavins Point Reach in 2005. This effort was focused on "natural" sandbars (defined as those deposited by the river's hydrology rather than mechanical means) on which vegetation growth was believed to be hindering use by least terns and piping plovers. This component of the 2006 monitoring reflected a postproject evaluation of vegetation control in a riverine system.

- Lake Oahe Vegetation Control- Implementation of vegetation control is proposed for sandbars occurring on upper Lake Oahe, between the North DakotaSouth Dakota border and RM 1304. The upper limit of this study area (RM 1304) is commonly defined as the northernmost extent of Lake Oahe, with reservoir conditions existing below RM 1304 and riverine conditions existing above RM 1304. Owing to drought in the upper Missouri River basin, the water level in Lake Oahe is at an all-time low, causing riverine conditions to extend well below RM 1304. Consequently, this component of the 2006 monitoring reflected a pre-project evaluation of a vegetation control project in both a riverine and a reservoir system.

- Garrison Reach-No ESH projects have been implemented or are proposed on this area. However, the area was the subject of an intensive productivity monitoring effort by USACE and USGS crews in 2006. As part of the USGS effort, habitat data were collected at tern and plover nest sites at the time of nest discovery. To evaluate change in habitat conditions from early to late summer, the habitat monitoring crew revisited nest sites and collected additional habitat data during August 2006. This data collection reflected use of the proposed procedures to evaluate habitat change over time.

- Lake Sakakawea-Vegetation control is proposed for several areas of Lake Sakakawea shoreline to improve piping plover nesting habitat conditions. The habitat monitoring crew collected habitat data on two of the proposed sites for which the specific locations were defined. This component of the 2006 monitoring reflected a preproject evaluation of vegetation control in a true reservoir system.

\section{Objectives}

One of the most fundamental goals of ecological monitoring is to detect change in a resource of management importance (Bailey and Herzog, 2004). Accordingly, design of an efficient and useful monitoring program requires baseline information on the abundance and/or distribution of those resources. It also requires a sampling approach that is of adequate intensity and extent to allow detection of changes that are important in a management context. With these principles in mind, the following objectives will be the focus of this monitoring program:

1. Evaluate changes in least tern and piping plover habitats in response to construction of ESH under the ESH Program.

2. Evaluate changes in least tern and piping plover habitats in response to manipulation of ESH through vegetation control.

3. Because the ESH Program focuses on providing habitat for least terns and piping plovers, these objectives focus on the principal information needs to evaluate success at delivering the desired habitat features. It is important to recognize that these objectives are intended to serve the long-term monitoring needs of the ESH Program. Through development of annual Action Plans (Phases 1 and 2 in the monitoring framework), objectives will be derived that are specific to the unique circumstances encountered each year.

\section{Indicator Variables}

Reeves and others (2003) reviewed a suite of 90 potential indicators that could be used to assess watershed condition. These were distilled into a core set on the basis of the following evaluation criteria:

- Changes in the system would be reflected in measurable changes in the indicator.

- The indicator must respond quickly enough to disturbance or recovery to provide results in the chosen timeframe.

- The indicator can be accurately and precisely measured or estimated.

- The indicator must be generally accepted as a useful indicator of ecological condition. 


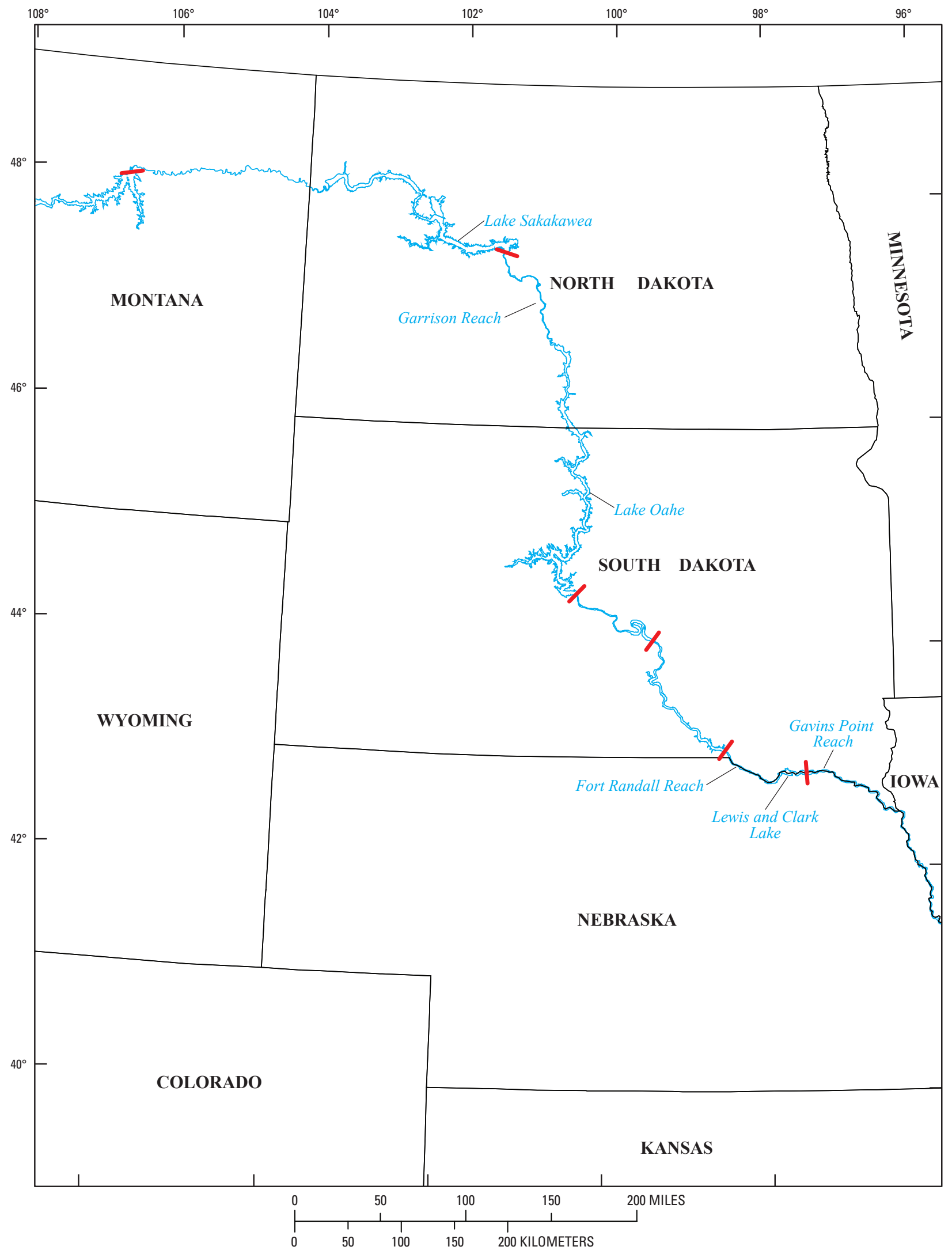

Figure 2. The Upper Missouri River system, including locations of selected reservoirs and free-flowing river reaches. Red symbols represent dams. 
- Measurement of the indicator must be cost effective at the required level of precision and accuracy.

These criteria provide a useful source of guidance for selecting indicators to be used in monitoring tern and plover habitats on the Missouri River. In developing this plan, we evaluated a preliminary set of indicators to quantify habitat conditions at each sampling point, using the same indicators on both reservoir shorelines and sandbars. A critical component of this evaluation was to determine the utility of these indicators for long-term monitoring of tern and plover habitats. Thus, it is possible that the list of indicators or the methods used to measure them described in this plan might not be suitable for future needs, particularly if there is a change in Missouri River management objectives or methods.

The intent is that the suite of indicator variables selected for monitoring would be useful not only for measuring habitat responses to the ESH Program, but also for evaluating nest site selection of terns and plovers. Accordingly, this suite of variables should be suitable for measurement at tern and plover nest sites. Because collection of habitat data at nest sites is important for evaluating least tern and piping plover use of habitats provided under the ESH Program, the procedures developed here will be simultaneously implemented at nest sites by crews conducting companion studies of least tern and piping plover productivity. Evaluating nest site selection is an important step toward understanding biological function of the Missouri River system. Perhaps more important in a monitoring context, this type of analysis would provide feedback regarding importance of the variables being measured, allowing refinement of habitat monitoring to target those variables that most clearly influence habitat use by terns and plovers.

\section{Approach to Data Collection}

One of the central questions in designing a monitoring protocol is where and when to collect data on the indicator species. Many different approaches are possible, ranging from a few samples collected in managed habitats, to a complex array of sampling in a rigorous, statistically valid experimental design. These approaches generally differ in the number and distribution of samples, with methods at the chosen sampling locations being similar among approaches (such as stem counts within a 1-meter-square $\left(\mathrm{m}^{2}\right)$ quadrat to measure stem density of woody vegetation). Decisions about where and at what frequency to conduct sampling have substantial bearing on the conclusions that can be drawn from the data.

Elzinga and others (2001) describe a continuum of data collection methods for monitoring (Types A-F, table 1) that represent a range of sampling intensity and therefore a range of possible statistical inference. The simplest form of monitoring (Type B) consists of data collection on a single sampling unit after the management action has been implemented, with no replication, no pretreatment data collection, and no experimental controls. This represents the simplest, quickest approach to monitoring, but provides very limited ability to draw definitive conclusions about the consequences of the management action. Advancing from Type B through Type F, sampling is intensified by addition of pretreatment monitoring (Type C), experimental controls (Type D), and replication of sampling units (Types E and F). An additional practice not addressed by Elzinga and others (2001) but that could aid in further extending inference from the monitoring data is random application of management actions among the suite of potential sampling units (Type G). The Type $\mathrm{G}$ form of monitoring is identical to Johnson's (2002) "manipulative experimentation," as it includes all three elements (experimental control, replication, and randomization) that together provide a powerful way to learn about causal mechanisms. Elzinga and others (2001) note that statistical analysis of data resulting from all of these approaches is possible, but that the "observational" approaches (Types A-D, table 1) provide limited information about cause and effect. Consequently, selection of a monitoring approach must include some consideration about the importance of demonstrating causal relationships from the data being collected.

\section{Sampling Units}

In considering replication of treatment and control groups in a manipulative experiment, it is important to define the sampling unit and the population from which it will be drawn. When the units that are sampled are representative of the larger population, inference can be extended to the population (Cochran, 1977). Sampling intensity dictates the strength of conclusions at several scales. First, each unit must be sampled at an adequate intensity to characterize its nature. In some cases, this may only require a single measurement, and in others, it may require multiple measurements. Second, enough sampling units must be included in the study to adequately characterize the population from which they were drawn. In situations requiring multiple measurements to characterize each sampling unit, it is tempting to view each measurement as providing information about the nature of the entire population. However, this view ignores a critical element in the definition of sampling units - they must be independent of each other to be considered separate units. Thus, measurements within a sampling unit provide information about that unit, and the "average" condition of the sampling units provides information about the nature of the population. Hurlbert (1984) emphasized the importance of defining independent sampling units and recognizing that repeatedly measuring the same unit does not always contribute additional information about the population. 
Table 1. Types of monitoring approaches with respect to a management action of interest. Values indicate whether each element is sampled under a given approach.

[0=no sampling, $1=$ one sampling unit, $>1=$ minimal replication, and $>>1=$ adequate replication $]$

\begin{tabular}{|c|c|c|c|c|c|}
\hline \multirow{2}{*}{ Type } & \multirow{2}{*}{ Approach } & \multicolumn{2}{|c|}{ Pre-action } & \multicolumn{2}{|c|}{ Post-action } \\
\hline & & Control & Treatment & Control & Treatment \\
\hline A & No monitoring & 0 & 0 & 0 & 0 \\
\hline B & Postmonitoring only & 0 & 0 & 0 & 1 \\
\hline $\mathrm{C}$ & Premonitoring and postmonitoring & 0 & 1 & 0 & 1 \\
\hline $\mathrm{D}$ & $\begin{array}{l}\text { Premonitoring and postmonitoring with } \\
\text { experimental control }\end{array}$ & 1 & 1 & 1 & 1 \\
\hline $\mathrm{E}$ & $\begin{array}{l}\text { Premonitoring and postmonitoring with } \\
\text { experimental control and minimal replication }\end{array}$ & $>1$ & $>1$ & $>1$ & $>1$ \\
\hline $\mathrm{F}$ & $\begin{array}{l}\text { Premonitoring and postmonitoring with } \\
\text { experimental control and good replication }\end{array}$ & $>1$ & $>>1$ & $>1$ & $>1$ \\
\hline G & $\begin{array}{l}\text { Premonitoring and postmonitoring with } \\
\text { experimental control, good replication, and } \\
\text { randomized application of treatments }\end{array}$ & $\begin{array}{l}>>1 \\
\text { (Random) }\end{array}$ & $\begin{array}{l}>>1 \\
\text { (Random) }\end{array}$ & $\begin{array}{l}>>1 \\
\text { (Random) }\end{array}$ & $\begin{array}{l}>>1 \\
\text { (Random) }\end{array}$ \\
\hline
\end{tabular}

\section{Units of Tern and Plover Nesting Habitat}

In the context of monitoring habitat conditions, it is imperative to define a unit of habitat as the sampling unit. Where making inference to a larger population of habitat units is desirable, it is critical that the units be definable and independent, and that their relationship to the population be known. Least tern and piping plover nesting habitats on the Missouri River present some unique challenges in this regard, because they are usually arranged in discrete units that are seemingly appropriate sampling units. However, both midchannel emergent sandbars and reservoir shorelines are highly dynamic habitats that change dramatically in form and extent both within and among seasons. These changes are in response to rising and falling water levels, and to redistribution of midchannel sand. In many cases, water level fluctuations are substantial enough that sandbars are extensive when flows are low and completely absent when flows are high. Because the amount of exposed sandbar habitat is directly tied to flow rate, sandbars do not represent a discrete, definable sampling unit. Additionally, the extensive changes in acreage and distribution of sandbars within and among years make it problematic to consider individual sandbars as discrete sampling units.

A similar problem with defining sampling units occurs on reservoir shorelines, where the amount of exposed habitat is a function of reservoir water elevation. Falling water levels generally produce wider areas of unvegetated shoreline, whereas rising water levels reduce width of available nesting habitat. Changing water levels also alter the overall length of shoreline throughout a reservoir, particularly where contours are sinuous and irregular.

\section{A Stratified Sampling Approach to Monitoring}

Stratified sampling is an approach to collection of data that takes advantage of known sources of variation in the population of potential sampling units, dividing the group of units into several nonoverlapping subgroups or strata. A sample of units to be measured is drawn from each stratum. This approach produces results of known precision for each stratum, and can produce gains in precision of estimates for the population as a whole if it reduces a heterogeneous population into several more homogeneous strata (Cochran, 1977). Gains in precision are largest when (Cochran, 1977):

1. The population is composed of units that vary widely in size.

2. The variables to be measured are closely related to the size of the units.

3. A good measure of unit size is available for defining strata.

In the case of Missouri River nesting habitats used by least terns and piping plovers, considerable heterogeneity in use by birds within river reaches is evident. Therefore, condition 1 is satisfied. There also is an implicit assumption that variation in habitat condition is one of the principal factors leading to heterogeneous distribution of birds. Thus, for monitoring of habitat conditions, the variables to be measured (habitat variables) are believed to be closely related to the size of strata (measured by relative bird use), and condition 2 is satisfied. Finally, the existence of a long-term data set on tern and plover nest locations provides a measure of bird distribution within reaches, satisfying the need to measure stratum 
size in condition 3 . Thus, stratified sampling would be a useful and appropriate approach to monitoring ESH projects.

Width of the river channel is a secondary stratification, which may also be important to consider in riverine habitats. River channel width varies extensively throughout the Upper Missouri River System (Biedenharn and others, 2001; Elliott and Jacobson, 2006); it is positively correlated with the number of unattached sandbars and the acres of sandbars and is a proxy for river geomorphology (Biedenharn and others, 2001; Elliott and Jacobson, 2006); and is easily measured with widely available geospatial/mapping software. Thus, river channel width satisfies the above conditions and could be useful information for stratification within bird use histories. Accordingly, river channel width could be useful for selecting segments to be paired for data analyses or for blocking on the variability associated with river geomorphology.

\section{Timing of Sampling}

A useful design for monitoring habitat change is the Before-After-Control-Impact (BACI) approach to sampling for projects that have not yet been constructed and that afford an opportunity for collection of habitat data prior to construction. These included the Kensler's Bend, Lewis and Clark Lake, Lake Oahe, and Lake Sakakawea study areas during 2006, and depending on the extent of ESH implementation, may include other areas in subsequent years. The BACI design includes sampling of both treatment and control sites before and after the treatment is applied, which allows treatment effects to be separated from temporal effects. Effective implementation of this design requires advance knowledge of where treatments will be implemented so that segments can be accurately characterized, which is expected to be the case for this study. Repeated evaluation of the same sites in multiple years will allow detection of responses due to temporal and treatment effects. Therefore, the design calls for random selection of segments once for the 2006 project sites, and monitoring of those same segments in subsequent years. Likewise, for new project sites that are identified in future years, new sets of segments should be selected to characterize those treatment effects.

Duration of monitoring for each segment will depend upon the nature of the project being monitored. Vegetation control by herbicide application is one of the principal ESH management efforts expected to be evaluated under this plan. On the basis of preliminary observations of vegetation growth patterns on Missouri River sandbars and the anticipated effects of herbicides being implemented by the USACE, some herbicide treatment effects may persist into the second year posttreatment. Therefore, segments selected to evaluate vegetation control projects should be monitored for at least 2 years after project implementation. Because construction projects are more likely to have long-term influence on bird use and productivity, a longer monitoring period will be necessary on segments selected for evaluation of constructed sandbar projects.
It is possible that some confounding of treatment and temporal effects might occur. For example, a control segment selected for 2006 might be chosen by the USACE in 2007 for implementation of an ESH project, and thus become a potential treatment segment for 2007. The reverse is not true, because treatment segments will remain treatment segments for a 2-year period after the ESH project. Therefore, if time allows, it would be beneficial to increase the number of control segments sampled in the event that their status changes in subsequent years.

\section{Field Data Collection-Habitat}

The methods described in this plan could be used for a number of purposes related to ESH quality, focusing on least terns and piping plovers. A traditional monitoring context would employ habitat data collected at points arranged throughout the defined area of interest in a manner that ensures that the points are representative of the area of interest.

For many reasons, it is sensible to consider each of the major river reaches and reservoirs (hereafter referred to as "reach"), as defined in the 2003 Amendment to the Missouri River Biological Opinion, as providing a "population" of habitats for which monitoring could be implemented. Each reach is managed as a quasi-discrete unit, and each has its own unique spatial, hydrological, and geological features that lead to substantial variation in use by terns and plovers. The Opinion identifies specific ESH acreage goals for each reach, and a comprehensive long-term monitoring program for each reach could provide a useful evaluation of changes in habitat quality as those acreage goals are met.

\section{Delineation and Selection of Strata}

Given the challenges in defining sampling units in a highly dynamic system and the desirable properties of a stratified sampling design, considerable emphasis should be placed on establishing boundaries for strata within the selected study reach. In some situations, particularly those in which habitat creation is concerned, sandbars are not a useful measurement unit for evaluating pretreatment and posttreatment habitat conditions. This is because, by definition, nesting habitat may be absent or limited under pretreatment conditions at an ESH construction site. A more useful experimental unit for measurement of habitat variables is a section of river or reservoir shoreline, in which the total amount of nesting habitat can be quantified prior to and after the management action. For example, documenting that tern and plover nesting habitat increased by $n$ acres from year $x$ to year $x+1$ on a river section owing to the ESH Program provides a useful basis for temporal and spatial comparisons. Another advantage to this approach is that tern and plover productivity data are readily partitioned into sections, which would allow for analyses of bird responses to habitat management. Moreover, sandbars are 
an inappropriate experimental unit for long-term monitoring projects because of their ephemeral nature in riverine systems.

Following are descriptions of approaches to stratification of river and reservoir shorelines that would be useful for habitat monitoring. The preferred approach is shown using examples from field work on the Gavins Point Reach and Lake Sakakawea during 2006.

\section{Rivers}

One of the initial challenges in this approach was to select a section length that is an appropriate unit for quantifying both productivity and habitat variables. A 4-river-mile section of river will be a useful unit of measurement for productivity data, on the basis of experience monitoring least tern and piping plover nests on the Gavins Point and Garrison reaches during 2005 and 2006 (NPWRC Task 2: Evaluation of procedures for monitoring numbers and productivity of least terns and piping plovers on the Missouri River). This section length was selected for use during the 2006 field season under the assumption that a crew of 4 technicians would be able to monitor all available nesting habitat on 2 sections per day. Assuming that this standard can be met, a 4-mile river section also would be a useful scale at which river reaches could be stratified for the purpose of habitat monitoring. Because River Miles (RM) are a standard unit of distance measurement on the Missouri River, they were retained as the basis of river stratification for this and companion studies. For the purposes of monitoring, each 4-mile section was divided into ten 0.4-RM segments. On the basis of experience conducting accuracy assessments of remote sensing data on the Gavins Point Reach during 2005 (NPWRC Task 3: Mapping, monitoring, and estimation of least tern and piping plover habitats on the upper Missouri River using Quickbird imagery), this is a practical unit of measurement for quantifying abundance of major habitat cover types.

The initial step in developing a stratification of the Gavins Point Reach was dividing the reach into 4-RM sections. The downstream RM marker was used as a unique identifier for each segment (for example 754 for RM 754-758). For each section, USACE productivity monitoring data were used to derive the average number of least tern and piping plover nests for the 5 years prior to initiation of habitat monitoring studies (2001-05). After determining the average number of nests, each section was assigned to a high, medium, or low use category. The goal was to assign approximately equal numbers of sections (4-6) to each category, but the natural "breaks" in nest count data might not always be evident. One to 13 nests were used for the Gavins Point Reach to define the low $(n=4)$ category, 19.8-34.2 nests to define the medium $(n=6)$ category, and 38.2-71 nests to define the high $(n=4)$ category (table 2$)$. These break points are specific to Gavins Point and to the objective of identifying three use categories. For other reaches and other objectives (such as delineating high and low use only), different break points will need to be identified.
The next step was to divide each section into 0.4-RM segments, and to assign additional attributes to each segment. The bird use categories derived for the 4-RM sections were applied to each component segment. Thus, section 01 (RM 754-758) consisted of ten 0.4-RM segments, each of which was classified as high bird use. Not all segments within the section will have identical histories of bird use. However, this approach recognizes that broad areas of the river are favored by nesting birds, with interannual changes in habitat conditions dictating distribution of nesting effort within sections. After this step was complete for Gavins Point, 140 segments were available for sampling. Because the management programs under evaluation are targeted at ESH, segments that did not contain ESH in 2005 were eliminated from consideration. Some situations may warrant retaining segments that are devoid of sandbars in the sample to be monitored. For example, a segment containing no sandbars that was targeted for construction of a new sandbar could be selected for preconstruction monitoring. Because sandbars do not persist through time, segments containing sandbars at the start of a monitoring program might not contain any in later years. For Gavins Point in 2006, 104 segments were identified that contained sandbars on the basis of 2005 photography.

At the segment level the secondary stratification of river channel width could be applied. For example, this stratification was applied to segments of interest on the Gavins Point Reach (see following); the river channel width (furthest expanse of water perpendicular to flow including "main" and "back" channels) was measured at the middle and borders of each segment $(n=3)$. The mean of width measurements were used to classify each segment as low ( $<700$ meters), medium (700-1,000 meters), and high (>1,000 meters) widths (table 3 ).

There were two distinct goals of the 2006 sampling on the Gavins Point Reach that illustrate different approaches to selecting a sample of segments for monitoring. Gavins Point contains three constructed sandbar complexes and numerous natural sandbars that were treated with herbicide for vegetation control during 2005. The monitoring program was designed to accommodate both management tools, but each has its own unique attributes.

Mechanical construction of emergent sandbars is a complex, costly process. Therefore, this management tool is applied relatively infrequently. Viewed in an experimental context, this application of a "treatment" does not lend itself to detection of responses, because it lacks two principal elements of a designed experiment (randomization and replication). However, it does allow assignment of a treatment status to each 0.4-RM segment on the basis of presence or absence of constructed sandbar habitat. Sample size will, by definition, be low for segments containing constructed habitat. Therefore, it is likely that selection of all "treated" segments within a river reach will be required to achieve a sample size suitable for statistical analysis. In many cases, even this approach will not generate a suitable sample size owing to the focused nature of these projects. However, a long-term program of monitoring following the procedures outlined in this plan will generate 
Table 2. Average number of piping plover and least tern nests found on the Gavins Point Reach of the Missouri River during 2001-05 by 4-river-mile section.

[RM, river mile; L, low; $\mathrm{M}$, medium; $\mathrm{H}$, high]

\begin{tabular}{cccccc}
\hline Section number & Downstream RM & Piping plover nests & Least tern nests & Total nests & Use category \\
\hline 01 & 754 & 39.2 & 31.8 & 71 & $\mathrm{H}$ \\
02 & 758 & 18 & 20.2 & 38.2 & $\mathrm{H}$ \\
03 & 762 & .6 & 1.4 & 2 & $\mathrm{~L}$ \\
04 & 766 & 5.4 & 7.6 & 13 & $\mathrm{~L}$ \\
05 & 770 & 10.4 & 23.8 & 34.2 & $\mathrm{M}$ \\
06 & 774 & 6.8 & 13 & 19.8 & $\mathrm{M}$ \\
07 & 778 & 13 & 34.6 & 47.6 & $\mathrm{H}$ \\
08 & 782 & .8 & 0.2 & 1 & $\mathrm{~L}$ \\
09 & 786 & 17.4 & 36 & 53.4 & $\mathrm{H}$ \\
10 & 790 & 14.4 & 19 & 33.4 & $\mathrm{M}$ \\
11 & 794 & 12 & 20.8 & 32.8 & $\mathrm{M}$ \\
12 & 798 & 10.8 & 19 & 29.8 & $\mathrm{M}$ \\
13 & 802 & 18.4 & 12.4 & 30.8 & $\mathrm{M}$ \\
\hline
\end{tabular}

a data set with many replicates of "treated" and "control" segments that will be useful in evaluating biological responses to ESH construction.

Habitat manipulation on existing sandbars occurs at an entirely different scale and intensity than construction of new sandbars. For example, vegetation was sprayed on approximately 181 acres of habitat on 23 separate sandbars on the Gavins Point Reach in 2005. Management actions of this nature provide more desirable statistical properties because they provide replication and interspersion of treated and untreated habitats. These properties increase the likelihood that a favorable sampling design can be established. To accommodate both ESH construction and management projects, each Gavins Point segment was assigned to an ESH stratum as follows:

- Construction segments contained (in 2005) constructed ESH (fig. 3).

- Sprayed segments contained habitat that had been sprayed in 2005 for vegetation control (fig. 4).

- Control segments contained neither sprayed nor constructed ESH (figs. 3 and 4).

The ESH strata used on Gavins Point in 2006 were designed specifically for the circumstances existing at the time habitat monitoring began. Although each river reach will present a different arrangement of existing and proposed treatments, a similar set of guiding principles should be followed in selecting segments for monitoring:
- Separate selections should be made for treated segments in each of the available ESH strata within a reach. Where $>1$ treatment has been applied within a reach, it would be improper to pool all treated segments and randomly select treated segments from the combined pool. Rather, each treatment applied within a reach should be considered separate and distinct from the other treatments for the purpose of segment selection.

- The number of treated segments selected will vary according to the number that received the treatment of interest, the number that can be feasibly sampled, and the likely variation in response variables within that treatment. For Gavins Point in 2006, it was determined that 30 segments were sprayed during 2005, and 12 of these were selected for habitat sampling. Five segments were determined to contain constructed habitat; because availability of these segments was limited, all five were selected for sampling.

- Where the number of available treatment segments requires subsampling, selection should be in a stratified random fashion. Of the 30 sprayed segments on Gavins Point, 6 were in the low use stratum, 17 in the medium use stratum, and 7 in the high use stratum. Because of this the stratification was derived so that about one-third of the reach fell into each stratum, four sprayed segments were randomly selected from each. An alternative would be to select segments according 
Table 3. Features of 0.4-river-mile segments of the Gavins Point Reach of the Missouri River in which habitat data were collected during 2006.

[ID, identifier; RM, river mile; L, low; M, medium; H, high; Y, yes; N, no]

\begin{tabular}{|c|c|c|c|c|c|c|}
\hline Segment ID & Downstream RM & Upstream RM & $\begin{array}{l}\text { Historical tern/ } \\
\text { plover use }\end{array}$ & River width & $\begin{array}{c}\text { Vegetation } \\
\text { control in 2005? }\end{array}$ & $\begin{array}{c}\text { Created sandbar } \\
\text { present? }\end{array}$ \\
\hline GAV01 & 754.0 & 754.4 & $\mathrm{H}$ & $\mathrm{L}$ & $\mathrm{N}$ & $\mathrm{Y}$ \\
\hline GAV02 & 754.8 & 755.2 & $\mathrm{H}$ & $\mathrm{L}$ & $\mathrm{N}$ & $\mathrm{Y}$ \\
\hline GAV03 & 757.2 & 757.6 & $\mathrm{H}$ & M & $\mathrm{N}$ & $\mathrm{N}$ \\
\hline GAV04 & 757.6 & 758.0 & $\mathrm{H}$ & $\mathrm{L}$ & $\mathrm{N}$ & $\mathrm{N}$ \\
\hline GAV05 & 758.4 & 758.8 & $\mathrm{H}$ & M & $\mathrm{N}$ & $\mathrm{N}$ \\
\hline GAV06 & 758.8 & 759.2 & $\mathrm{H}$ & M & $\mathrm{Y}$ & $\mathrm{N}$ \\
\hline GAV07 & 759.2 & 759.6 & $\mathrm{H}$ & M & $\mathrm{Y}$ & $\mathrm{N}$ \\
\hline GAV08 & 760.4 & 760.8 & $\mathrm{H}$ & $\mathrm{L}$ & $\mathrm{N}$ & $\mathrm{N}$ \\
\hline GAV09 & 761.2 & 761.6 & $\mathrm{H}$ & M & $\mathrm{N}$ & $\mathrm{Y}$ \\
\hline GAV10 & 764.0 & 764.4 & $\mathrm{~L}$ & M & $\mathrm{N}$ & $\mathrm{N}$ \\
\hline GAV11 & 766.4 & 766.8 & $\mathrm{~L}$ & M & $\mathrm{N}$ & $\mathrm{N}$ \\
\hline GAV12 & 768.0 & 768.4 & $\mathrm{~L}$ & $\mathrm{H}$ & $\mathrm{N}$ & $\mathrm{N}$ \\
\hline GAV13 & 769.6 & 770.0 & $\mathrm{~L}$ & $\mathrm{H}$ & $\mathrm{N}$ & $\mathrm{Y}$ \\
\hline GAV14 & 770.0 & 770.4 & M & $\mathrm{H}$ & $\mathrm{N}$ & $\mathrm{Y}$ \\
\hline GAV15 & 771.6 & 772.0 & M & $\mathrm{L}$ & $\mathrm{N}$ & $\mathrm{N}$ \\
\hline GAV16 & 772.8 & 773.2 & M & $\mathrm{L}$ & $\mathrm{Y}$ & $\mathrm{N}$ \\
\hline GAV17 & 774.0 & 774.4 & M & $\mathrm{L}$ & $\mathrm{N}$ & $\mathrm{N}$ \\
\hline GAV18 & 774.4 & 774.8 & $\mathrm{M}$ & $\mathrm{M}$ & $\mathrm{N}$ & $\mathrm{N}$ \\
\hline GAV19 & 774.8 & 775.2 & M & $\mathrm{L}$ & $\mathrm{N}$ & $\mathrm{N}$ \\
\hline GAV20 & 780.4 & 780.8 & $\mathrm{H}$ & $\mathrm{H}$ & $\mathrm{N}$ & $\mathrm{N}$ \\
\hline GAV21 & 780.8 & 781.2 & $\mathrm{H}$ & $\mathrm{H}$ & $\mathrm{N}$ & $\mathrm{N}$ \\
\hline GAV22 & 782.8 & 783.2 & $\mathrm{~L}$ & $\mathrm{H}$ & Y & $\mathrm{N}$ \\
\hline GAV23 & 784.0 & 784.4 & $\mathrm{~L}$ & $\mathrm{H}$ & $\mathrm{Y}$ & $\mathrm{N}$ \\
\hline GAV24 & 784.4 & 784.8 & $\mathrm{~L}$ & $\mathrm{H}$ & $\mathrm{Y}$ & $\mathrm{N}$ \\
\hline GAV25 & 784.8 & 785.2 & $\mathrm{~L}$ & $\mathrm{H}$ & $\mathrm{Y}$ & $\mathrm{N}$ \\
\hline GAV26 & 788.8 & 789.2 & $\mathrm{H}$ & $\mathrm{M}$ & $\mathrm{N}$ & $\mathrm{N}$ \\
\hline GAV27 & 789.2 & 789.6 & $\mathrm{H}$ & $\mathrm{M}$ & $\mathrm{Y}$ & $\mathrm{N}$ \\
\hline GAV28 & 789.6 & 790.0 & $\mathrm{H}$ & $\mathrm{H}$ & $\mathrm{Y}$ & $\mathrm{N}$ \\
\hline GAV29 & 790.0 & 790.4 & M & $\mathrm{H}$ & $\mathrm{Y}$ & $\mathrm{N}$ \\
\hline GAV30 & 796.0 & 796.4 & $\mathrm{M}$ & $\mathrm{L}$ & $\mathrm{Y}$ & $\mathrm{N}$ \\
\hline GAV31 & 800.8 & 801.2 & $\mathrm{M}$ & $\mathrm{M}$ & $\mathrm{Y}$ & $\mathrm{N}$ \\
\hline GAV32 & 801.2 & 801.6 & $\mathrm{M}$ & $\mathrm{L}$ & $\mathrm{N}$ & $\mathrm{N}$ \\
\hline GAV33 & 807.6 & 808.0 & $\mathrm{~L}$ & $\mathrm{~L}$ & $\mathrm{~N}$ & $\mathrm{~N}$ \\
\hline GAV34 & 808.0 & 808.4 & $\mathrm{~L}$ & $\mathrm{~L}$ & $\mathrm{~N}$ & $\mathrm{~N}$ \\
\hline
\end{tabular}


to proportional allocation of treatments among strata. That approach would generate 20 percent $(6 / 30)$ of the selected segments in the low stratum, 56 percent (17/30) in the medium stratum, and 23 percent (7/30) in the high stratum.

- The number of control segments should be approximately equal to the number of treatment segments. In 2006, 5 control segments were selected to correspond with the 5 constructed habitat segments, and 12 separate controls to correspond with the 12 sprayed habitat segments. However, a preferable approach is to select a single set of control segments to be used in one analysis with multiple treatment levels (for example "sprayed" and "constructed" treatments in 2006).

- Selection of control segments should, to the extent possible, generate a sample that is representative of the strata from which treatment segments were chosen. For Gavins Point in 2006, the principal concern was with bird use history as a stratification feature. This was achieved by randomly selecting the 12 control segments for the sprayed habitat in the same proportions as the treated segments (4 each from low, medium, and high bird use strata; table 3). Control segments for the created sandbar segments also were randomly selected in the same proportions as the treatments (1 low, 1 medium, and 3 high bird use strata; table 3 and figs. 5-10). However, it is not necessary that sample sizes of control and treatment segments be identical for each stratum. Rather, the important consideration is that the selected control segments are representative of the strata from which they were chosen.
- The power of the BACI design is its ability to distinguish temporal effects from treatment effects. To accomplish this, it is critical to monitor treatment and control sampling units both before and after implementation of the management action of interest. This, in turn, requires advance knowledge of where treatments will be implemented so that segments can be properly classified. In a multiyear study, this design could minimize effects of annual variation if each of four possible treatment classes (premanagement control, premanagement treatment, postmanagement control, postmanagement treatment) were sampled each year.

- Definition of treatment segments will depend on the implementation of the ESH Program and the defined monitoring objectives. For example, it is possible that several different herbicides could be used to control vegetation growth on sandbars. These could be combined into a single "sprayed" treatment to address objectives related to the overall system responses to vegetation spraying under the ESH Program. Conversely, sprayed segments could be assigned to two or more treatment categories depending on the management tools (such as different herbicides) employed to control vegetation growth. Similarly, treatments could be assigned on the basis of whether post-herbicide management (such as mowing) was employed. Increasing the number of treatments will increase the complexity of statistical models required to analyze the data, but will enhance the ability to detect system responses to specific management applications. 


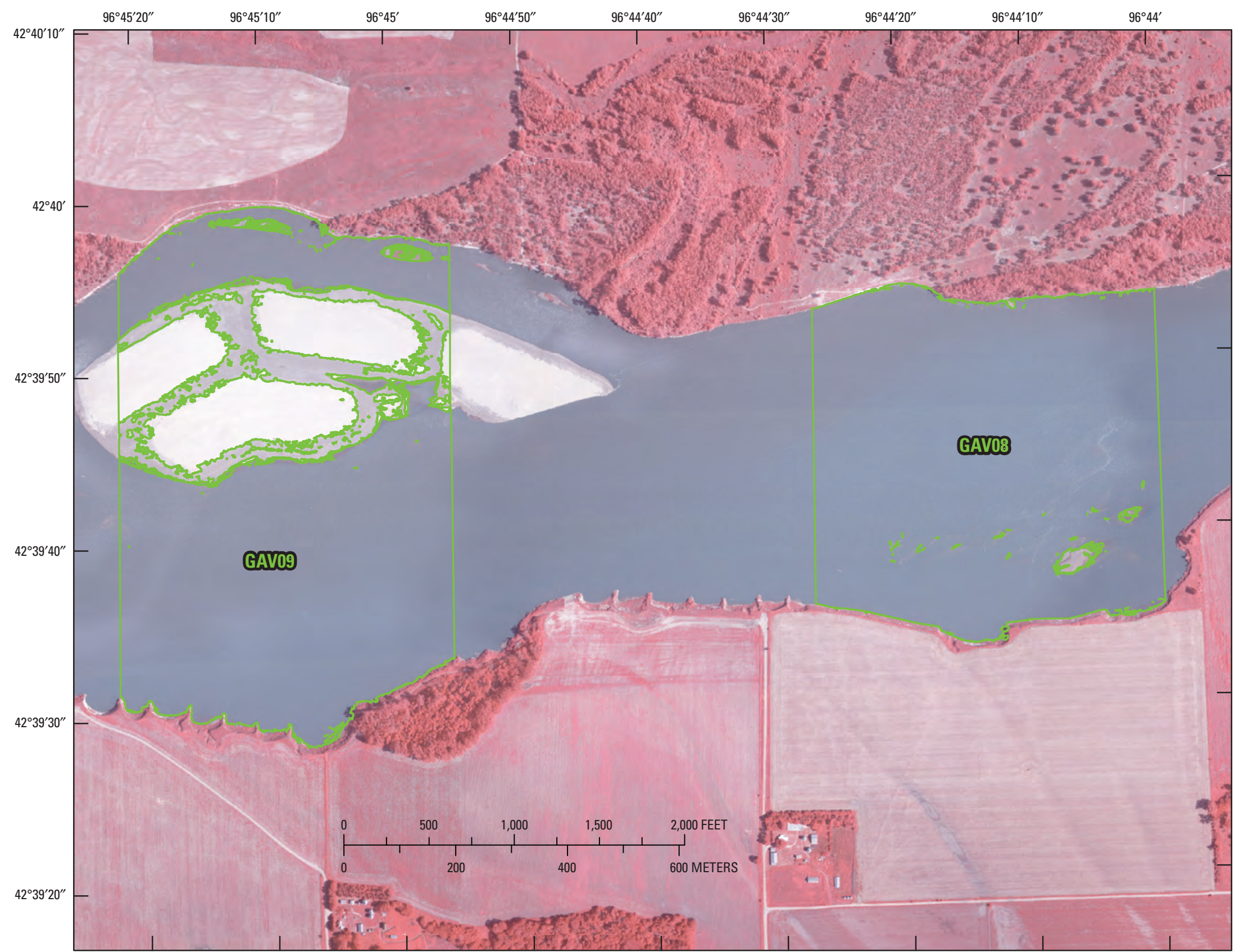

Figure 3. Example of 0.4-river-mile segments on the Gavins Point Reach, illustrating segments containing constructed emergent sandbar habitat (GAV09) and containing unmanaged natural emergent sandbar habitat (GAV08). Background image is 2005 color infrared photography. Green lines represent perimeters of habitat types within sampling segments. 


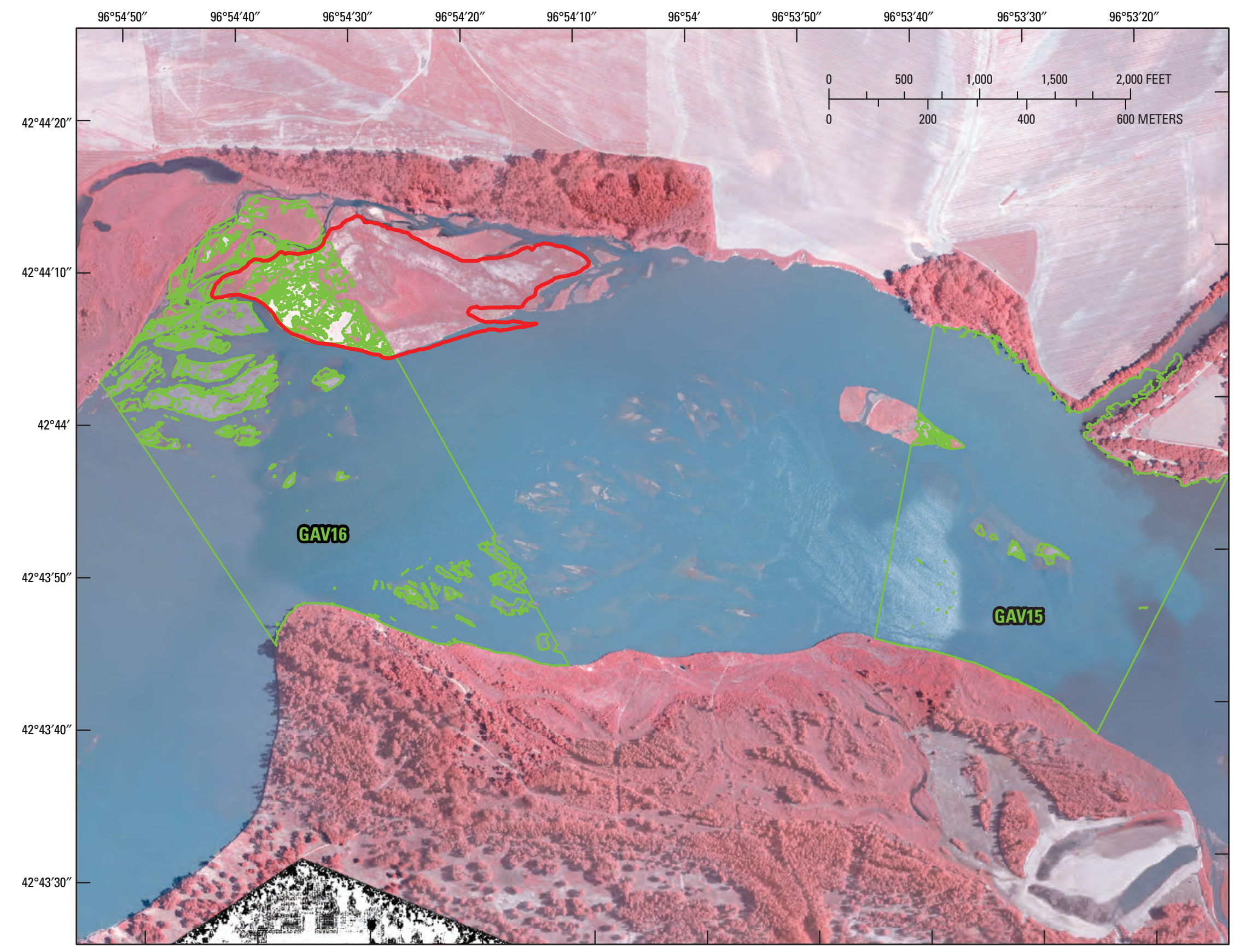

Figure 4. Example of 0.4-river-mile segments on the Gavins Point Reach, illustrating segments containing sprayed emergent sandbar habitat (GAV16; sprayed habitat is represented by the red polygon) and containing unmanaged natural emergent sandbar habitat (GAV15). Background image is 2005 color infrared photography. Green lines represent perimeters of habitat types within sampling segments. 


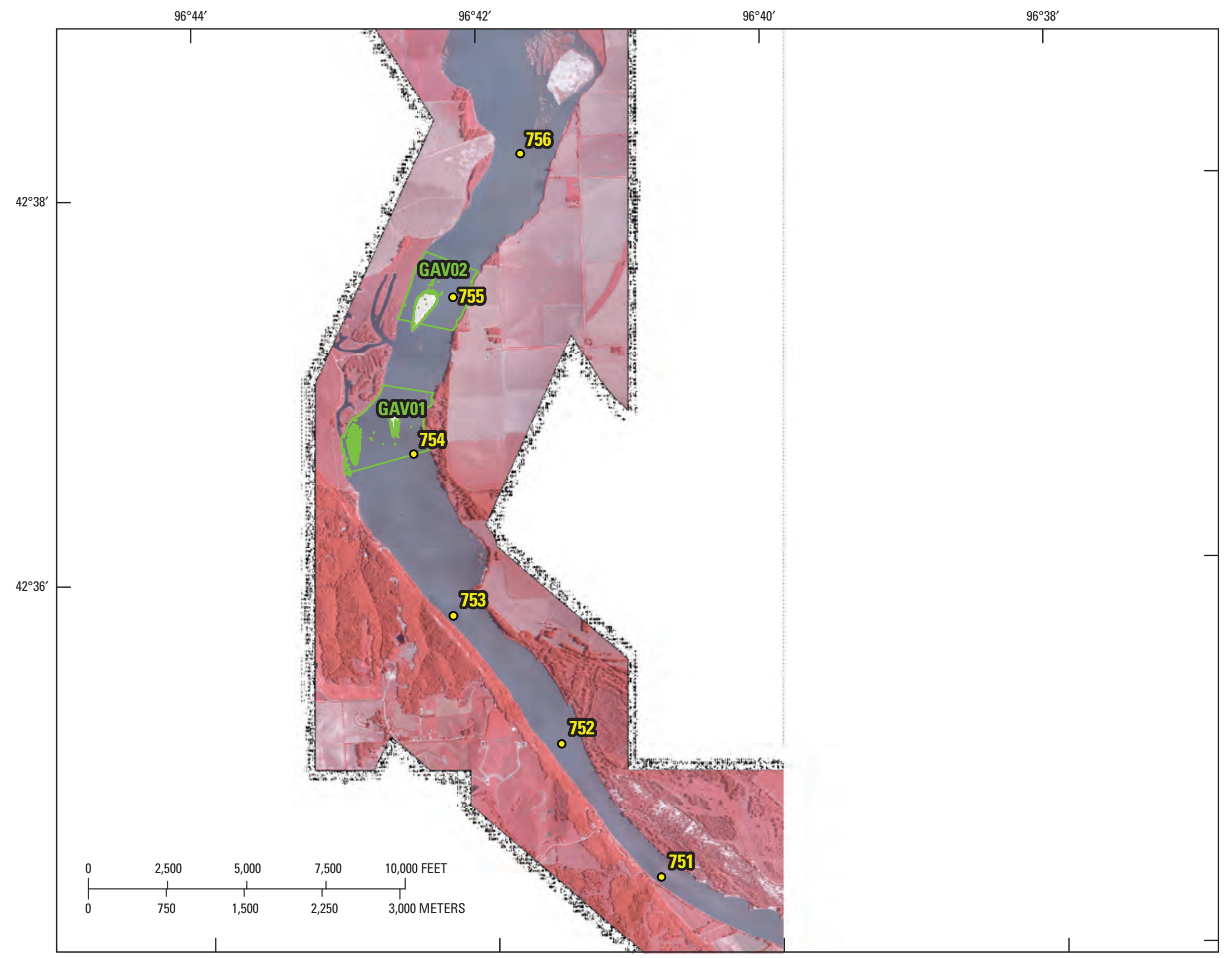

Figure 5. Segments of the Gavins Point Reach of the Missouri River (RM 752-756) on which habitat data were collected for emergent sandbar habitat monitoring during 2006. Background image is 2005 color infrared photography. Green lines represent perimeters of habitat types within sampling segments, and yellow dots represent river miles. 


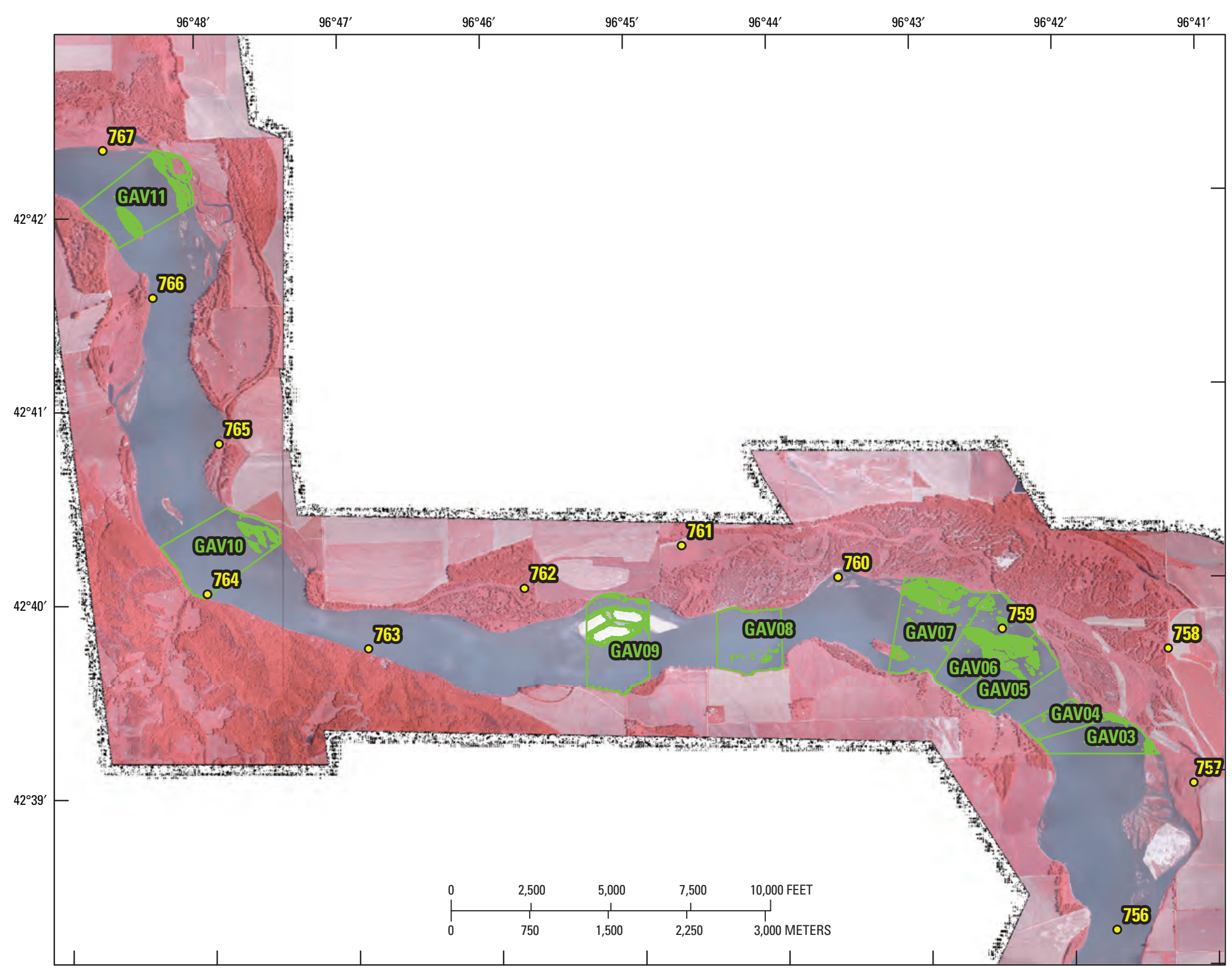

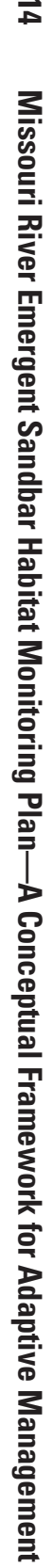

Figure 6. Segments of the Gavins Point Reach of the Missouri River (RM 757-767) on which habitat data were collected for emergent sandbar habitat monitoring during 2006. Background image is 2005 color infrared photography. Green lines represent perimeters of habitat types within sampling segments, and yellow dots represent river miles. 


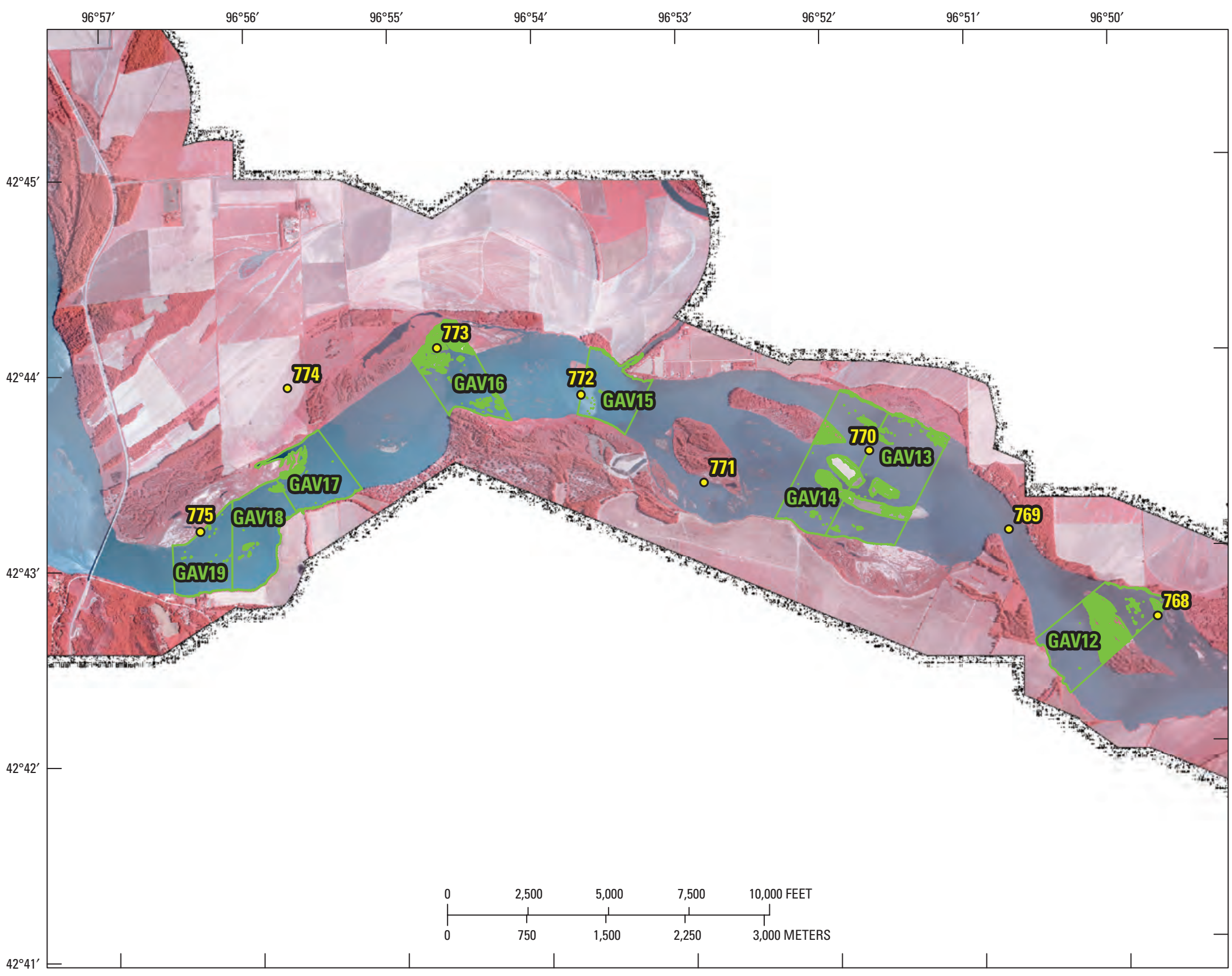

Figure 7. Segments of the Gavins Point Reach of the Missouri River (RM 768-776) on which habitat data were collected for emergent sandbar habitat monitoring during 2006. Background image is 2005 color infrared photography. Green lines represent perimeters of habitat types within sampling segments, and yellow dots represent river miles. 


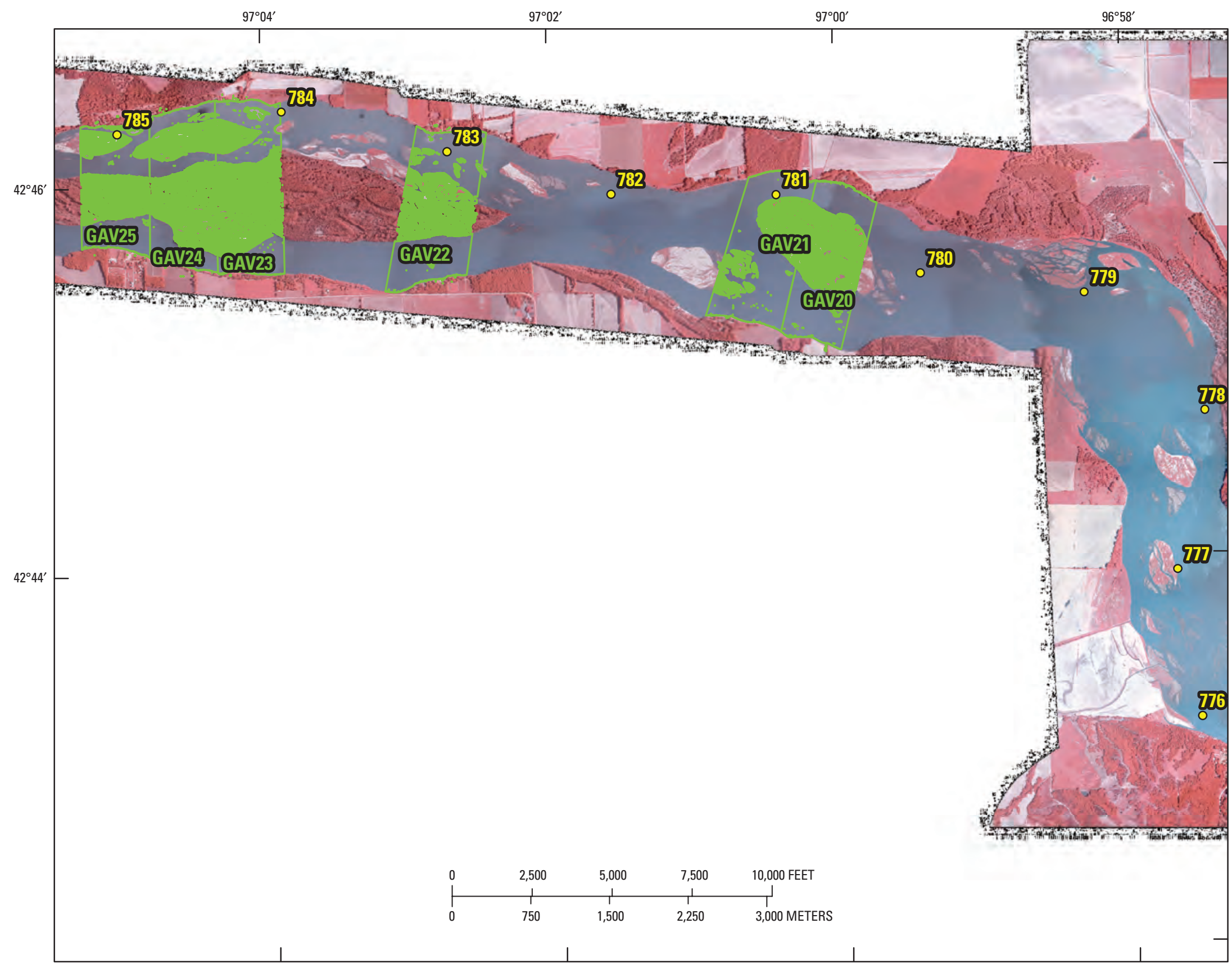

Figure 8. Segments of the Gavins Point Reach of the Missouri River (RM 777-786) on which habitat data were collected for emergent sandbar habitat monitoring during 2006. Background image is 2005 color infrared photography. Green lines represent perimeters of habitat types within sampling segments, and yellow dots represent river miles. 


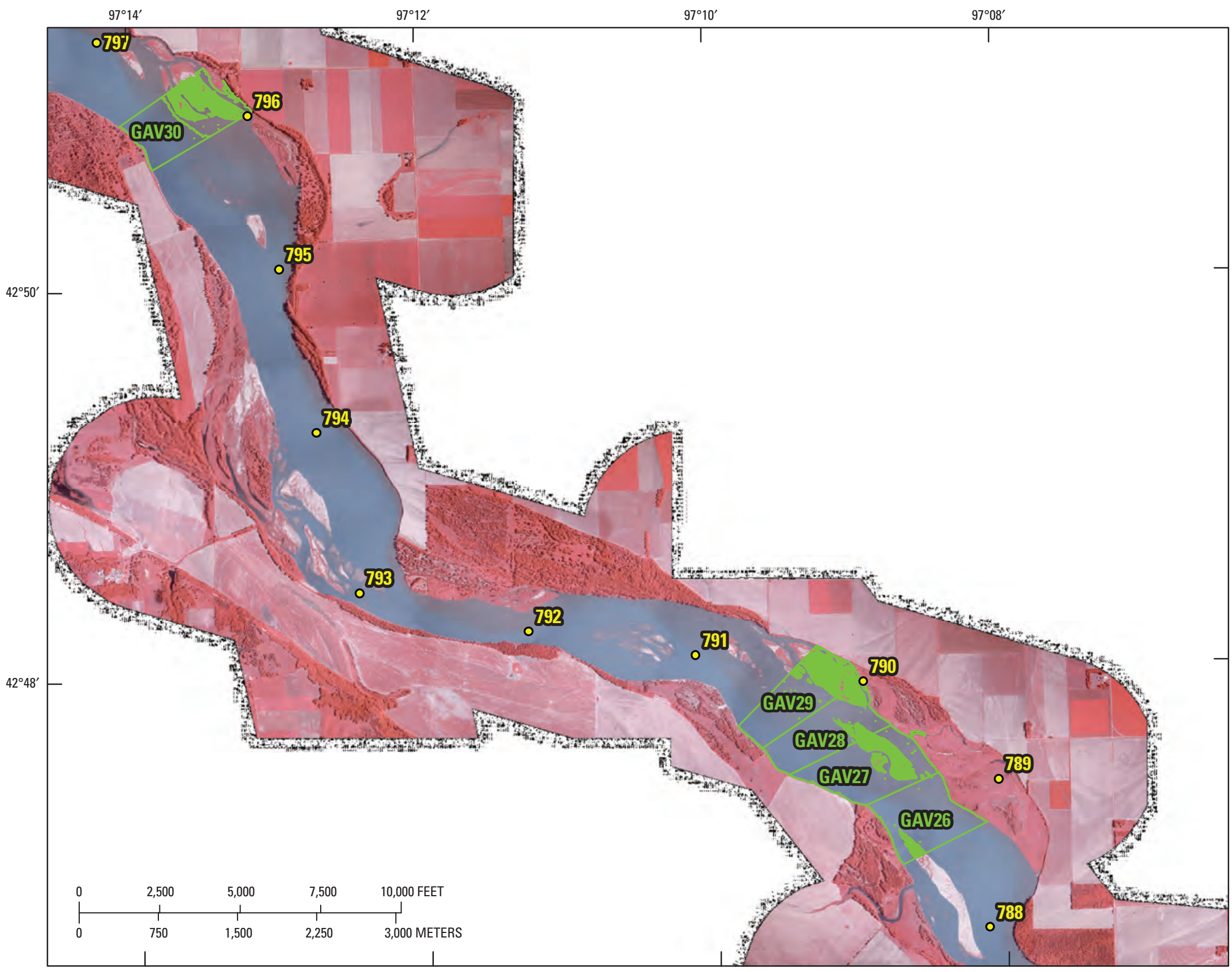

Figure 9. Segments of the Gavins Point Reach of the Missouri River (RM 788-797) on which habitat data were collected for emergent sandbar habitat monitoring during 2006. Background image is 2005 color infrared photography. Green lines represent perimeters of habitat types within sampling segments, and yellow dots represent river miles. 


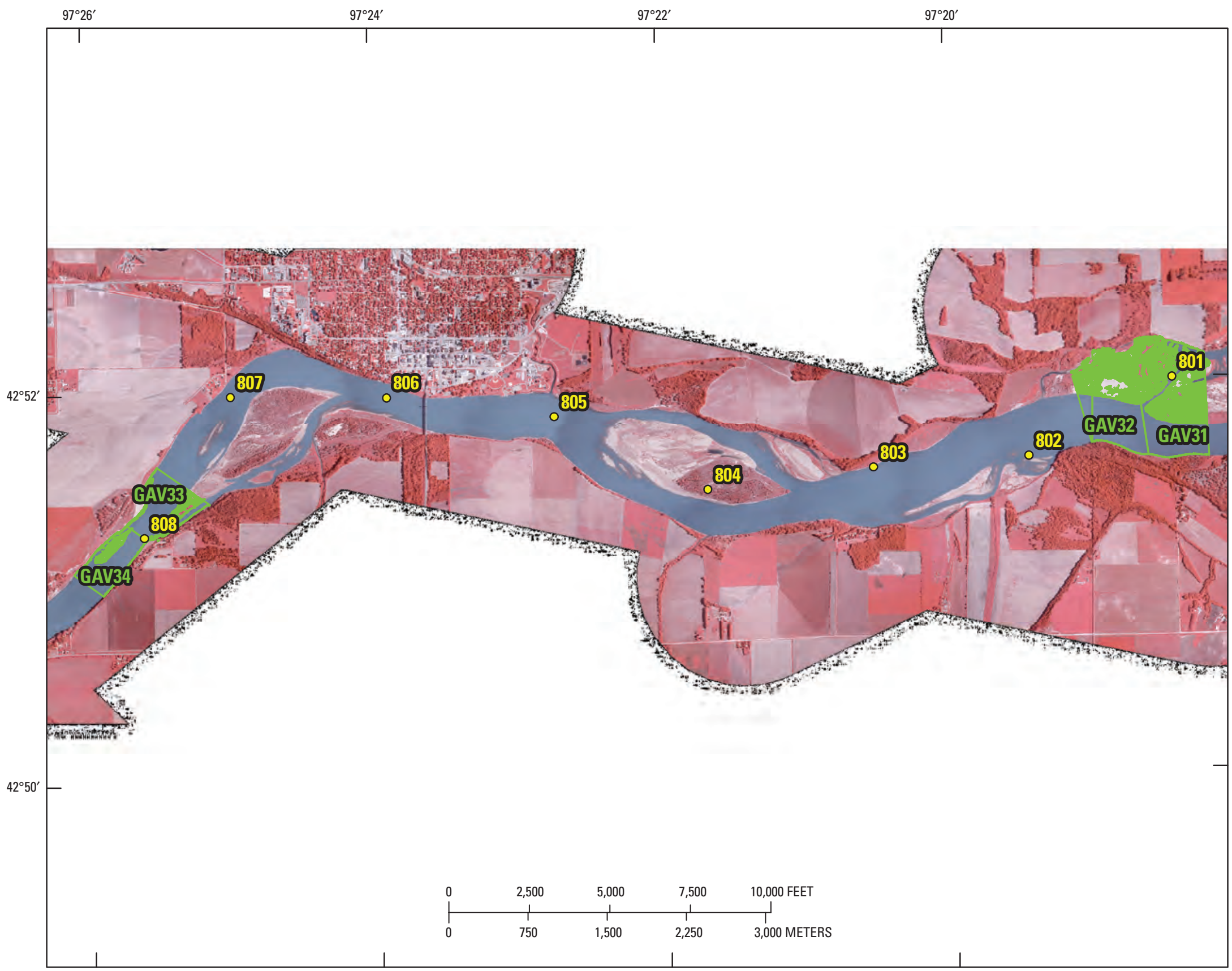

Figure 10. Segments of the Gavins Point Reach of the Missouri River (RM 801-808) on which habitat data were collected for emergent sandbar habitat monitoring during 2006. Background image is 2005 color infrared photography. Green lines represent perimeters of habitat types within sampling segments, and yellow dots represent river miles. 
During the 2006 field season, several circumstances were encountered on other reaches that illustrate variations on this approach to stratification:

Lake Oahe-The upper Missouri River system is generally managed as a series of alternating river reaches and reservoirs, with a standard RM marker serving as the division between adjacent elements. For example, RM 1304 marks the division between Lake Oahe and the Garrison Reach. This convention standardizes the definition of each reach or reservoir, but does not account for the influence of changing water conditions on habitat structure. For example, a pattern of dry weather leading up to 2006 generated record-low water levels on Lake Oahe that dramatically reduced the lower portion of the lake (which truly functions as a lake) and produced riverine conditions in which midchannel sandbars dominate on the upper portion.
The area of interest for monitoring in 2006 (the North Dakota-South Dakota border to RM 1304) lies within the upper portion of Lake Oahe, and was targeted for vegetation spraying during 2007. Because this area was functionally more similar to a free-flowing river than to a reservoir, similar procedures were followed to those used on Gavins Point to select segments for monitoring. Strata were delineated on the basis of total nest numbers from 2001-05 (table 4), using $0-2$ nests for the low stratum $(n=4), 8-15$ nests for the medium stratum $(\mathrm{n}=7)$, and $22-58$ nests for the high stratum $(\mathrm{n}=8)$.

This exercise illustrates an important feature of any stratification developed for ESH monitoring-it should represent the spatial extent and target species upon which the management action is focused. Because potential vegetation control sites on Lake Oahe were selected from the North Dakota

Table 4. Total number of least tern and piping plover nests found on the North Dakota portion of Lake 0 ahe during $2001-05$ by 4-river-mile section.

[RM, river mile; L, low; M, medium; $\mathrm{H}$, high]

\begin{tabular}{cccccc}
\hline $\begin{array}{c}\text { Segment } \\
\text { number }\end{array}$ & $\begin{array}{c}\text { Downstream } \\
\text { RM }\end{array}$ & $\begin{array}{c}\text { Least tern } \\
\text { nests }\end{array}$ & $\begin{array}{c}\text { Piping plover } \\
\text { nests }\end{array}$ & Total nests & Use category \\
\hline 01 & 1232 & 3 & 51 & 54 & $\mathrm{H}$ \\
02 & 1236 & 0 & 8 & 8 & $\mathrm{M}$ \\
03 & 1240 & 1 & 14 & 15 & $\mathrm{M}$ \\
04 & 1244 & 2 & 27 & 29 & $\mathrm{H}$ \\
05 & 1248 & 14 & 36 & 50 & $\mathrm{H}$ \\
06 & 1252 & 1 & 1 & 2 & $\mathrm{~L}$ \\
07 & 1256 & 0 & 0 & 0 & $\mathrm{~L}$ \\
08 & 1260 & 0 & 0 & 0 & $\mathrm{~L}$ \\
09 & 1264 & 13 & 14 & 27 & $\mathrm{H}$ \\
10 & 1268 & 5 & 19 & 24 & $\mathrm{H}$ \\
11 & 1272 & 1 & 8 & 9 & $\mathrm{M}$ \\
12 & 1276 & 3 & 5 & 8 & $\mathrm{M}$ \\
13 & 1280 & 6 & 7 & 13 & $\mathrm{M}$ \\
14 & 1284 & 9 & 21 & 30 & $\mathrm{H}$ \\
15 & 1288 & 25 & 33 & 58 & $\mathrm{H}$ \\
16 & 1292 & 8 & 14 & 22 & $\mathrm{H}$ \\
17 & 1296 & 0 & 1 & 1 & $\mathrm{~L}$ \\
18 & 1300 & 8 & 4 & 12 & $\mathrm{M}$ \\
19 & 1304 & 1 & 7 & 8 & $\mathrm{M}$ \\
\hline 19 & & & & &
\end{tabular}


portion of the lake, that spatial extent represents the population of segments from which the units to be measured were drawn. It also represents the spatial extent upon which the stratification was based (table 4). It is possible that 2 or more different stratifications might be necessary for a given reach if ESH projects of differing scope are planned or implemented. For example, if a second set of vegetation control projects was simultaneously planned for Lake Oahe, but the potential area of implementation was not restricted to North Dakota, then a second stratification would be necessary to obtain suitable control segments for those projects. Likewise, it is feasible that a project could be designed for the primary purpose of benefiting one species (terns or plovers). In this case, a stratification based on nesting history of just that species would be necessary.

After the stratification for Lake Oahe was derived, selection of sites for sampling followed a similar sequence to that on Gavins Point. It was anticipated that the field crew would be able to sample 24 segments. Thus 12 treatment segments were randomly selected, and 12 control segments were randomly selected with similar bird use histories to the treatment segments (table 5 and fig. 11).

Table 5. Features of 0.4-river-mile segments of the North Dakota portion of Lake Oahe on which habitat data were collected during 2006.

[ID, identifier; RM, river mile; $\mathrm{M}$, medium; $\mathrm{H}$, high]

\begin{tabular}{|c|c|c|c|c|c|}
\hline Segment ID & Downstream RM & Upstream RM & Vegetation control? & Site name & Bird use stratum \\
\hline OAH01 & 1232.0 & 1232.4 & No & Control & $\mathrm{H}$ \\
\hline OAH02 & 1234.0 & 1234.4 & No & Control & $\mathrm{H}$ \\
\hline OAH03 & 1240.8 & 1241.2 & No & Control & M \\
\hline OAH04 & 1242.8 & 1243.2 & No & Control & M \\
\hline OAH05 & 1243.6 & 1244.0 & No & Control & M \\
\hline OAH06 & 1273.2 & 1273.6 & Yes & Hogback Island & M \\
\hline OAH07 & 1274.4 & 1274.8 & No & Control & M \\
\hline OAH08 & 1277.2 & 1277.6 & No & Control & M \\
\hline ОАН09 & 1277.6 & 1278.0 & No & Control & M \\
\hline OAH10 & 1278.8 & 1279.2 & Yes & One Horse & M \\
\hline OAH11 & 1279.2 & 1279.6 & Yes & One Horse & M \\
\hline OAH12 & 1281.6 & 1282.0 & Yes & Eckroth Corner & M \\
\hline OAH13 & 1282.0 & 1282.4 & Yes & Eckroth Corner & M \\
\hline OAH14 & 1282.4 & 1282.8 & Yes & Glencoe & M \\
\hline OAH15 & 1284.0 & 1284.4 & Yes & Barrels & $\mathrm{H}$ \\
\hline OAH16 & 1284.8 & 1285.2 & Yes & Fire Island & $\mathrm{H}$ \\
\hline OAH17 & 1285.2 & 1285.6 & Yes & Fire Island & $\mathrm{H}$ \\
\hline OAH18 & 1286.8 & 1287.2 & Yes & Silo & $\mathrm{H}$ \\
\hline OAH19 & 1287.2 & 1287.6 & No & Control & $\mathrm{H}$ \\
\hline OAH20 & 1287.6 & 1288.0 & Yes & Castillo's & $\mathrm{H}$ \\
\hline $\mathrm{OAH} 21$ & 1290.0 & 1290.4 & No & Control & $\mathrm{H}$ \\
\hline $\mathrm{OAH} 22$ & 1291.2 & 1291.6 & No & Control & $\mathrm{H}$ \\
\hline $\mathrm{OAH} 23$ & 1292.4 & 1292.8 & Yes & Rifle Range & $\mathrm{H}$ \\
\hline OAH24 & 1293.6 & 1294.0 & No & Control & $\mathrm{H}$ \\
\hline
\end{tabular}




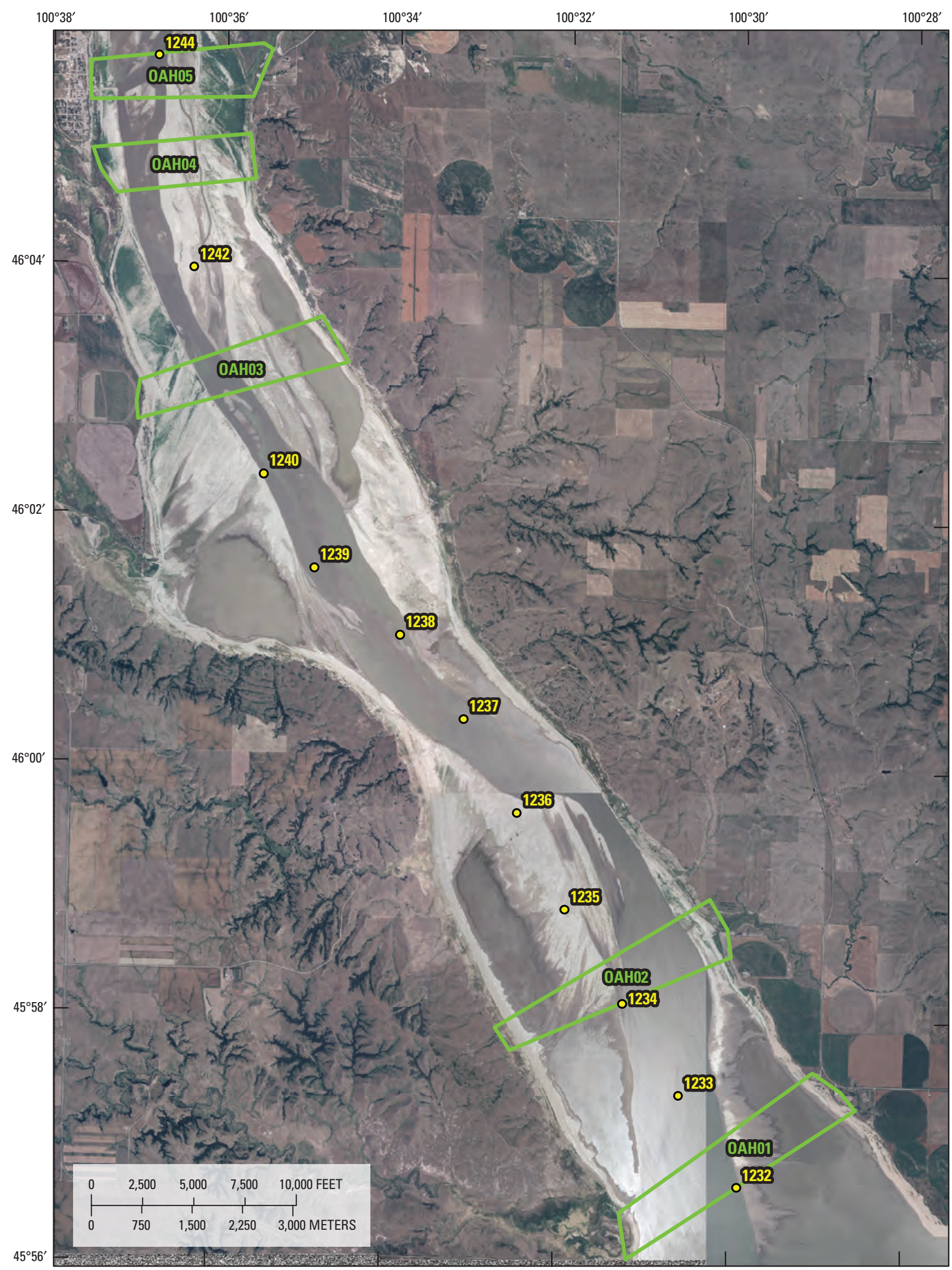

Figure 11. Segments of the North Dakota portion of Lake Oahe on which habitat data were collected for emergent sandbar habitat monitoring during 2006. Background image is 2004 U.S. Department of Agriculture National Agricultural Imagery Program aerial photography. Green lines represent perimeters of sampling segments, and yellow dots represent river miles. 


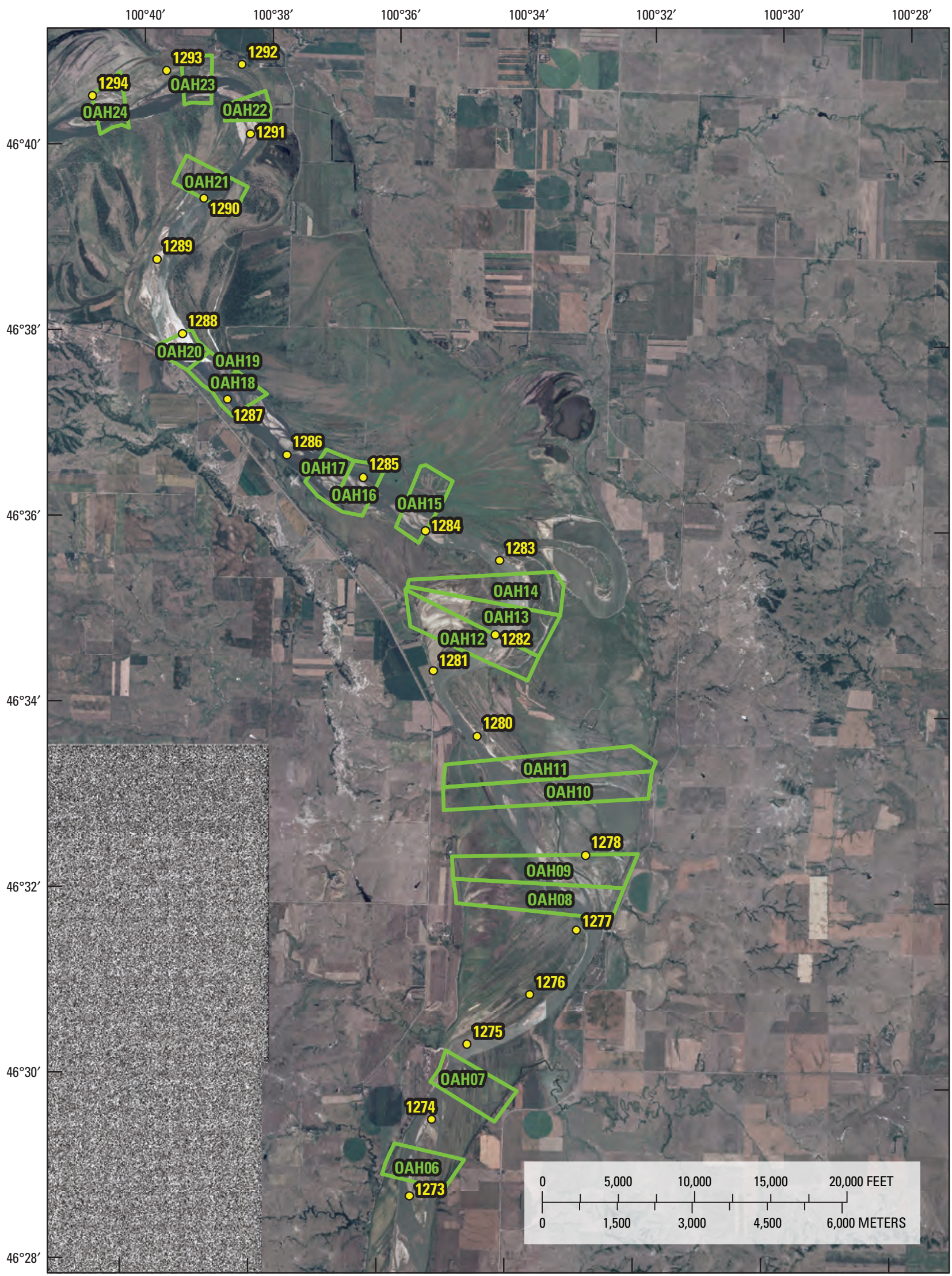

Figure 11. Continued 
Lewis and Clark Lake-Planned construction of a sandbar near RM 827 prompted initiation of habitat monitoring in 2006. This site is near the junction between the Fort Randall Reach and Lewis and Clark Lake. Although the rivermile designation of the site formally places it within the lake, existing conditions more nearly mimic those of the river reach. Additionally, the planned project is a midchannel sandbar, which is a characteristic habitat type for river reaches. These features pointed toward drawing control sites from the Fort Randall Reach for this construction project. Thus, sampling was based on a stratification of Fort Randall (table 6). Similar habitat conditions existed from RM 827 upstream to the confluence of the Missouri and Niobrara Rivers at RM 845.
Thus, sampling of control segments was restricted to sites below the Niobrara River. Because the proposed construction site fell within a medium bird use stratum (SEG01; table 6), selection of control sites was restricted to the remaining segments in segment 1 and those in segment 4 . Because the construction site potentially spanned two segments, two control segments were randomly selected (table 7 and fig. 12).

Kensler's Bend-This reach of the river begins near RM 734 and extends to RM 754 near Ponca State Park. Kensler's Bend is unique in that several ESH projects have been considered, but there are no existing sandbars and there is no history of bird use. Thus, the only basis available for stratification of the reach is the planned ESH projects. On the

Table 6. Total number of least tern and piping plover nests found on the Fort Randall Reach of the Missouri River during 2001-05 by 4-river-mile section.

[RM, river mile; L, low; M, medium; H, high]

\begin{tabular}{cccc}
\hline Segment number & Downstream RM & Tern and plover nests & Use category \\
\hline 01 & 824 & 15 & M \\
02 & 828 & 0 & $\mathrm{~L}$ \\
03 & 832 & 60 & $\mathrm{H}$ \\
04 & 836 & 22 & $\mathrm{M}$ \\
05 & 840 & 91 & $\mathrm{H}$ \\
06 & 844 & 0 & $\mathrm{~L}$ \\
07 & 848 & 84 & $\mathrm{H}$ \\
08 & 852 & 63 & $\mathrm{H}$ \\
09 & 856 & 0 & $\mathrm{~L}$ \\
10 & 860 & 7 & $\mathrm{M}$ \\
11 & 864 & 67 & $\mathrm{H}$ \\
12 & 868 & 174 & $\mathrm{H}$ \\
13 & 872 & 9 & $\mathrm{M}$ \\
14 & 876 & 0 & $\mathrm{~L}$ \\
\hline
\end{tabular}

Table 7. Features of segments of the Fort Randall Reach of the Missouri River on which habitat data were collected in 2006.

[ID, identifier, RM, river mile]

\begin{tabular}{cccc}
\hline Segment ID & Downstream RM & Upstream RM & Created sandbar planned? \\
\hline LCL01 & 826.4 & 826.8 & Yes \\
LCL02 & 826.8 & 827.2 & Yes \\
LCL03 & 836 & 836.4 & No \\
LCL04 & 838.4 & 838.8 & No \\
\hline
\end{tabular}




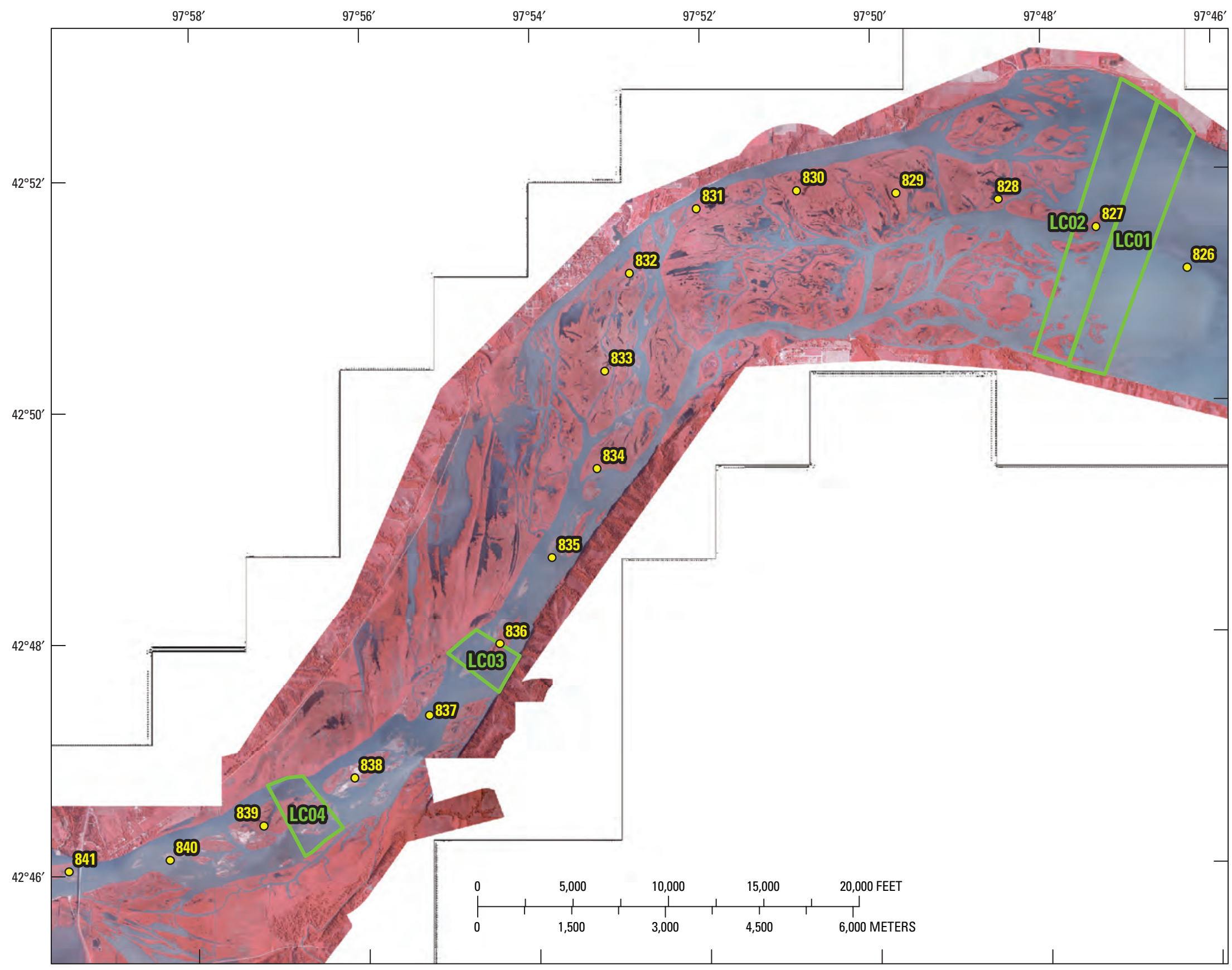

Figure 12. Segments of the Fort Randall Reach of the Missouri River that were sampled in 2006 to characterize a proposed emergent sandbar habitat project near RM 827, at the headwaters of Lewis and Clark Lake. Background image is 2005 color infrared aerial photography. Green lines represent perimeters of sampling segments, and yellow dots represent river miles. 
basis of information provided by the USACE, a determination was made whether each 0.4-RM segment of the reach was likely to contain a portion of one or more future ESH projects, with the remaining segments serving as controls (table 8).

The most likely scenario was for one of the five projects to be constructed, but there was no basis for selecting which was the most likely candidate. Thus, one segment was randomly selected from each of the five construction sites and five corresponding control segments (fig. 13).

Table 8. Features of segments of the Kensler's Bend Reach of the Missouri River on which habitat data were collected in 2006.

[ID, identifier; RM, river mile; ESH emergent sandbar habitat]

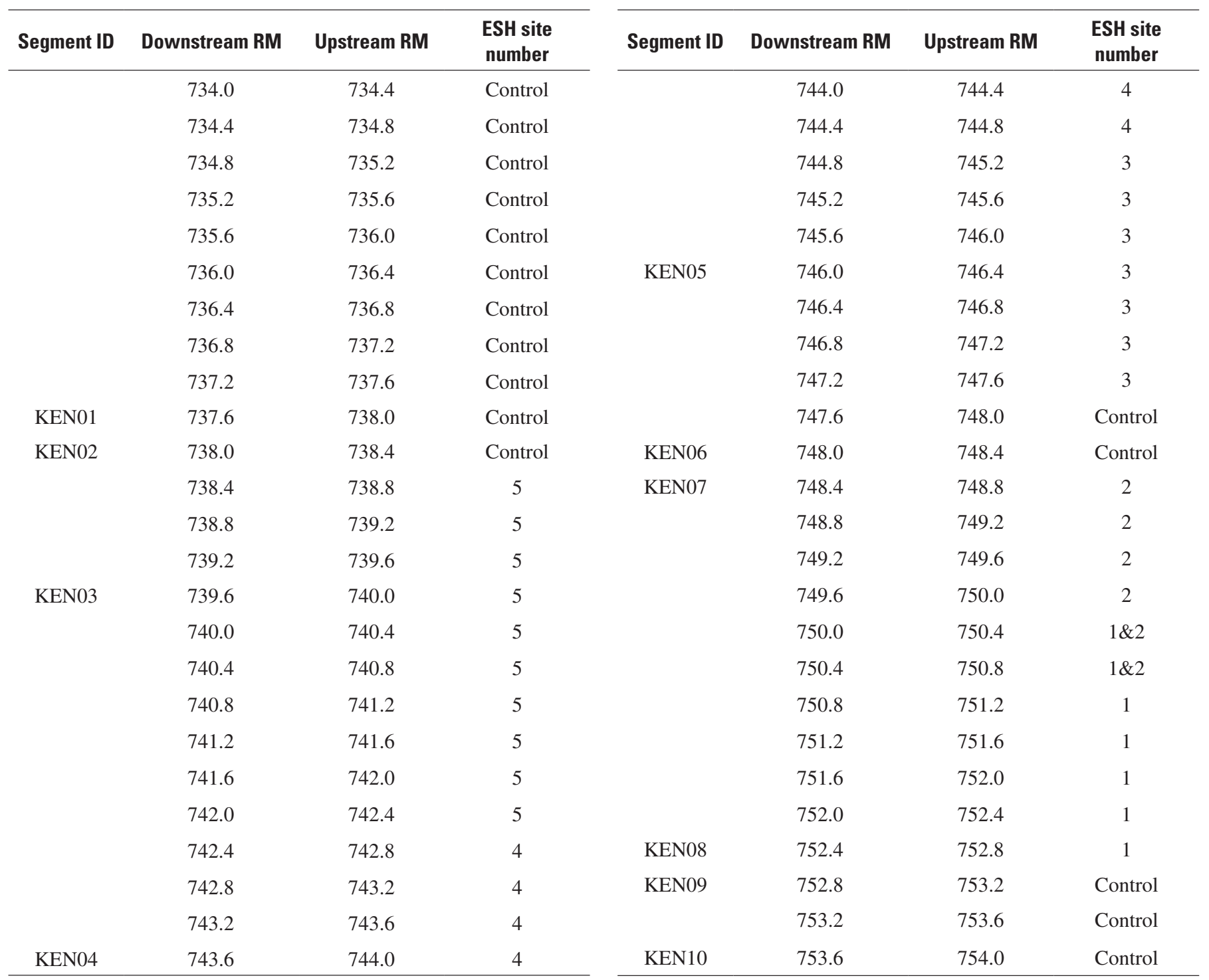




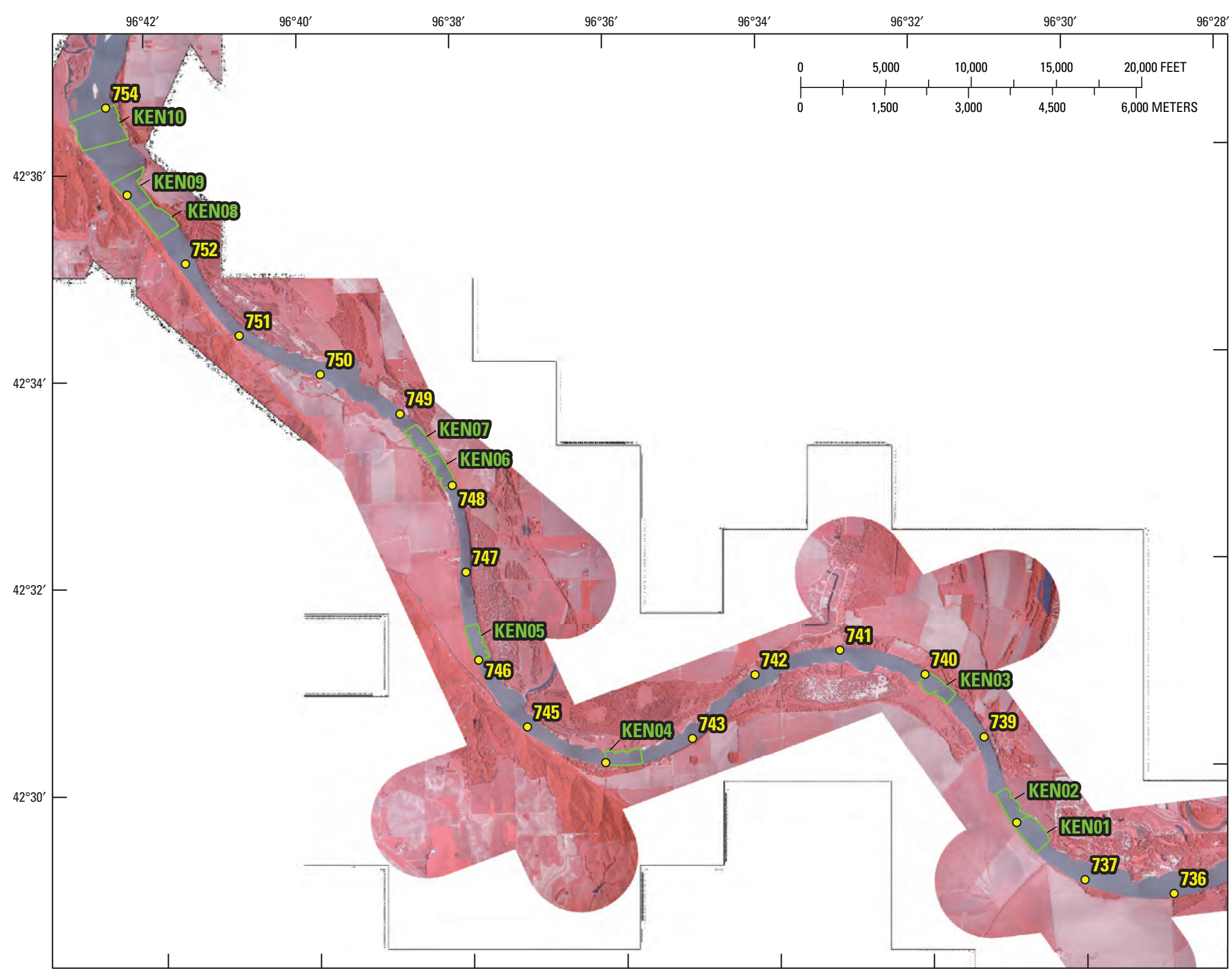

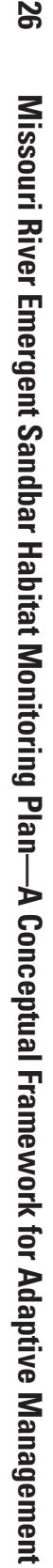

Figure 13. Segments of the Kensler's Bend Reach of the Missouri River on which habitat data were collected for emergent sandbar habitat monitoring during 2006 . Background image is 2005 color infrared aerial photography. Green lines represent perimeters of sampling segments, and yellow dots represent river miles. 


\section{Reservoirs}

One challenge in stratification of reservoir systems is to develop a stratification that is useful for long-term monitoring, throughout potentially extensive changes in water levels. During the time when plover productivity has been monitored expansively at Lake Sakakawea (1998-2006) there has been a large range of lake water levels. Similarly, throughout this time period locations of plover "colonies" have shifted slightly; 10-kilometer (km) sections of Lake Sakakawea shoreline were chosen to classify into strata because $10 \mathrm{~km}$ appears to be a unit of shoreline long enough to encompass "shifts" of colony locations through the years 1998 to 2005 . We delineated Lake Sakakawea by using 2004 color imagery from the U.S. Department of Agriculture's National Agricultural Inventory Program (NAIP) and divided the shoreline into $10-\mathrm{km}$ sections from a random start point. The boundaries of each section were lines perpendicular to the shoreline on either end because the length of the shoreline will vary with lake elevations. Islands were grouped into sections with respect to location and so that grouped islands had shorelines approximately equal to $10 \mathrm{~km}$. Historical piping plover nesting data (1998-2005) was used to classify each $10-\mathrm{km}$ section into strata: high (>40 nests), moderate (10-40 nests), or low ( $<10$ nests). However, 10-km sections of shoreline are too large for effective habitat and productivity monitoring and are not a realistic size for a single proposed ESH project. Therefore, each 10-km section was divided into five 2-km segments; 2-km segments were the sampling unit for habitat and productivity monitoring (see companion study [NPWRC Task 5: Habitat selection, productivity, and estimation of available nesting habitat for piping plovers on Lake Sakakawea]). The goal of the companion study is to develop estimates of habitat use and availability for the entire reservoir, but the study design is not tailored to detection of outcomes from habitat management projects. However, data from the companion study can be used within the framework of a monitoring plan to provide site-specific data from habitat conditions at ESH project sites and randomly located control areas before and after treatments. For example, the companion study sampled seventeen 2-km segments in 2006 and will sample thirty 2-km segments in 2007-09 (table 9), these segments will provide ample control areas for monitoring proposed ESH projects (those that do not happen to be in future ESH project areas).
In July 2006, the USACE planned to move forward on two of the seven ESH projects on Lake Sakakawea for fall 2006 (Sonny's and Randy's Islands, figs. 14 and 15). Productivity on these sites was not monitored because notification came after the breeding season was largely over, but the habitat was intensively sampled on these sites in August 2006. Thus, the random segments used for the companion study can be considered control areas for the two new ESH sites on Lake Sakakawea, making a replicated BACI habitat monitoring design. According to our stratification of Lake Sakakawea, Sonny's and Randy's Islands were classified into the low density strata; thus, they would be compared to randomly selected controls from low density strata. Unfortunately, there was not more advanced planning so that productivity data could be incorporated into this design. This underscores the importance of planning and communication between agencies involved in the ESH Program. As new ESH projects are intitiated on Lake Sakakawea, they should be paired with randomly selected segments within the same strata and landform so they can be incorporated into this habitat monitoring plan and productivity monitoring.

\section{Nest Sites}

Monitoring habitat at nest sites in conjunction with monitoring of habitat for the ESH Program should provide an important link between habitat quality and breeding productivity. Furthermore, this should provide a better understanding of the habitat characteristics that attract least terns and piping plovers to a given area to nest and those that lead to the most successful outcomes (hatched nests and fledged young). Continued examination of tern and plover selection and success on given habitat allows for a monitoring program to use the principles of adaptive management as a check to ensure that the proper indices of habitat are being measured at the appropriate spatial scale or identify new important indices.

During the 2006 field season, USGS field crews conducted research studies on least tern productivity (Task 1; Gavins Point Reach), evaluation of productivity monitoring procedures (Task 2; Garrison Reach), and reservoir shoreline habitat (Task 5; Lake Sakakawea). These studies all involved searching for and monitoring fate of piping plover and least tern nests. Standard practice during these studies was to collect habitat data at nest sites at the time of nest discovery.

Table 9. Summary of stratification of Lake Sakakawea, including numbers of 2-kilometer segments, segments sampled in 2006, and projected number of segments in 2007-09.

[Stratified by historical piping plover nest densities (1998-2005). \%, percent]

\begin{tabular}{lccc}
\hline \multicolumn{1}{c}{ Strata } & Number & Number (\%) sampled in 2006 & Number (\%) projected sample for 2007-09 \\
\hline Low & 510 & $4(1)$ & $9(2)$ \\
Medium & 105 & $4(4)$ & $6(6)$ \\
High & 70 & $9(13)$ & $15(21)$ \\
\hline
\end{tabular}




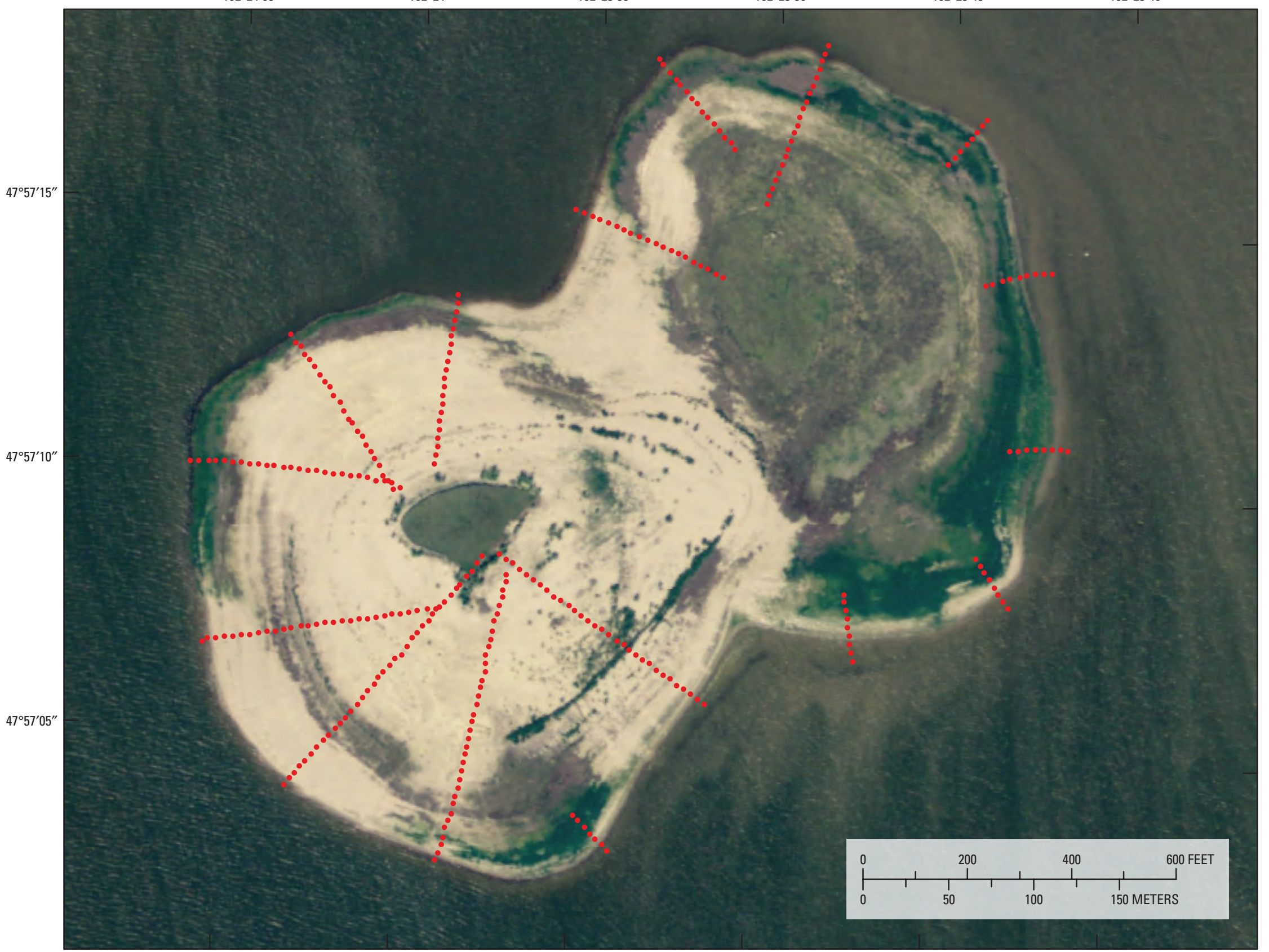

Figure 14. Spatial extent of habitat data for a proposed emergent sandbar habitat project on "Sonny's Island," Lake Sakakawea in 2006, depicting locations of transects composed of habitat evaluations every 5 meters. Background imagery is 2005 U.S. Department of Agriculture National Agricultural Imagery Program photography. 


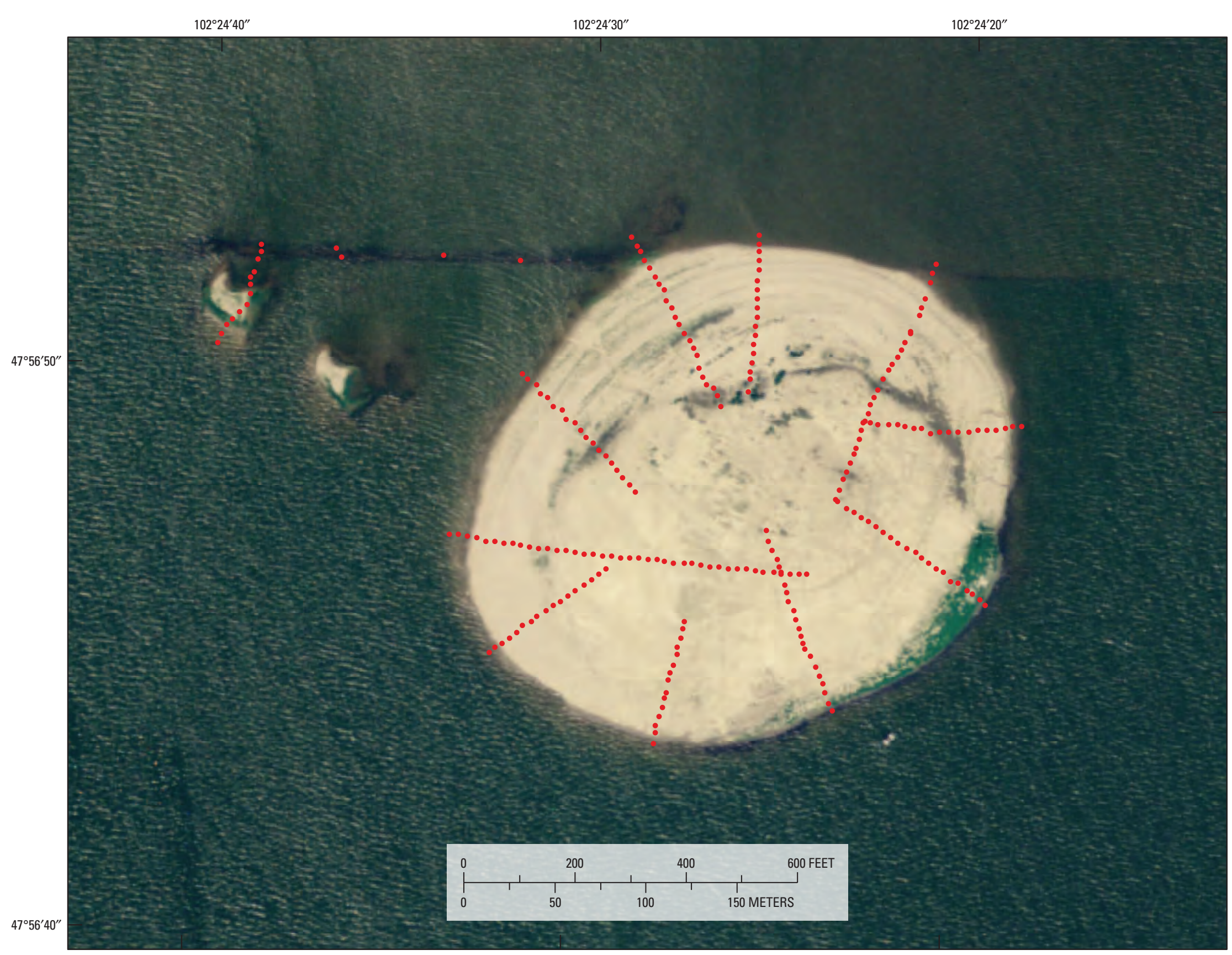

Figure 15. Spatial extent of habitat data for a proposed emergent sandbar habitat project on "Randy's Island," Lake Sakakawea in 2006, depicting locations transects composed of habitat evaluations every 5 meters. Background imagery is 2005 U.S. Department of Agriculture National Agricultural Imagery Program photography. 
Protocols used by field crews conducting these studies were identical to those used by the habitat crew that was tasked with evaluating procedures for this monitoring plan. This resulted in habitat data being collected at 272 least tern nests on the Gavins Point Reach, 122 least tern and 245 piping plover nests on the Garrison Reach, and 59 piping plover nests on Lake Sakakawea. From this experience, it was concluded that rapid evaluation of habitat features at nest sites is feasible, and that the required adjustments to nest monitoring protocols would be fairly minor. Accordingly, the collection of habitat data at all piping plover and least tern nest sites should be standard practice.

\section{Sampling Approach}

After segments of river reaches or reservoir shorelines have been selected for sampling, the next step is to decide where to sample within the selected areas. As with selecting segments, taking advantage of prior knowledge regarding habitat conditions within the segment will maximize the efficiency of the monitoring effort. There are very different considerations which must be made between river, reservoir, and nest site sampling, which are illustrated in the following sections using examples from the 2006 field season. In all cases, the goal of sampling is to characterize the unit being sampled, whether it is a river segment, a reservoir shoreline segment, or a nest site.

\section{Rivers}

Each river segment represents a defined area of fixed extent. One way to characterize a segment would be to select random points and visit each to determine the habitat type present and to quantify features of that habitat (such as stem density of herbaceous vegetation). While this approach would provide unbiased estimates of habitat variables within the segment, it would not capitalize on prior knowledge of habitat distribution, and would not minimize variance in measures of habitat condition within habitat types.

Stratification was a useful tool for minimizing variance in estimates within reaches. Similarly, it also would be a useful tool for allocation of sampling effort within segments. However, the nature and extent of data upon which to base a stratification will vary among river reaches. The approach in 2006 on the Gavins Point Reach illustrates a desirable set of circumstances, because a preliminary map of habitat types had been prepared on the basis of 2005 color infrared aerial photography (USGS Northern Prairie Wildlife Research Center, unpub. data, 2007). The most obvious means to initially stratify a river segment is to separate aquatic from terrestrial habitats, where aquatic habitats represent open water that is devoid of vegetation and exposed sand, and terrestrial habitats represent all other cover types. The 2005 habitat map provides information on the abundance and distribution of the various terrestrial cover types that were used to stratify terrestrial sampling.

Early in the 2006 field season, it was determined that a crew of three technicians could sample 1-2 segments per day if each segment consisted of 10 aquatic and 50 terrestrial sampling points (fig. 16). Because no further refinement of aquatic habitats is possible, the 10 aquatic points were randomly distributed among the available open water habitat, as indicated on the 2005 habitat map. The 50 terrestrial sampling points were distributed among the remaining habitat types (table 10) in proportion to the abundance within the segment. Thus, a habitat that consisted of 20 percent of the terrestrial acreage in a given segment would receive 10 random points $(50 \times 0.2)$ for habitat sampling (fig. 17).

The decision to sample 50 terrestrial and 10 aquatic points per segment was based largely on logistical considerations. This level of effort allowed the technicians adequate time to sample 34 segments on the Gavins Point Reach in approximately 6 weeks, allowing sufficient time for them to accomplish other sampling goals on other reaches. Given adequate staffing and support (such as vehicles, boats), the number of sampling points per segment could be increased. Conversely, an extensive monitoring program with limited staff and logistical support could necessitate sampling fewer segments or fewer points per segment. In all cases, these decisions should be viewed in terms of the ability to achieve the monitoring program's stated objectives, and should be discussed with a statistician to ensure that statistical implications of altering sample size are known.

Monitoring on Gavins Point during 2006 was conducted under favorable circumstances, because recent (2005) color infrared aerial photography of the reach was available as was a draft habitat classification based on that photography. These are two key elements that are present to varying degrees for other reaches, although several concurrent research efforts under the Missouri River Recovery Program will provide greater access to these tools in the future. In the interim, it is possible that future monitoring efforts will be initiated on reaches for which availability of spatial data is less than ideal. Experiences during 2006 on three such reaches illustrate potential approaches to these situations:

Lake Oahe and Lewis and Clark Lake-The portion of Lake Oahe under consideration for 2006 was not covered by 2005 color infrared aerial photography, nor were other desirable forms of spatial data (such as Quickbird satellite imagery) readily available. The best available data was the NAIP photography from 2004. Because these data are less suitable for quantifying abundance of habitat cover types, there has not been (and probably will not be) any concerted effort to derive habitat maps from it. Similarly, Lewis and Clark Lake was covered by the 2005 color infrared aerial photography, but analysis of that photography to derive habitat polygons has not been conducted. Given a need to conduct habitat monitoring where a habitat map is not available, there are two potential options. One option would be to manually digitize habitat polygons from existing photography for the segments 


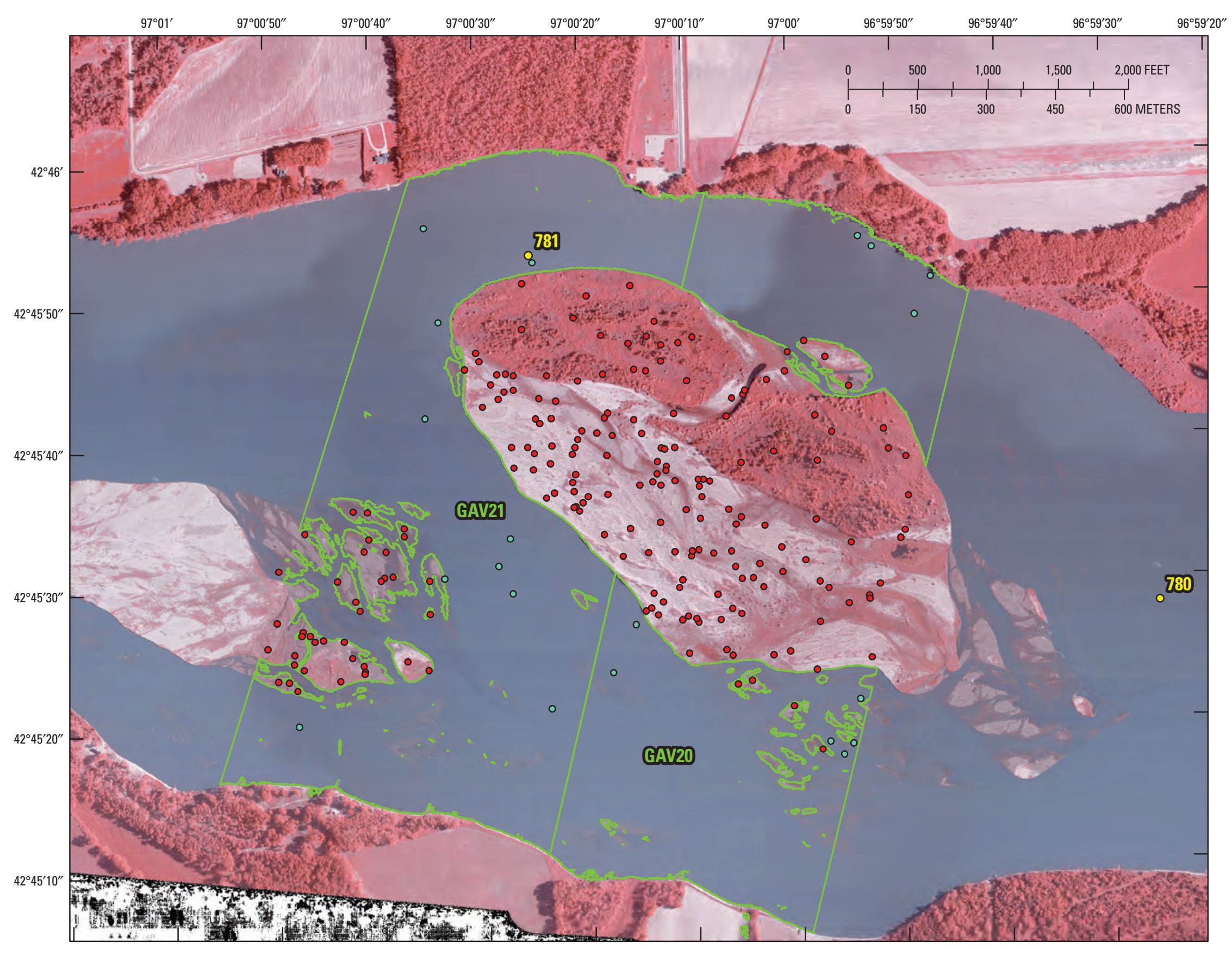

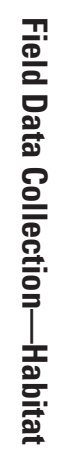

Figure 16. Example of distribution of terrestrial (red dots; $n=50$ per segment) and aquatic (blue dots; $n=10$ per segment) sampling points within two segments of the Gavins Point Reach of the Missouri River. Background image is 2005 color infrared aerial photography. Green lines represent perimeters of sampling segments, and yellow dots represent river miles. 
Table 10. Habitat types used to allocate sampling effort for emergent sandbar habitat monitoring on the Gavins Point Reach of the Missouri River in 2006.

\begin{tabular}{ll}
\hline \multicolumn{1}{c}{ Habitat type } & \multicolumn{1}{c}{ Description } \\
\hline $\begin{array}{l}\text { Dry sand } \\
\text { Wet sand }\end{array}$ & $\begin{array}{l}\text { Dry coarse- to fine-grained sand at the highest elevations on sandbars and 0-30 percent vegetation cover. } \\
\text { Wet coarse- to fine-grained sand, silt and clay and 0-30 percent vegetation cover. }\end{array}$ \\
$\begin{array}{l}\text { Sparsely vegetated } \\
\text { Vegetated }\end{array}$ & $\begin{array}{l}\text { Dry sand and wet substrate containing 30-50 percent vegetation cover. } \\
\text { Areas with greater than 50 percent vegetation canopy coverage, including herbaceous vegetation woodlands, and } \\
\text { shrublands. }\end{array}$ \\
Wetlands & $\begin{array}{l}\text { Isolated areas of wet substrate and herbaceous vegetation that are not physically connected to the river. } \\
\text { Coarse- to fine-grained sand that is under water but visible. } \\
\text { Water }\end{array}$ \\
\hline
\end{tabular}

on which sampling was planned. Although this approach could produce a general habitat map that would be useful for stratified sampling, it would be extremely labor intensive and is not a desirable solution.

A second alternative would be to digitize a single polygon corresponding to the segment boundaries, and randomly select points within the polygons (fig. 18). Although this approach is much more rapid than manually digitizing habitat polygons, it does not provide an ability to stratify the sample locations according to habitat type. However, data from a completely random set of points within the segment do provide an unbiased measure of abundance for each of the habitat types. An additional drawback to this method is that open water frequently dominates river segments, but features of this habitat type are not nearly as important to quantify as are features of terrestrial habitats. Therefore, the solution in 2006 was to select twice as many habitat points per segment $(n=100)$ as would have been selected using stratification. This provides no guarantee that an adequate number of sample points will occur in terrestrial habitats. In some situations, particularly when the amount of terrestrial habitat is small relative to segment size, it may be necessary to increase the number of random points.

When random points are used in this fashion, it may not always be necessary to collect the full suite of habitat data at each random point. Field crews in 2006 were instructed to visit random points sequentially, collecting aquatic habitat data at the first 10 random points that occurred in the open water habitat type, and to collect terrestrial habitat data at all random points that occurred in terrestrial habitats. Any random points beyond the initial 10 that fell in open water were classified according to habitat type, but quantitative habitat data were not collected. On the Lewis and Clark Lake sites sampled in this manner, technicians found that an average of 20 random points per segment fell in terrestrial habitats; whereas, on the Lake Oahe sites, an average of 50 random points per segment fell in terrestrial habitats. Therefore, additional random points would be necessary in future years to achieve 50 terrestrial points per segment on Lewis and Clark Lake.
Kensler's Bend-A slightly different situation occurred on Kensler's Bend in 2006. Current (2005) color infrared aerial photography was available for this reach, however, habitat mapping had not been completed. Ideally, flood-plain terrestrial habitats would have been sampled but because these projects had not been formally announced to the public, and landowners had not been contacted, these areas were not sampled. It was evident, however, that ESH was not currently available. Because it was known that all segments would consist exclusively of open water, the sampling was tailored toward characterization of aquatic habitats. As with the other reaches, the goal was to obtain aquatic data on 10 points per segment. Given habitat conditions on Kensler's Bend, which contains many features of channeled rivers, there was greater uncertainty about finding suitable fish sampling conditions. Therefore, 20 random points per segment were generated (fig. 19) and technicians were instructed to sample the points in sequence, collecting a fish sample at the first point that presented suitable sampling conditions (see "Fish Sampling" section). As plans for Kensler's Bend projects come closer to construction, it is essential to reallocate effort and sample areas to include terrestrial habitats.

\section{Reservoirs}

Habitat types are not distributed randomly on reservoir systems. They are largely dependent upon the history of water levels at that location; commonly specific habitat types occur in rings/bands at various elevations. Reservoir systems also have large variation in elevations, slopes, and aspects relative to riverine systems. Thus, sampling of habitat on Lake Sakakawea incorporated a systematic approach of transects perpendicular to the shoreline spaced every 100 meters (m), and each transect was sampled for habitat characteristics every $5 \mathrm{~m}$. Moreover, this systematic approach along with measuring elevation at sampling points allows for the distance to shoreline and elevation measurements to control for the variation in habitat characteristics dependent on past water levels 


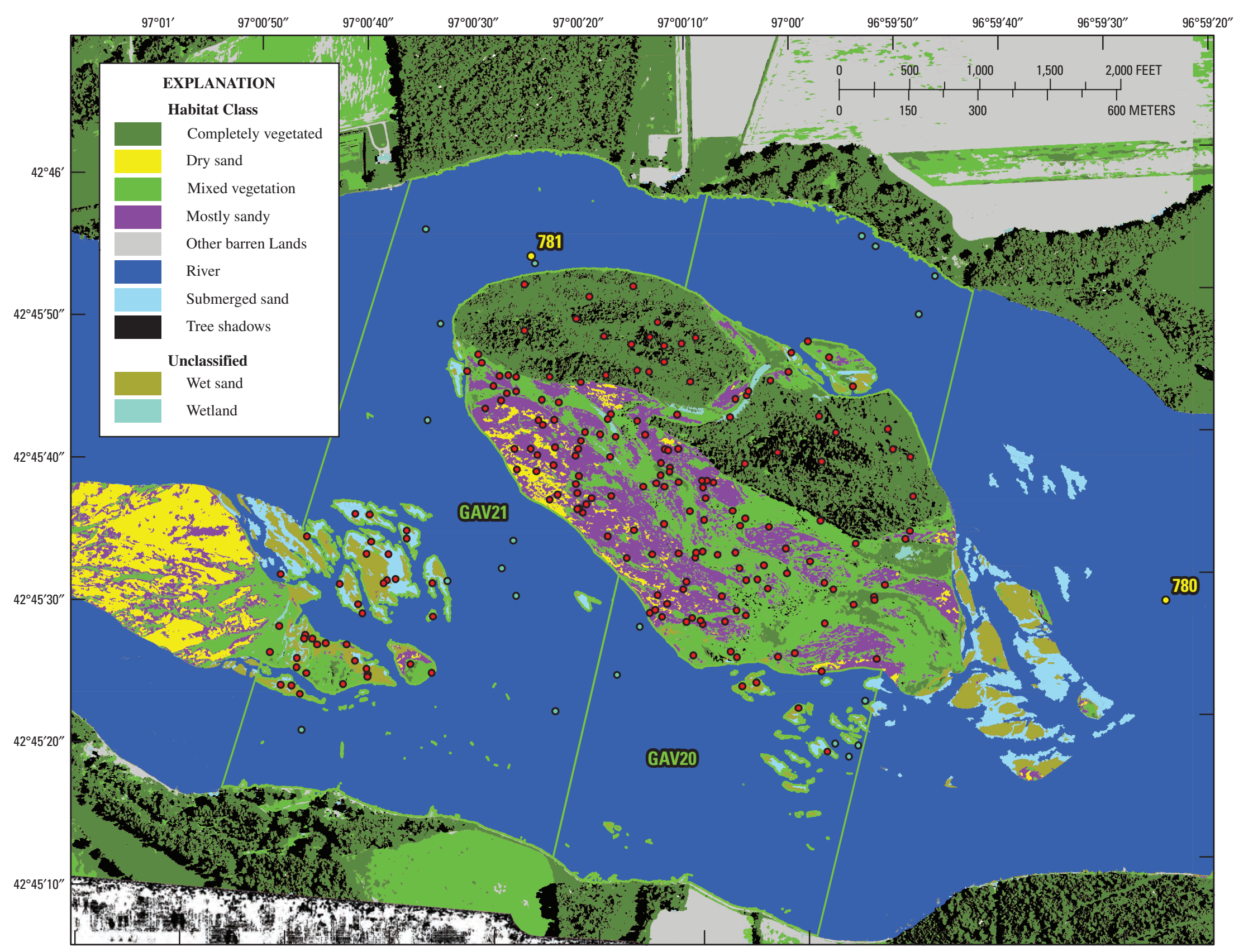

Figure 17. Example of distribution of terrestrial (red dots; $n=50$ per segment) and aquatic (blue dots; $n=10$ per segment) sampling points within two segments of the Gavins Point Reach of the Missouri River, showing the distribution of habitat types used to derive point locations. Green lines represent perimeters of sampling segments, and yellow dots represent river miles. 


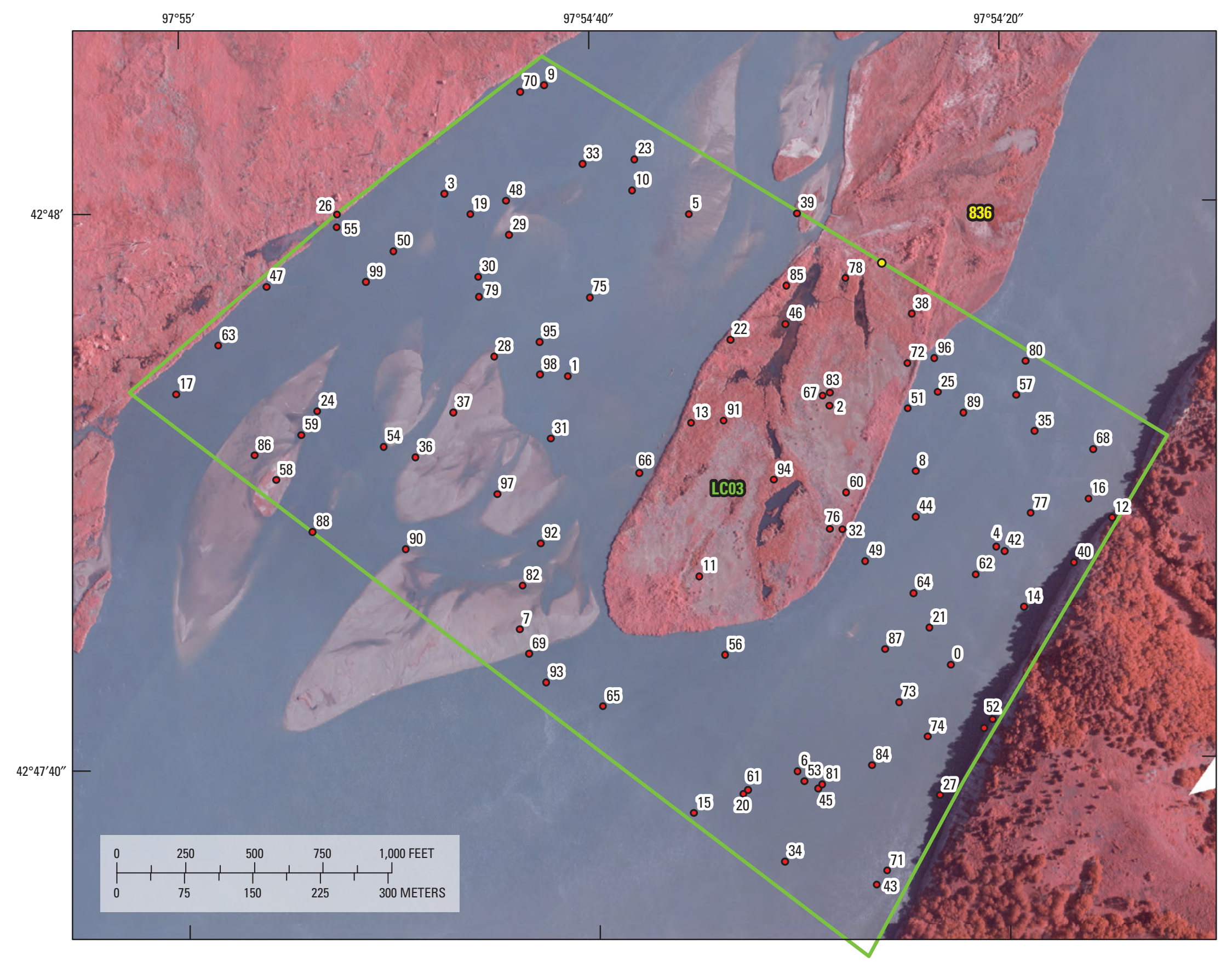

Figure 18. Example of 100 completely random points distributed in a 0.4-river-mile habitat sampling segment on Lewis and Clark Lake, for which terrestrial habitat was known in advance to be present, but for which a habitat classification had not been derived. The background image is 2005 color infrared aerial photography. The green lines represent sampling segment boundaries, and the yellow dot represents river miles. 


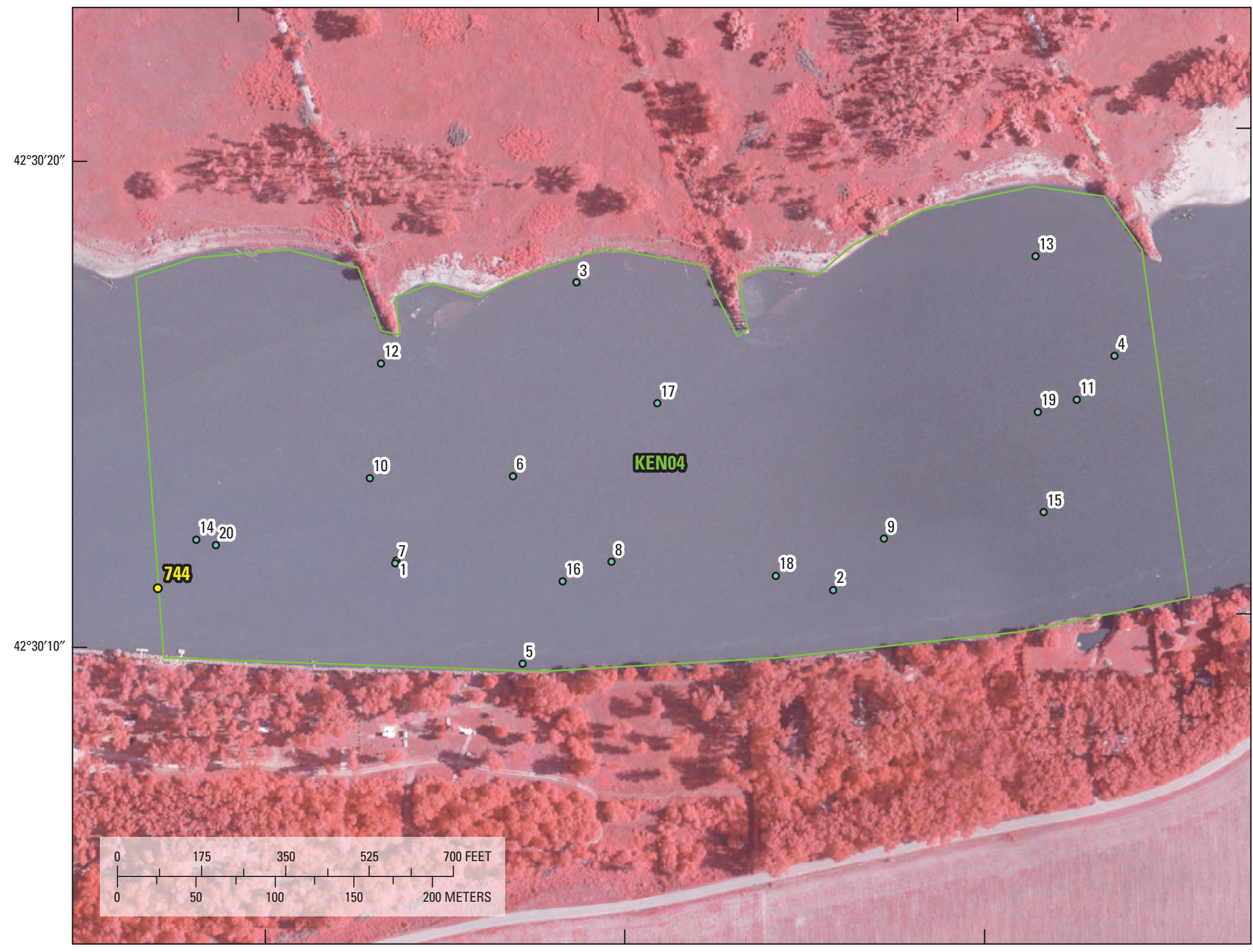

Figure 19. Example of 20 completely random points distributed in a 0.4-river-mile habitat sampling segment on Kensler's Bend, for which terrestrial habitat was known in advance to be completely lacking. The background image is 2005 color infrared aerial photography. The green lines represent sampling segment boundaries, and the yellow dot represents river miles. 
and ensures that habitat types distributed in rings/bands are sampled.

The first transect in each segment was located on the segment boundary and proceeded inland perpendicular to the shoreline (beach aspect was determined by visually averaging the aspect of the shoreline $25 \mathrm{~m}$ either side of the transectshoreline interface). Each segment boundary essentially serves as a random start point for the systematic sample because the shoreline of the lake was divided into sections and subsequently segments on the basis of a random start point. When entire islands were sampled, the start point for the first transect on the island was located randomly (established with random azimuth from the approximate center to the shoreline of the island). Subsequent transects were located $100 \mathrm{~m}$ of shoreline away from the previous, until the end of the 2-km segment. Within each transect, measurements continued (measuring habitat characteristics every $5 \mathrm{~m}$ ) until (1) the terrain sloped downward toward the lake (in the case of a point or island; figs. 14 and 15), (2) five measurements were considered vegetated ( $>50$ percent vegetation cover) and the next $50 \mathrm{~m}$ along the transect also was vegetated (see figs. 14 and 15), or (3) maximum pool elevation (565 $\mathrm{m}$ [1,854 feet] above NAVD 88) was reached.

\section{Nest Sites}

As part of the productivity monitoring on the Gavins Point, Garrison, and Lake Sakakawea Reaches, habitat was assessed around nests at several spatial and temporal scales (table 11). Each reach presented different objectives, opportunities, and limitations to measuring habitat on nesting sites (see companion studies [Tasks 7.1, 7.2, and 7.5]). Despite reach specific sampling, in all cases habitat characteristics were measured within a $1-\mathrm{m}^{2}$ quadrat centered about the nest (table 11). It is important that sampling is standardized at as many levels or spatial scales as possible; in this case all of the sampling within a $1-\mathrm{m}^{2}$ quadrat, at the nest and at various spatial or temporal scales, contained a set of variables that were ubiquitous to all reaches.

On the Gavins Point Reach nesting densities of least terns were relatively high, and it was important to understand nest site selection on a micro scale (such as why a bird selected a particular location over others within a small area; hereafter referred to as nest site selection). We measured habitat characteristics at the nest and at four plots $3 \mathrm{~m}$ away from the nest (on cardinal directions; fig. 20 and table 11). Examination of 1-m-square plots that were used by terns versus those adjacent but not used will be valuable in refining the nest site requirements of terns, and ultimately provide information about important nest site habitat characteristics that should be included in future habitat monitoring.

Intensive productivity work prevented extensive habitat monitoring across spatial scales on the Garrison Reach. However, in order to assess the differences at a given site within a season, habitat characteristics were measured at least tern and piping plover nest sites upon discovery, and nest sites were revisited in the postbreeding season (mid- to late August) on the Garrison Reach. This approach will be informative in determining the value of conducting post-breeding-season habitat measurements as an index to the habitat that was there when the birds initiated nesting.

The complexity of factors that appear to influence habitat availability and selection and concomitant breeding productivity of piping plovers on Lake Sakakawea demonstrate the need for an integrated program of monitoring and research. Habitat conditions on Lake Sakakawea are highly variable including large variations in substrate, slope, aspect, vegetation, and landform (island versus shoreline). This system appears much more complicated and there is limited literature available about habitat selection and use. Furthermore, the lake has become a very important breeding area for piping plovers; recent reports suggest Lake Sakakawea may have become the single most used area for plovers in the summer, throughout their breeding range (Haig and others, 2005; Threatened and Endangered Species Section, Omaha District, USACE, unpub. data, 2006). Despite the relatively high use of the lake for breeding, nesting densities generally are lower than those on the river, seemingly because the areas of habitat on the lake are expansive. Therefore, these conditions on Lake Sakakawea present both opportunity and necessity to understand what habitat characteristics drive habitat selection of piping plovers at multiple spatial scales and which characteristics lead to successful outcomes for plovers (such as eggs hatched and chicks fledged).

Habitat characteristics were measured on the randomly selected 2-km segments in order to examine habitat selection at a landscape scale on Lake Sakakawea (fig. 21); the following sections of this report examine the characteristics that influence the number of pairs of piping plovers using the 2-km segments of shoreline habitat. Moreover, the habitat characteristics of the beach $(0.5-\mathrm{km}$ linear shoreline distance on either side of the nest; fig. 21) that lead to breeding success (nest survival, number of fledged young, and age-adjusted chick body mass) are examined. In order to understand nest site and nest area (such as what site a bird chooses within the selected territory) selection, habitat characteristics were recorded at eight systematically selected locations within a radius of 10 $\mathrm{m}$ surrounding the nest and at two randomly select reference sites within a 100- to 150 -m radius of each nest to represent available nesting habitat (fig. 21). These eight points were positioned 3 and $10 \mathrm{~m}$ from the nest or random point on each cardinal direction (fig. 20). Examination of multiple plots of used and unused areas within the nest area also allows for interpretation of site heterogeneity/uniformity, which may be an important habitat characteristic for piping plovers.

\section{Habitat Variables}

The foregoing sections describe methods for delineating the spatial extent of sampling, determining an appropriate sampling unit, and establishing locations for points at which 
Table 11. Numbers of least tern and piping plover nests where habitat characteristics were evaluated for reaches of the Missouri River in summer 2006.

[N, number; $n$, evaluation of 1-meter-square plot centered on nest at time of discovery; $3 \mathrm{~m}$, valuations on four 1-meter-square plots positioned 3 meters from nest on cardinal directions; r, return visit postbreeding season to evaluate habitat; $10 \mathrm{~m}$, evaluations on four 1-meter-square plots positioned 10 meters from nest on cardinal directions; 2rand, two random points where n, 3m, and 10m were evaluated; s, segment of shoreline 1 kilometer centered on nest evaluated with transects]

\begin{tabular}{lclrl}
\hline \multicolumn{1}{c}{ Reach } & River miles & \multicolumn{1}{c}{ Species } & N & \multicolumn{1}{c}{ Measurements } \\
\hline Gavins Point & $754-795$ & Least Tern & 272 & $\mathrm{n}, 3 \mathrm{~m}$ \\
\multirow{2}{*}{ Garrison } & & Least Tern & 122 & $\mathrm{n}, \mathrm{r}$ \\
& $1,304-1,388$ & Piping Plover & 245 & $\mathrm{n}, \mathrm{r}$ \\
Lake Sakakawea & $1,390-1,508$ & Piping Plover & 59 & $\mathrm{n}, 3 \mathrm{~m}, 10 \mathrm{~m}, 2$ rand, $\mathrm{s}$ \\
\hline
\end{tabular}

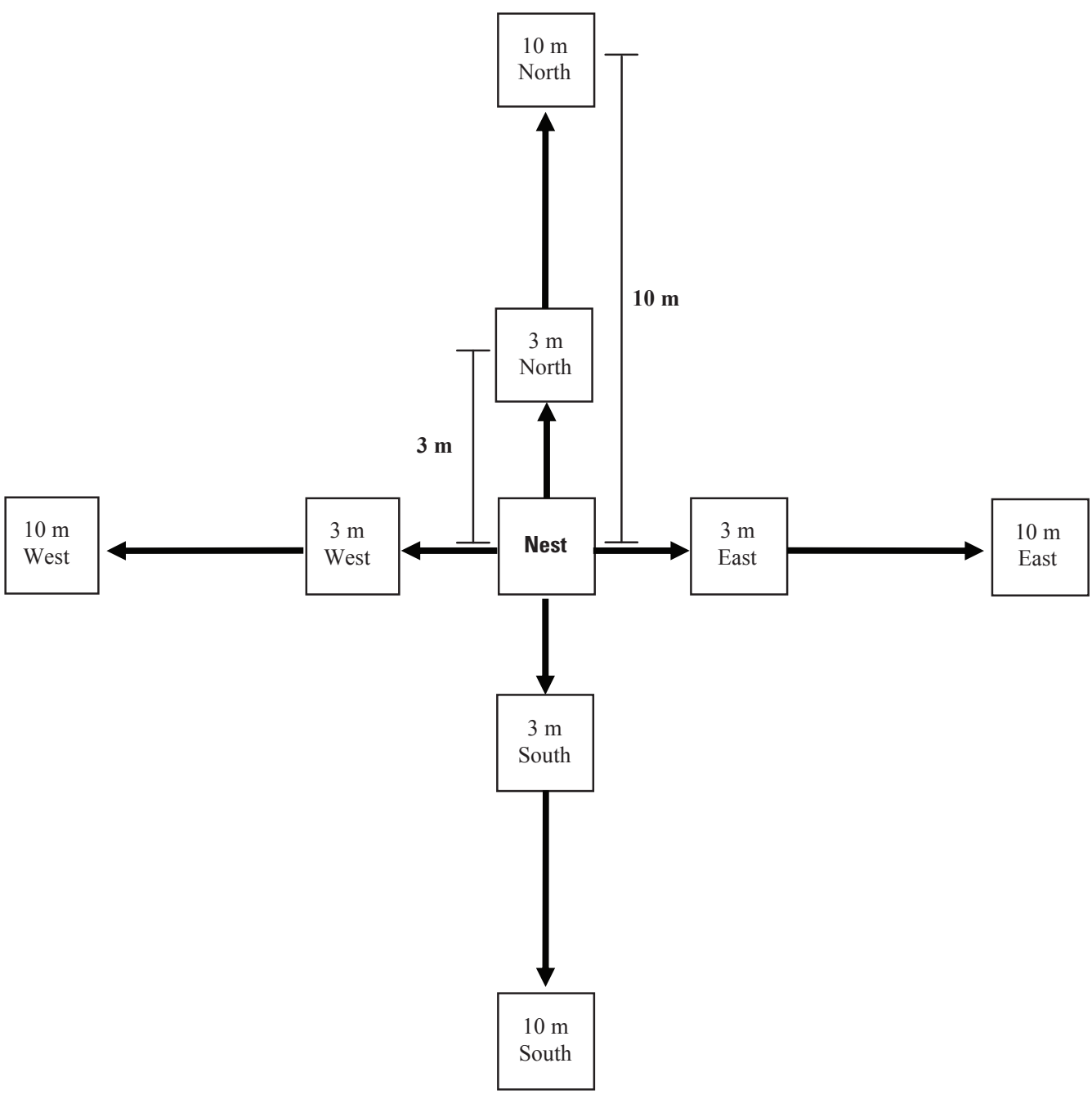

Figure 20. Schematic of nest site, 3 meter, and 10 meter plot (1-meter-square plots) locations for evaluating nest-site and nest-area habitat characteristics. 


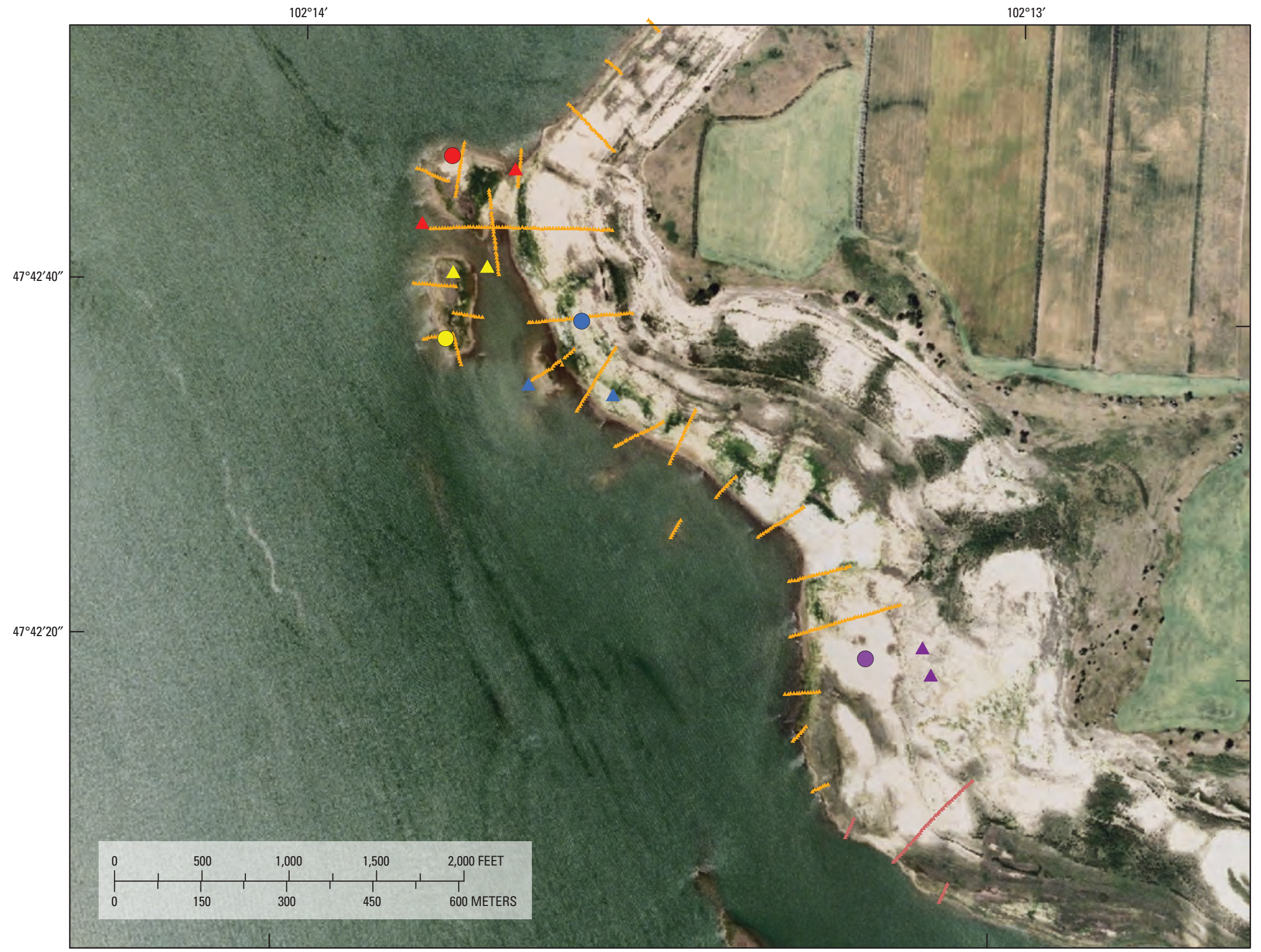

Figure 21. Example of spatial extent of segment habitat data for Lake Sakakawea in 2006, depicting locations of nests (circles), random points (triangles; paired with nests by color), transects composed of habitat evaluations every 5 meters (yellow lines), and additional transects needed for nest-beach scale analysis (1 kilometer centered on nest; orange lines). Background imagery is 2004 U.S. Department of Agriculture-National Agricultural Imagery Program photography. 
habitat data will be collected. Each monitoring effort will present a unique set of circumstances that will dictate allocation of points within and among sampling units. Regardless of these circumstances, a universal set of habitat features can and should be measured at each point. Consistency in collection of habitat data throughout the upper Missouri River system will generate a data set that could ultimately lend itself to valuable meta-analyses. Consequently, a set of habitat features are outlined in this report that should be useful in describing relative value of sandbar and shoreline habitats as tern and plover nesting habitat, as well as indices of foraging habitat value. By adhering to this set of variables, both in long-term habitat monitoring efforts and in collecting nest-site habitat data in productivity studies, analyses of nesting habitat selection by terns and plovers will be enabled.

Measures of substrate composition, vegetation abundance, and vegetation structure were used in selecting the variables to be included for habitat monitoring because these are generally considered to be the principal features driving nest site selection by least terns and piping plovers. A suite of variables was used that could be readily measured within a $1-\mathrm{m}^{2}$ sampling frame without additional equipment that might impede mobility of technicians and limit their ability to sample extensively. Consequently, all of the selected variables can be measured either by count or by visual estimate within a 1- $\mathrm{m}^{2}$ quadrat. By eliminating measures that require two technicians (such as cover boards), technicians were able to work independently of each other. This expedited data collection, minimized potential disturbance to terns and plovers, and maximized the number of points that could be sampled per segment.

Visual estimation of percent cover for vegetation types (Nudds, 1977) can be problematic, and is typified by substantial variation in estimates between individuals. A widely applied method for minimizing this variation is to assign Daubenmire cover classes rather than point estimates of percent cover (Daubenmire, 1959). This approach was useful for estimating abundance of plants, and also of the various components of sandbar substrates. Identical break points between classes were used for each variable measured by using Daubenmire classes (table 12). Although this approach is generally applied only to vegetation, it also was useful for classifying substrate composition. Thus, for each substrate class (table 13), a Daubenmire cover class was assigned that reflected the relative abundance of that substrate type within the $1-\mathrm{m}^{2}$ quadrat. Using cover classes in this fashion eliminates the need for time-consuming quantitative measures of substrate composition, requires no additional equipment, and allows for some uncertainty in assignment of cover classes. Consequently, it is a useful tool for rapidly assessing substrate conditions at the sampling point.
Table 12. Daubenmire cover classes and corresponding ranges of percent cover.

$[\%$, percent $]$

\begin{tabular}{ccc}
\hline Class & \% Cover range & Midpoint \% \\
\hline 0 & 0 & 0 \\
1 & $>0-5$ & 2.5 \\
2 & $6-15$ & 10 \\
3 & $16-30$ & 23 \\
4 & $31-45$ & 38 \\
5 & $46-70$ & 58 \\
6 & $71-100$ & 85 \\
\hline
\end{tabular}

Table 13. Size range of substrate classes used to describe habitats on the Missouri River.

$[<$, less than; $>$, greater than $]$

\begin{tabular}{lc}
\hline Substrate class & Size range \\
\hline Silt & $<0.125 \mathrm{~mm}$ \\
Sand & $0.125-2 \mathrm{~mm}$ \\
Small pebble & $2-10 \mathrm{~mm}$ \\
Gravel & $10-64 \mathrm{~mm}$ \\
Cobble & $64-256 \mathrm{~mm}$ \\
Boulder & $>25.6 \mathrm{~cm}$ \\
\hline
\end{tabular}




\section{Terrestrial Variables}

Technicians collected habitat data using Trimble GeoXT handheld PC/GPS units, which enabled them to rapidly record the necessary data at each preselected sampling point. Upon arriving at a terrestrial sampling location, technicians recorded the unique identification information for the point (reach, segment number, point number, and observer initials), as well as a set of standard weather classification variables (table 14). The Trimble GPS units were programmed to record the Universal Transverse Mercator (UTM) coordinates of the sampled location while the technician collected habitat data.

At each terrestrial point, a suite of habitat variables reflecting vegetation abundance and cover and substrate composition was recorded (table 15). In sampling Lake Sakakawea, technicians also recorded elevation, slope, and aspect of the sampling location because these factors are believed to contribute strongly to nest site selection by piping plovers. Elevation reference points were established by driving an iron rod into the substrate and recording the UTM coordinates and elevation using RTK GPS. Laser levels were used to establish, by difference, the elevation of habitat sampling points within range of the fixed reference point. Similar measures may be employed on river sandbars, although methods for measuring sandbars have not been developed in this context.

By definition, the suite of variables for terrestrial points could only be recorded where terrestrial habitat conditions existed. Technicians were instructed to record the habitat conditions that occurred at the time of sampling. Therefore, a point expected to be terrestrial but exhibiting aquatic conditions would be recorded as belonging to an aquatic habitat class (such as Open Water). Likewise, points expected to be aquatic but exhibiting terrestrial conditions would be assigned to the appropriate terrestrial habitat class. Because technicians did not have any prior expectation of the specific terrestrial habitat class of each point, their assessment of habitat class provides some measure of accuracy for the image classification analysis being conducted by the USGS (NPWRC Task 3 : Mapping, monitoring, and estimation of least tern and piping plover habitats on the upper Missouri River using Quickbird imagery).

Forage habitat likely influences selection of nesting habitat and success of brood rearing, and would be important to consider when determining why or why not an ESH site was successful. Collection of invertebrate data is important to understand the availability of forage habitat. The variation among samples from our invertebrate sampling experiment was examined (see "Invertebrate Sampling" section) for guidance on sample size for incorporating invertebrate sampling into a segment-based monitoring plan. It appears that five samples per segment would be adequate to index invertebrate availability for piping plovers. These samples should be allocated within wet sand terrestrial points because wet sand is apparently the preferred foraging habitat for piping plovers on the river system (Le Fer, 2006). It remains unclear what invertebrate foods piping plovers select and prefer, and identification of invertebrate samples can be labor intensive. Thus, it would be appropriate to simply count the number of invertebrates caught in three different size classes by length (small $<3$ millimeter $(\mathrm{mm}$ ), medium $3 \mathrm{~mm}$ to 1 centimeter $(\mathrm{cm})$, and large $>1 \mathrm{~cm})$. Given the time required to collect an invertebrate sample and the time constraints on sampling in areas occupied by terns and plovers, it would be advisable to initiate invertebrate sampling at the first five wet sand points encountered while sampling a segment, and sticky traps could

Table 14. Standard classification scheme for weather observations at sampling points.

[\%, percent; F, Fahrenheit; mph, miles per hour; <, less than; >, greater than]

\begin{tabular}{|c|c|c|c|c|c|c|c|}
\hline \multicolumn{2}{|c|}{ Cloud cover } & \multicolumn{2}{|c|}{ Temperature } & \multicolumn{2}{|c|}{ Wind speed } & \multicolumn{2}{|c|}{ Precipitation } \\
\hline Response & $(\%)$ & Response & (F) & Response & (mph) & Response & Type \\
\hline 0 & $0-10$ & 0 & $0-10$ & 0 & $<4$ & 0 & None \\
\hline 1 & $11-20$ & 1 & $11-20$ & 1 & $5-7$ & 1 & Fog \\
\hline 2 & $21-30$ & 2 & $21-30$ & 2 & $8-12$ & 2 & Drizzle \\
\hline 3 & $31-40$ & 3 & $31-40$ & 3 & $13-18$ & 3 & Rain \\
\hline 4 & $41-50$ & 4 & $41-50$ & 4 & $19-24$ & 4 & Flurries \\
\hline 5 & $51-60$ & 5 & $51-60$ & 5 & $25-31$ & 5 & Snow \\
\hline 6 & $61-70$ & 6 & $61-70$ & 6 & $32-38$ & 6 & Hail \\
\hline 7 & $71-80$ & 7 & $71-80$ & 7 & $>38$ & & \\
\hline 8 & $81-90$ & 8 & $81-90$ & & & & \\
\hline 9 & $91-100$ & 9 & $>90$ & & & & \\
\hline
\end{tabular}


Table 15. Terrestrial habitat variables recorded at emergent sandbar habitat monitoring points on the Missouri River and the relationship with ongoing productivity monitoring and remote sensing efforts.

[ESH, emergent sandbar habitat; PM, productivity monitoring; RS, remote sensing; $\boldsymbol{V}$, rank of importance for each monitoring effort [variables with more checks are ranked more important]; >, greater than; $\mathrm{m}$, meter]

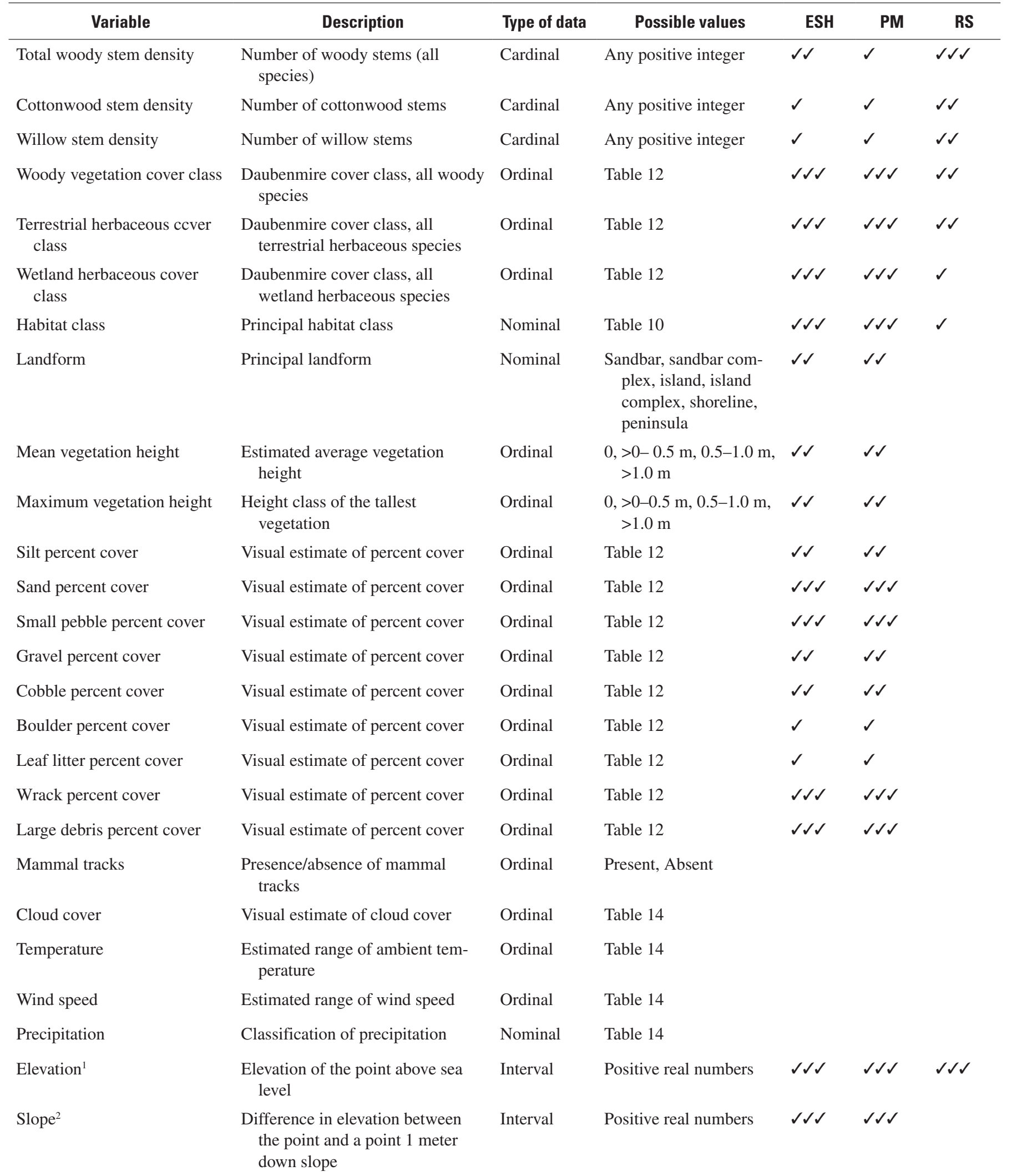


Table 15. Terrestrial habitat variables recorded at emergent sandbar habitat monitoring points on the Missouri River and the relationship with ongoing productivity monitoring and remote sensing efforts. - Continued

[ESH, emergent sandbar habitat; PM, productivity monitoring; RS, remote sensing; $\checkmark$, rank of importance for each monitoring effort [variables with more checks are ranked more important]; >, greater than; m, meter]

\begin{tabular}{|c|c|c|c|c|c|c|}
\hline Variable & Description & Type of data & Possible values & ESH & PM & RS \\
\hline Distance to water ${ }^{2}$ & $\begin{array}{l}\text { Distance from the point to the } \\
\text { nearest standing water- } \\
\text { measured in ArcGIS }\end{array}$ & Interval & Positive real numbers & $\checkmark$ & $\checkmark$ & \\
\hline Invertebrate index & $\begin{array}{l}\text { Count of invertebrates obtained by } \\
\text { sticky stick sampling }\end{array}$ & Cardinal & Positive integers & $\checkmark \checkmark \checkmark$ & $\checkmark \checkmark \checkmark$ & \\
\hline
\end{tabular}

${ }^{1}$ Elevation data, although important for understanding vegetation dynamics, water-level management, and patterns of nest initiation and fate, is time intensive and requires an accuracy that may prohibit assessment during breeding season. Postseason assessment is likely preferred but potentially less accurate.

${ }^{2}$ Variables of interest for ESH projects on reservoirs.

be collected upon completion of the terrestrial sampling points ( $>30$ minutes; recording the time traps were in place).

\section{Aquatic Variables}

A similar approach was followed at aquatic sampling points. Four principal habitat variables were recorded upon arriving at each point (table 16). As with terrestrial points, the actual conditions observed at the time of sampling were recorded. However, there were few circumstances when points expected to be aquatic were actually terrestrial. In contrast, points expected to be terrestrial were frequently aquatic when visited. Technicians were instructed to record aquatic habitat variables for a minimum of 10 points per segment, and record just the habitat class (such as open water) for those in excess of 10 aquatic points. Technicians also were instructed to visit aquatic points in a predetermined (random) sequence, and to collect a fish sample at the first point where water depth was $<1 \mathrm{~m}$.

\section{Fish Sampling}

Small fish are prey for least terns; therefore, assessing aquatic habitat and the fish community during the breeding season is an appropriate component of ESH monitoring. The Missouri River fish population assessment effort (Drobish, 2006) and Benthic Fish Asssessment (Berry and others, 2004) provide general background information on status, trends and habitat associations of Missouri River fishes, but provide no information on local availability of fish during May-June (the peak of breeding), or on fish responses to ESH projects. Sampling areas adjacent to ESH complements and does not replace existing efforts.

Small fish are best caught by using a small mesh net; care must be taken to select gear that is suitable for work in shallower water $(<2 \mathrm{~m})$ and that can be deployed and retrieved quickly with personnel and/or boats. A variety of gear has been evaluated for sampling fish in riverine environments (Kushlan, 1981; Miranda and Collazo, 1997; Herzog and others, 2005). Mini-Missouri benthic trawls (Herzog and Hrabik, Missouri Department of Conservation, oral commun., 2006) are an active fishing gear that can be deployed from a boat or by hand, depending on site conditions. The trawl is fished upstream from the bow of a boat, trawling in reverse when water depth is $>1 \mathrm{~m}$. Hand trawling is conducted by two people dragging it downstream when water depth is $<1 \mathrm{~m}$. For either deployment method, trawls should be $>100 \mathrm{~m}$ in length, which can be easily judged using a premeasured float line anchored adjacent to the sampling area. Each sample should be accompanied by standard measurements from the Missouri River Fish Protocols (Drobish, 2006) including start/end depth and GPS location, turbidity, flow, and substrate composition. Captured fish should be identified, measured for total length, and weighed. Fish should be kept wet until measured and returned to the river when measurements are complete; deceased individuals should be preserved in 70 percent ethyl alcohol after fixing in 30 percent formaldehyde, and labeled and retained as voucher specimens. Skill in identifying small, juvenal fish species is essential for rapid processing, and vouchers are valuable for training. Confirming identities of fish through comparison of voucher specimens and photographs with reference collections is essential.

One fish sample per river segment was collected in 2006 to characterize fish available to foraging least terns. However, variation among multiple trawls from the same segment (Stucker and Sherfy, U.S. Geological Survey, unpub. data, 2006; NPWRC Task 7.1) indicated that a minimum of three $100 \mathrm{~m}$ trawls would provide an adequate index to fish abundance in the segment. To obtain a random sample from shallow water habitat, field technicians should visit the randomly located aquatic points in numeric order and collect 
Table 16. Aquatic habitat variables measured at emergent sandbar habitat monitoring points on the Missouri River and the relationship with ongoing productivity monitoring and remote sensing efforts.

[ESH, emergent sandbar habitat; PM, productivity monitoring; RS, remote sensing; $\checkmark$, rank of importance for each monitoring effort [variables with more checks are ranked more important]; $\leq$, less than or equal to; in, inches; cm, centimeter]

\begin{tabular}{|c|c|c|c|c|c|}
\hline Variable & Description & $\begin{array}{l}\text { Type of } \\
\text { data }\end{array}$ & ESH & PM & RS \\
\hline Water depth & Reading from incremented staff resting on river bed & Interval & $\checkmark \checkmark \checkmark$ & $\checkmark \checkmark \checkmark$ & \\
\hline Velocity & Surface-flow rate measured with digital flow meter & Interval & & & \\
\hline Total fish count & $\begin{array}{l}\text { Count by species of all fish captured by hand trawl } \leq 7 \mathrm{~cm} \text { (approxi- } \\
\text { mately } 3 \text { in) }\end{array}$ & Cardinal & $\checkmark \checkmark \checkmark$ & $\checkmark \checkmark \checkmark$ & \\
\hline Total fish biomass & $\begin{array}{l}\text { Biomass of all fish captured by hand trawl; estimated by length-mass } \\
\text { relationships }\end{array}$ & Interval & $\checkmark$ & $\checkmark$ & \\
\hline
\end{tabular}

a fish sample by hand trawling at the first three points where water depth is $<1 \mathrm{~m}$.

\section{Invertebrate Sampling}

Terrestrial and aquatic invertebrates are the primary foods for piping plovers (Haig and Elliott-Smith, 2004), thus measuring amounts of invertebrate forage for plovers should be incorporated into a monitoring program. However, sampling plover forage is innately problematic because it is unclear exactly what invertebrates piping plovers consume and prefer on the Missouri River. Invertebrate forage for piping plovers has typically been sampled by taking soil cores (active sampling) or using sticky traps/sticky sticks (passive sampling; Loegering and Fraser, 1995; Elias and others, 2000). Using soil cores or other active sampling is usually preferable because there are few biases associated with activity or catchability, as long as the technique is appropriate for the invertebrates targeted. However, soil cores seem unlikely to catch larger-fast moving invertebrates, which piping plovers likely eat, given their typical foraging style of running and pecking (Haig and Elliott-Smith, 2004). Moreover, without an intense sampling regime, active techniques tend to yield many zero counts when invertebrate density is low, which causes problems with data analysis (zero inflation), and in effect poorly estimates invertebrate densities. Therefore, using sticky traps might provide a better index of invertebrate densities, if the inherent biases in catchability due to variations in invertebrate activity are understood.

An experiment was conducted in order to examine the diurnal variation in catchability of sticky sticks on two reaches of the Missouri River (Garrison and Lake Sakakawea). Representative locations were selected on the Garrison Reach and Lake Sakakawea that contained areas of each of the three habitat types: dry sand, wet sand, and vegetated. Four exclosures were randomly located within each habitat; three sets of sticky sticks were placed at 0800 hours (each set was composed of one horizontal and one vertical; Loegering and Fraser, 1995; Elias and others, 2000). Every three hours one set of sticks was pulled from each exclosure and replaced with a fresh set, leaving the other two sets of sticky sticks in place for 12 and 24 hours. The experiment was repeated the next day; however, on the second day the experiment was disrupted by severe thunderstorms on the Garrison Reach, so data were not useable. Invertebrates $>3 \mathrm{~mm}$ long were counted on each stick; counts for each set of sticky sticks were as follows: count vertical $+(2 \times$ count horizontal $)$. The data were analyzed separately for each reach, using generalized linear models with a Poisson distribution (PROC GLIMMIX; SAS Institute, 2006).

Larger numbers of invertebrates $(>3 \mathrm{~mm})$ were caught in the morning time interval (0800-1100) than in any other time interval on Lake Sakakawea (fig. 22). There also was a weak positive relationship between cloud cover and catch rates. Whereas, on the Garrison Reach there was an interaction between time interval and habitat; in dry and wet sand habitats the largest number of invertebrates were caught in the first two time intervals (0800-1100 and 1100-1400), and there was no relationship with time interval in the vegetated habitats (fig. 23). Thus, there clearly is diurnal variation in catch of sticky sticks, and some evidence that weather also is important. Sticky sticks were examined to see if the sticks could be left out for 12 or 24 hours to account for this bias, but 


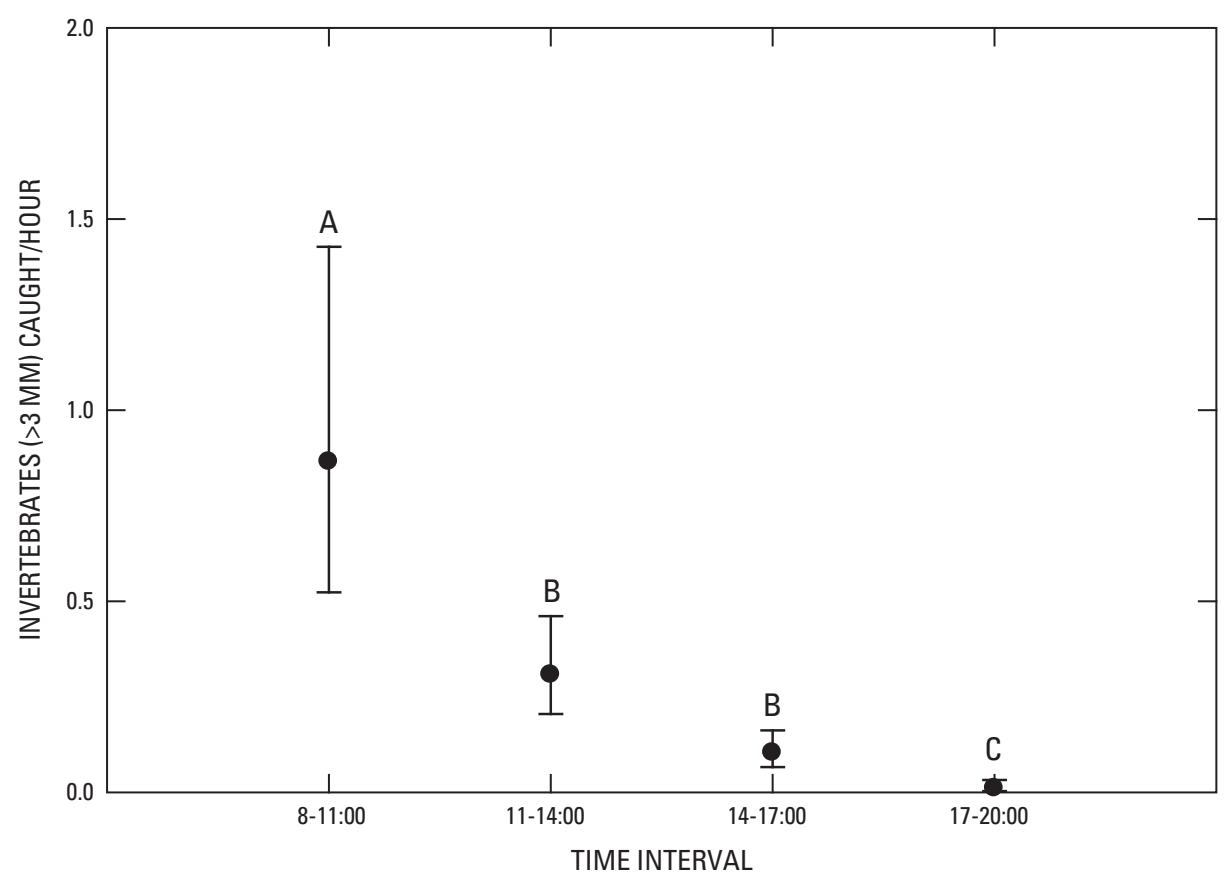

Figure 22. Least-square geometric mean counts per hour of invertebrates ( $>3 \mathrm{~mm})$ captured on sticky-stick traps during four time intervals at Lake Sakakawea in summer 2006.

the 12- and 24-hour sets caught fewer invertebrates than that of the 12 hours of catch summed from four 3-hour intervals. This suggests that sticky sticks do not have a consistent catch rate for periods 12 hours or greater; they likely get fouled with sand or other debris. Therefore, sticky sticks may be a useful way to index invertebrate forage for plovers, but to minimize bias and unexplained variation, they should be used only between the hours of 0800 and 1100 , and within a narrow window of weather parameters.

\section{Timing of Habitat Sampling}

Habitat sampling often is conducted in late summer, after the peak nesting season, because the intensity of productivity monitoring leaves little available time for other data collection. This approach carries an implicit assumption that data collected in late summer are representative of habitat conditions at nest initiation. There are two potentials for bias (systematically inaccurate or unrepresentative) in sampling nesting habitat after the breeding season: first, certain habitats may not be available for sampling after the breeding season; and second, habitat characteristics within a location of interest may change from the time birds initiate nests to completion of breeding efforts. To evaluate this assumption and potential biases, habitat characteristics were measured and recorded habitat class at 345 least tern and piping plover nest sites at the time of nest discovery and remeasured habitat at all 345 nest sites during mid-August on the Garrison Reach in 2006.
Habitat classes recorded at a nest upon discovery were compared to those recorded in August to evaluate the conditions under which habitats selected for nesting would be available for habitat sampling in August (table 17). Specifically, the probability was examined that a given nest site was available for habitat sampling (for example, not inundated) during August in relation to the initial habitat classification and the date of the initial habitat assessment (logistic regression, binomial distribution, logit link function, DF = 340; PROC GENMOD, SAS Institute, 2002). Date of initial habitat assessment was positively correlated with the probability that a site would be available for sampling in August $\left(\chi^{2}=21.85\right.$, $P<0.001)$. The probability that a site would be available for sampling in August varied by initial habitat classification $\left(\chi^{2}=14.26, P=0.003\right)$ and was significantly below 1 for all initial habitat classes (fig. 24). Probability of availability was lowest for nest sites located in wet sand habitats ( $n=59$; fig. 24 and table 17).

Changes in vegetation and substrate characteristics were examined for nest sites that were available to be sampled (for example, not inundated) in August ( $n=219)$. The midpoint percentage associated with each Daubenmire classification was used (table 12) for all of the following calculations and analyses. The change in vegetation was calculated by subtracting the initial midpoint percentage from the postbreeding-season assessment. The change in each substrate characteristic was calculated with the following formula: 


$$
\% \Delta=\frac{\text { Substrate }_{P B S}}{\sum \text { Substrates }_{P B S}}-\frac{\text { Substrates }_{I}}{\sum \text { Substrates }_{I}},
$$

where $\% \Delta$ is percent change, $P B S$ is post-breeding-season classification, $I$ is initial classification, and $\Sigma$ Substrates is the sum of midpoint percentages from silt, sand, small pebble, gravel, cobble, and boulder. Separate t-tests were used for each characteristic of interest (PROC GLM, SAS Institute, 2002) to examine if the mean change was different from zero. Mean herbaceous vegetation cover $($ estimate $=3.591, \mathrm{SE}=0.713$, $\mathrm{T}=5.04, P<0.001$ ), woody stem counts (estimate $=0.717$, $\mathrm{SE}=0.33, \mathrm{~T}=2.17, P=0.031$ ), and percent cover of silt (estimate $=6.935, \mathrm{SE}=2.305, \mathrm{~T}=3.01, P=0.003$ ) increased between breeding season and August measurements. Percent cover of woody vegetation, sand, small pebble, gravel, and cobble were similar between measurements (all $P_{\mathrm{S}}>0.05$ )

Implications for timing of nest-site habitat evaluation-Data indicate that on the Garrison reach during 2006 there was a $0.29-0.57$ probability (depending on the initial habitat classification; fig. 24) that a nest found during the breeding season would not be available to be sampled (for example, inundated) in mid-August. If nest-site habitat were to be sampled postbreeding season, data suggest that the sample of available nests would be $29-57$ percent smaller, and would be biased by initiation date and habitat class. However, these data are from only one year and might represent extreme events (such as water dynamics/management) occurring in 2006; nonetheless, these data demonstrate the possibility of a substantial bias in availability of habitat, at a minimum. Moreover, there were subtle changes in herbaceous vegetation cover and substrate that would further bias estimates of nestsite habitat if measurements in August were used. Therefore, if an unbiased measurement of nest-site habitat is needed, clearly the habitat should be assessed upon nest discovery to obtain accurate estimates of nesting habitat used by least terns and piping plovers.

Implications for timing of other habitat measurements-If comparisons between treatment and control segments (before and after the treatments are administered) are the only analysis of interest, then measuring habitat during the postbreeding season may provide an adequate index for comparison among these groups. However, depending on river flows and water levels, key foraging habitats available to plovers during the breeding season might be unavailable for sampling during the postbreeding season (fig. 24). Moreover, if estimates of the amount of suitable habitat created/managed are required, then measurements during the breeding season would be desirable because measurements taken during the postbreeding season would be biased low, underestimating amount of habitat present at start of breeding.

Understanding why areas are used or not used is an important step in the adaptive management process to ensure that the ESH Program is providing the best habitat for the money spent. Measuring habitat during the breeding season would provide better information about availability of habitat
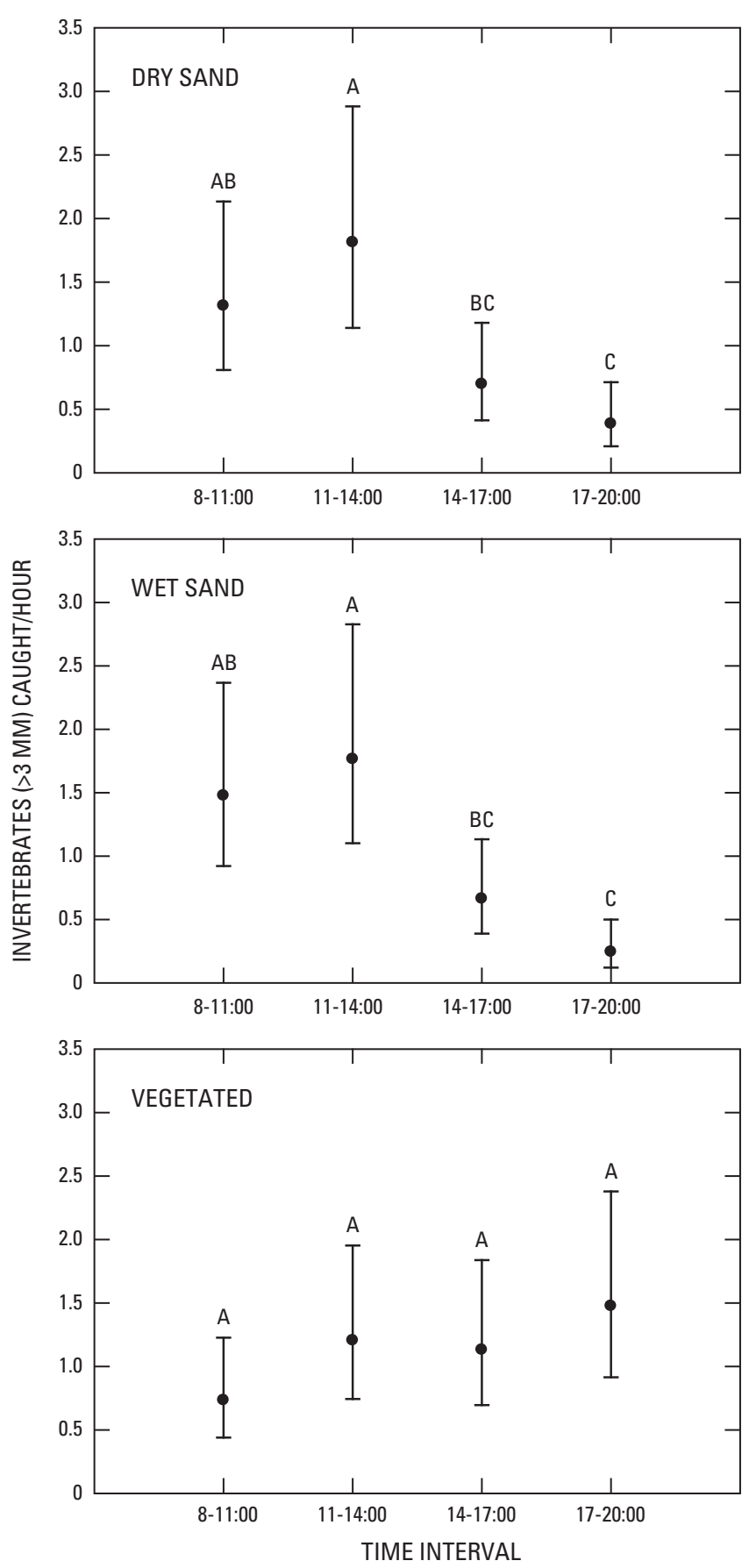

Figure 23. Least-square geometric mean counts per hour of invertebrates (>3 mm) captured on sticky-stick traps by habitat type (tiers) during four time intervals at the Garrison Reach of the Missouri River in summer 2006.

in relation to the habitat used (nest-site measurements), and thus would provide better information on why an area was used or not used. 
Table 17. Habitat classes recorded at nest upon discovery (initial) and during August revisits for least tern and piping plover nests $(n=345)$ on the Garrison Reach of the Missouri River in 2006.

\begin{tabular}{lcccc}
\hline \multirow{2}{*}{ August habitat class } & \multicolumn{4}{c}{ Initial habitat class } \\
\cline { 2 - 5 } & Wet sand & Dry sand & Sparse vegetation & Vegetated \\
\hline Open water & 32 & 81 & 8 & 5 \\
Wet sand & 17 & 37 & 5 & 0 \\
Dry sand & 5 & 99 & 5 & 0 \\
Sparse vegetation & 3 & 31 & 8 & 2 \\
Vegetated & 2 & 2 & 0 & 3 \\
\hline
\end{tabular}

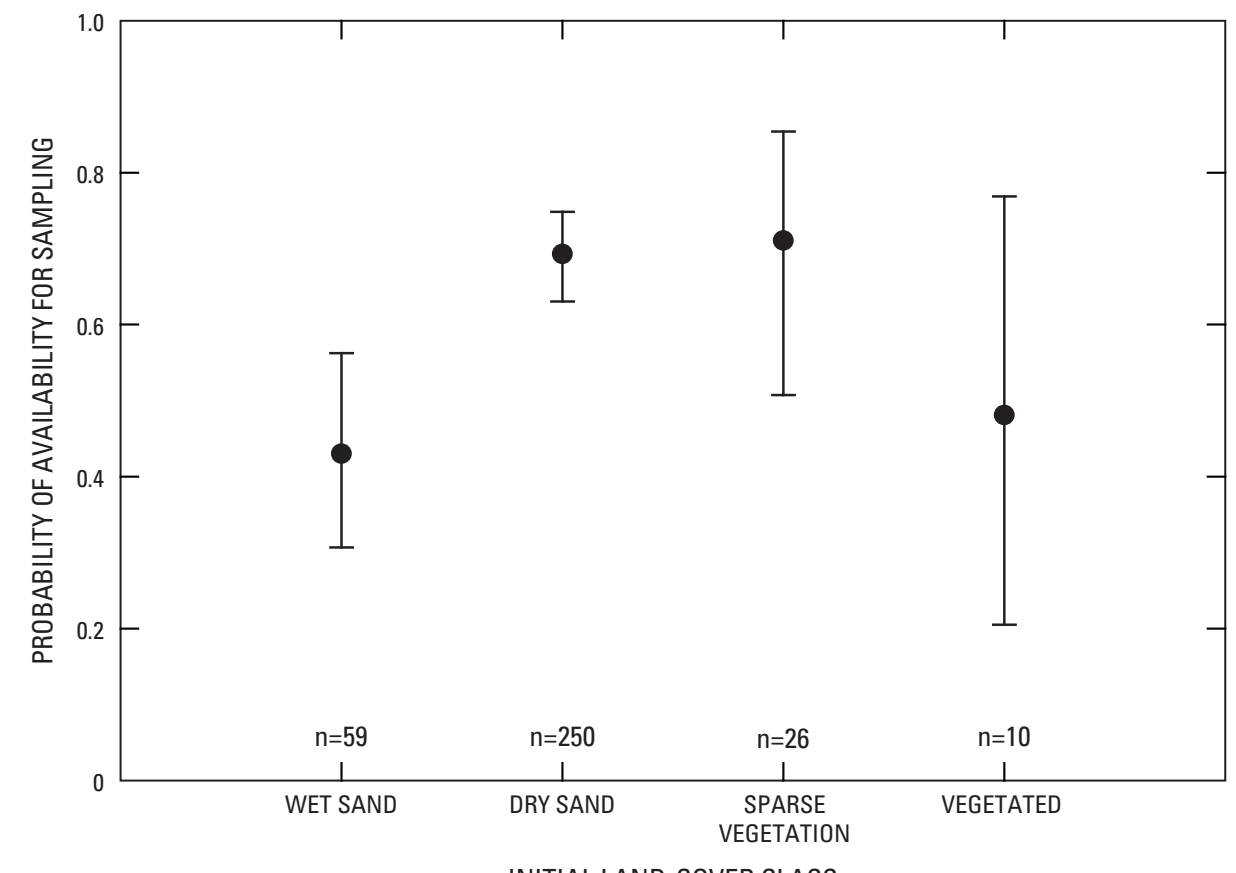

INITIAL LAND-COVER CLASS

Figure 24. Least-square mean probability (95-percent confidence interval) that a nest site was available for sampling (not inundated) in August for each initial habitat classification after controlling for date of initial habitat assessment.

\section{Sample Sizes for Terrestrial Points}

The rationale for "on the ground" terrestrial habitat sampling is to measure the quality of habitat available for least terns and piping plovers on emergent sandbars and shorelines along the upper-Missouri River System. To assess the variability of various habitat characteristics of interest, 50 data collection points were randomly allocated proportionally within the following habitats on the Gavins Point Reach (see "Sampling Approach, Rivers" section) in 2006: wet sand, dry sand, sparsely vegetated, vegetated, wetland, and submerged sand (table 10). However, 98.1 percent of tern and plover nests $(n=673)$ USGS technicians found, throughout the upper-

Missouri River System in 2006, were located on wet sand, dry sand, or sparsely vegetated habitat classes. Therefore, monitoring of habitat quality should be focused on wet sand, dry sand, and sparsely vegetated habitat classes.

Preliminary analyses were done on habitat data from the Gavins Point Reach in 2006 to assess variability and the ability to detect potential differences in key habitat characteristics among control segments and segments containing created sandbars or vegetation removal. These analyses were limited 
to points that fell in the a priori habitat classes of wet sand, dry sand, and sparsely vegetated; including 52.5 percent of terrestrial points sampled (mean of 27 samples per segment). A control segment was randomly paired with created segments within bird use and river width strata, so that there were five segments containing created habitat each paired with a control with a similar bird use history and river width. Analysis of variances (ANOVAs) were done including all segments $(n=34)$ each assigned to a treatment level (such as control, created, vegetation modification; table 3 ). The result of the paired and the complete analyses were that means of key habitat variables of interest (such as percent cover of small pebbles, herbaceous vegetation, and woody vegetation) were estimable with standard errors small enough to detect appreciable differences among treatment classes. However, these data consist only in a control-impact design; if pretreatment data were available, the ability to detect differences would be expected to increase because preexisting site-to-site variability would be controlled in the model. Therefore, the sampling design, including 30 terrestrial points, allocated proportionally among wet sand, dry sand, and sparsely vegetated habitats would be an adequate sample to ensure that appreciable differences in habitat characteristics are statistically detectable. However, it is equally important that an adequate number of control and treatment segments be sampled to provide precise estimates of means.

\section{Field Data Collection-Productivity}

Monitoring productivity enables a direct and accurate evaluation of biological response by birds (number of nests, nest fate, nest success, chicks fledged) to management actions. Monitoring least terns and piping plovers on the Missouri River to assess productivity is essential to accurately evaluate management actions and meet reporting requirements under the 2003 amended Biological Opinion for Missouri River Operations (U.S. Fish and Wildlife Service [USFWS] 2003). In light of the Federal Endangered Species Act listing for both species and data requirements in the Biological Opinion, particular attention to accurate and valid productivity monitoring procedures is warranted. In order to provide the highest value data, productivity monitoring must follow standardized procedures that eliminate subjectivity, ensure frequent nest visits, and collect data that are geospatially and temporally accurate. Geospatial and temporal linkages between habitat and productivity data are critical for an accurate understanding of the relationship between habitat and productivity. Northern Prairie Wildlife Research Center is conducting research (NPWRC Task 7.2) to review and evaluate ongoing monitoring efforts by the USACE on the Missouri River. Planned products from this research include a field manual that describes scientifically valid procedures for collecting data for monitoring adult populations and reproductive success of least terns and piping plovers.

Productivity monitoring is conducted by the USACE on all parts of the Missouri River system that would be subject to ESH monitoring under this plan. Additional productivity data may also be available from concurrent NPWRC studies on least tern ecology (Gavins Point and Lewis and Clark Lake).

\section{Spatial Data}

Acquisition and storage of spatial data, and documenting metadata, from satellite or digital orthophotography, are essential for visually documenting habitat condition. Data resulting from interpretation of spatial data are integral in comprehensive analyses of management actions on habitat and bird productivity. Spatial data should be collected at a time coinciding with nesting and brood rearing (late May through mid-July). Habitat data collected closest to the acquisition date can be used as ground truthing points for aiding interpretation of spatial data, but may need to be supplemented with more intensive local surveys. NPWRC is currently conducting research (NPWRC Task 7.3: Inventory, mapping, estimation, and monitoring of least tern and piping plover habitats on the upper Missouri River using Quickbird imagery) with a primary goal of developing a cost-effective method to inventory, map, estimate, and monitor least tern and piping plover habitats of the upper Missouri River using remotely sensed imagery.

\section{Other Species}

The sampling scheme outlined in this plan readily accommodates additional components with little additional expense. For example, surveys may be easily incorporated to document occurrence and distribution of other species to meet project related or regulatory objectives. Species that should be considered for inclusion in the monitoring effort include documenting presence of State and federally listed species, predator presence, colonial or secretive waterbird occurrence, and recreational disturbance.

Creation and modification of habitat may have the unintended consequence of providing opportunities for establishment or proliferation of invasive or unintended species. Documentation of these and similar species are important for evaluation of current management and initiation of new management efforts for control. Species listed by State weed boards and http://www.invasivespeciesinfo.gov/ can be monitored; of concern for the Missouri River area are expansion in range and extent of purple loosestrife (Lythrum salicaria) and saltcedar (Tamarix spp), and extensive growth of yellow sweet clover on sandbars. Additionally, spread of epizootics within high density colonial situations may necessi- 
tate consideration for monitoring health of piping plovers and least terns. All carcasses should be collected after consultation with the USFWS and submitted to the USGS Wildlife Health Lab in Madison, Wis., for analysis. Susceptibility of these species to various diseases is unknown, but disease concerns include: aspergillosis, avian botulism, avian influenza, Newcastle disease, avipoxviruses, and West Nile virus.

\section{Data Analysis}

Data collected in accordance with this plan will be wellsuited for analysis using mixed model ANOVA to evaluate variation in monitoring indicators relative to ESH management. When feasible (for example, advance knowledge of project sites is adequate to allow preproject monitoring), these models should follow a BACI design. However, analyses to detect these responses should be limited to the subsegments that were selected for that purpose. For example, on the Gavins Point Reach in 2006, 24 segments were selected to evaluate vegetation control projects and 10 segments were selected to evaluate sandbar creation projects. The ANOVA for vegetation control would be limited to those 24 segments, and a separate ANOVA for sandbar creation would be generated using the other 10 segments. In these situations, the BACI design would not apply because no pretreatment data are available. However, for other sites (such as Lake Oahe, Lake Sakakawea, Lewis and Clark Lake, Kensler's Bend), this design would be feasible. For all ANOVAs, the segments should be considered the primary experimental unit.

Following the initial season of data collection on any monitoring effort, a power analysis should be conducted to evaluate the adequacy of sampling efforts to detect meaningful effect sizes between treated and untreated segments. This analysis should be used to adjust number of points sampled per segment and/or number of segments sampled per study area. However, this approach is only likely to be useful for large-scale applications of vegetation control (such as on the Gavins Point Reach in 2006), in which there is an abundance of treated segments from which to make random selections. In other cases, such as construction of a single sandbar on a river reach, ability to increase the number of segments will be constrained by spatial extent of the treatments.

\section{Implementation}

The preceding sections outline the approach to habitat monitoring that was conceived and evaluated during the 2006 field season. Although distribution of effort might vary from year to year, the level of field effort expended in 2006 should provide guidance on expected quantity of data that can be obtained in one field season. The field crew consisted of three people (one leader and two technicians) whose exclusive duty was to collect habitat data in accordance with this plan. The crew was equipped with a four-wheel drive truck, an 18-foot tunnel hull jon boat with a 75-horsepower outboard motor, and three Trimble GeoXT units. They conducted their sampling beginning on June 2, 2006, on the Gavins Point Reach, and ending on August 8, 2006, on Lake Sakakawea. A total of 66 riverine and 19 lake segments were visited, providing habitat data at over 11,000 point locations (table 18). Because one field crew sampled all of these reaches, a portion of the field season was devoted to travel, setting up new bases of operations, and becoming familiar with new surroundings. A greater number of points could be sampled if multiple field crews were established, eliminating the need to mobilize a single field crew to all locations.

Table 18. Distribution of habitat sampling achieved by a three-technician crew on the Missouri River during the 2006 field season.

\begin{tabular}{|c|c|c|c|c|c|}
\hline Reach & Number of segments & Terrestrial points & $\begin{array}{c}\text { Aquatic points } \\
\text { (with habitat data) }\end{array}$ & $\begin{array}{l}\text { Aquatic points } \\
\text { (classified only) }\end{array}$ & $\begin{array}{c}\text { Total points } \\
\text { sampled }\end{array}$ \\
\hline Gavins Point & 34 & 1,444 & 337 & 313 & 2,094 \\
\hline Lewis and Clark Lake & 4 & 78 & 40 & 322 & 440 \\
\hline Garrison & 0 & 364 & 0 & 0 & 364 \\
\hline Lake Sakakawea $^{1}$ & 19 & 6,044 & 0 & 0 & 6,044 \\
\hline Total & 85 & 8,830 & 657 & 1,531 & 11,018 \\
\hline
\end{tabular}

${ }^{1}$ Four crews of two technicians sampled Lake Sakakawea. 


\section{Permits}

State and Federal permits are required for work in habitats of, or with, listed species. It is essential that monitoring work comply with existing permits, or that permits are sought/amended to meet regulatory requirements. Permits usually include conditions that are designed to protect the species of concern. Typical conditions for work near nesting least terns and piping plovers include limits on time spent by investigators in nesting colonies. Strict compliance with time limits in colonies is essential, even in the absence of specific permit conditions providing limits. It is imperative that the habitat monitoring effort be coordinated with other concurrent research or monitoring projects in the same area, so that potential cumulative effects of multiple investigator visits to nesting colonies are avoided.

Habitat monitoring does not require direct interactions with nesting birds that are a necessary component of productivity monitoring. Nevertheless, efforts to conduct habitat assessment during the nesting season require a cautious approach with particular attention to avoiding direct and indirect impacts to birds. It is essential that field personnel monitoring habitat be trained to recognize nests and behavioral cues of birds that suggest nests are nearby, and that they cease sampling efforts within appropriate time limits. Given this training and guidance, in 2006 it was possible for the NPWRC habitat crew to assess $>10,000$ points during the nesting season.

\section{Selected References}

Bailey, D., and Herzog, F., 2004, Landscape monitoring, in Wiersma, G.B., ed., Environmental monitoring: Boca Raton, Florida, CRC Press, p. 307-355.

Barbour, M.T., Gerritsen, J., Snyder, B.D., and Stribling, J.B., 1999, Rapid bioassessment protocols for use in streams and wadeable rivers-periphyton, benthic macroinvertebrates, and fish. Second edition. U.S. Environmental Protection Agency, Office of Water, EPA/841-B-99-002, 339 p.

Berry C.R., Jr., Wildhaber, M., and Galat, D.L., 2004, Fish distribution and abundance, v. 3, Population structure and habitat use of benthic fishes along the Missouri and Lower Yellowstone Rivers: U.S. Geological Survey, Cooperative Research Units, Brookings, South Dakota, South Dakota State University, 282 p.
Biedenharn, D.S., Soileau, R.S., Hubbard, L.C., Hoffman, P.H., Thorne, C.R., Bromley, C.C., and Watson, C.C., 2001, Missouri River-Fort Peck Dam to Ponca State Park geomorphological assessment related to bank stabilization: U.S. Army Corps of Engineers Report, U.S. Army Engineer Research and Development Center, Coastal Hydraulics Laboratory, $160 \mathrm{p}$.

Bureau of Land Management, 1996, Sampling vegetation attributes Interagency technical reference: Bureau of Land Management, National Applied Resource Sciences Center, BLM/RS/ST-96/002+1730, 158 p.

Christensen, N.L., Bartuska, A.N., Brown, J.H., and others, 1996, The report of the Ecological Society of America committee on the scientific basis for ecosystem management: Ecological Applications, v. 6, no. 3, p. 665-691.

Cochran, W.G., 1977, Sampling techniques 3d ed., New York, John Wiley \& Sons, 428 p.

Daubenmire, R.F., 1959, Canopy coverage method of vegetation analysis: Northwest Scientist v. 33, p. 43-64.

Diedrich, Jackie, 2004, Wild \& Scenic Rivers Act: Section 7-Technical report of the Interagency Wild \& Scenic Rivers Coordinating Council: U.S. Forest Service, $42 \mathrm{p}$.

Drobish, M.R., ed., 2008, Missouri River standard operating procedures for fish sampling and data collection, v. 1.3: U.S. Army Corps of Engineers, Omaha District, Yankton, South Dakota, 204 p.

Elias, S.P., Fraser, J.D., and Buckley, P.A., 2000, Piping plover foraging ecology on New York barrier islands: Journal of Wildlife Management v. 64, p. 346-354.

Elliott, C.M., and Jacobson, R.B., 2006, Geomorphic classification and assessment of channel dynamics in the Missouri National Recreation River, South Dakota and Nebraska: U.S. Geological Survey Scientific Investigations Report 2006-5313, 66 p.

Elzinga, C.L., Salzer, D.W., and Willoughby, J.W., 1998, Measuring and monitoring plant populations, Technical reference 1730-1: Bureau of Land Management, National Science and Technology Center, 492 p.

Elzinga, C.L., Salzer, D.W., Willoughby, J.W., and Gibbs, J.P., 2001, Monitoring plant and animal populations: Malden, Massachusetts, Blackwell Science, 370 p. 
Gutreuter, S., Burkhardt, R., and Lubinski, K., 1995, Long term resource monitoring procedures fish monitoring: National Biological Service, Environmental Management Technical Center, LTRMP Program Report 95-P002-1, $42 \mathrm{p}$.

Haffner, C.D., 2005, Breeding season spatial requirements of Great Lakes piping plovers (Charadrius melodus) in northern lower Michigan: Minneapolis, Minnesota, University of Minnesota, M.S. thesis, 40 p.

Haig, S.M., and Elliott-Smith, E., 2004, Piping plover, in The birds of North America online, Poole, A., ed.: Ithaca, New York, Cornell Laboratory of Ornithology, accessed February 27, 2007, at http://bna.birds.cornell.edu/BNA/account/ Piping_Plover/.

Haig, S.M., Ferland, C.L., Cuthbert, F.J., Dingledine, J., Goosen, J.P., Hecht, A., and McPhillips, N., 2005, A complete species census and evidence for regional declines in piping plovers: Journal of Wildlife Management, v. 69, issue 1 , p. 160-173.

Herzog, D.P., Barko, V.A., Scheibe, J.S., Hrabik, R.A., and Ostendorf, D.E., 2005, Efficacy of a benthic trawl for sampling small-bodied fishes in large river systems: North American Journal of Fisheries Management, v. 25, p. 594-603.

Hurlbert, S.H., 1984, Pseudoreplication and the design of ecological field experiments: Ecological Applications, v. 54, p. 187-211.

Johnson, D.H., 2002, The importance of replication in wildlife research: Journal of Wildlife Management, v. 66, p. 919-932.

Knetter, J.M., Lutz, R.S., Cary, J.R., and Murphy, R.K., 2002, A multi-scale investigation of piping plover productivity on Great Plains Alkali Lakes, 1994-2000. Wildlife Society Bulletin, v. 30, no. 3, p. 683-694.

Kruse, C.D., Higgins, K.F., and Vander Lee, B.A., 2002, Influence of predation on piping plover, Charadrius melodus, and least tern, Sterna antillarum, productivity along the Missouri River, South Dakota: Canadian Field-Naturalist, v. 115 , p. $480-486$.

Kushlan, J.A., 1981, Sampling characteristics of enclosure fish traps: Transactions of American Fisheries Society, v. 110, p. 557-562.

Le Fer, D., 2006, Piping plover foraging ecology in the Great Plains: Blacksburg, Virginia, Virginia Polytechnic Institute and State University, Ph.D. dissertation, 151 p., 15 figs.
Loegering, J.P., and Fraser, J.D., 1995, Factors affecting piping plover chick survival in different brood-rearing habitats: Journal of Wildlife Management, v. 59, p. 646-655.

Miranda, L., and Collazo, J.A., 1997, A modified throw-trap to sample prey for wading bird studies: J. Field Ornithology, v. 68 , no. 4 , p. $602-606$.

Nudds, T.D., 1977, Quantifying the vegetation structure of wildlife cover: Wildlife Society Bulletin, v. 5, p. 113-117.

Reeves, G.H., Hohler, D.B., Larsen, D.P., Busch, D.E., Kratz, K., Reynolds, K., Stein, K.F., Atzet, T., Hays, P., and Tehan, M., 2003, Aquatic and riparian effectiveness monitoring plan for the Northwest Forest Plan: U.S. Forest Service General Technical Report 577, 70 p.

Ringold, P.L., Alegria, J., Czaplewski, R.L., Mulder, B.S., Tolle, T., and Burnett, K., 1996, Adaptive monitoring design for ecosystem management: Ecological Applications, v. 6, p. 745-747.

Ringold, P.L., Mulder, B., Alegria, J., Czaplewski, R.L., Tolle, T., and Burnett, K., 1999, Establishing a regional monitoring strategy: the Pacific Northwest Forest Plan: Environmental Management, v. 23, p. 179-192.

Rogers, S.J., and Owens, T.W., 1995, Long term resource monitoring procedures_-vegetation monitoring: National Biological Service, Environmental Management Technical Center, LTRMP Program Report 95-P002-3, 10 p. + Appendixes A-E.

SAS Institute, 2002, SAS/STAT User's Guide, Version 6. SAS Institute, Cary, N.C., 1,686 p.

SAS Institute, 2006, The GLIMMIX Procedure, Cary, N.C., $256 \mathrm{p}$.

Schmidt, J.C., 1999, Summary and synthesis of geomorphic studies conducted during the 1996 controlled flood in Grand Canyon, in Webb, R.H., Schmidt, J.C., Marzolf, G.R., and Valdez, R.A., eds., Geophysical Monograph 110_The controlled flood in Grand Canyon: American Geophysical Union, p. 329-341.

Spellerberg, I.F., 2005, Monitoring ecological change (2d ed.): Cambridge, England, Cambridge University Press, 391 p.

Tazik, D.J., Warren, S.D., Diersing, V.E., Shaw, R.B., Brozka, R.J., Bagle, C.F., and Whitworth, W.R., 1992, U.S. Army Land Condition-Trend Analysis (LCTA) Plot Inventory Field Methods: U.S. Army Corps of Engineers RL Technical Report N-92/03, 84 p. 
Thiel, P.A., and Sauer, J.S., 1995, Long term resource monitoring program procedures-macroinvertebrate monitoring: National Biological Service, Environmental Management Technical Center, LTRMP Program Report 95-P002-2, 9 p. + Appendices A-G.

U.S. Fish and Wildlife Service, 2003, U.S. Fish and Wildlife Service 2003 Amendment to the 2000 Biological Opinion on the Missouri River Main Stem Reservoir System, Operation and Maintenance of the Missouri River Bank Stabilization and Navigation Projects, and Operation of the Kansas River System, 298 p.

Urquhart, N.S., and Kincaid, T.M., 1999, Designs for detecting trend from repeated surveys of ecological resources: Journal of Agricultural, Biological, and Environmental Statistics, v. 4, p. 404-414.

Vander Lee, B., 2004, Draft long-term monitoring and assessment plan for least tern and piping plover habitat on the Missouri River: Unpublished U.S. Army Corps of Engineers report, $19 \mathrm{p}$.

Walters, C., 1986, Adaptive management in renewable resources: New York, Macmillan Publishing Co., 374 p.

Walters, C.J., and Holling, C.S., 1990, Large-scale management experiments and learning by doing: Ecology, v. 71, p. 2060-2068.

Weeks, D.P., Vana-Miller, D.L., and Pranger, H., 2005, Nebraska-South Dakota water resources information and issues overview report: National Park Service, Water Resources Division, Technical Report NPS/NRWRD/ NRTR-2005/326, 81 p.

Ziewitz, J.W., Sidle, J.G., and Dinan, J.J., 1992, Habitat conservation for nesting least terns and piping plovers on the Platte River, Nebraska: Prairie Naturalist, v. 24, p. 1-20. 
Publishing support provided by:

Helena Publishing Service Center

For more information concerning this publication, contact:

Director, Northern Prairie Wildlife Research Center

U.S. Geological Survey

8711 37th Street Southeast

Jamestown, North Dakota 58401

(701) 253-5500

Or visit the Northern Prairie Wildlife Research Center Web site at: http://www.npwrc.usgs.gov/ 



¿3.

